\title{
Complex Regional Pain Syndrome Type I : measurements and treatment
}

Citation for published version (APA):

Forouzanfar, T. (2004). Complex Regional Pain Syndrome Type I : measurements and treatment.

[Doctoral Thesis, Maastricht University]. Universiteit Maastricht. https://doi.org/10.26481/dis.20040416tf

Document status and date:

Published: 01/01/2004

DOI:

10.26481/dis.20040416tf

Document Version:

Publisher's PDF, also known as Version of record

\section{Please check the document version of this publication:}

- A submitted manuscript is the version of the article upon submission and before peer-review. There can be important differences between the submitted version and the official published version of record.

People interested in the research are advised to contact the author for the final version of the publication, or visit the DOI to the publisher's website.

- The final author version and the galley proof are versions of the publication after peer review.

- The final published version features the final layout of the paper including the volume, issue and page numbers.

Link to publication

\footnotetext{
General rights rights.

- You may freely distribute the URL identifying the publication in the public portal. please follow below link for the End User Agreement:

www.umlib.nl/taverne-license

Take down policy

If you believe that this document breaches copyright please contact us at:

repository@maastrichtuniversity.nl

providing details and we will investigate your claim.
}

Copyright and moral rights for the publications made accessible in the public portal are retained by the authors and/or other copyright owners and it is a condition of accessing publications that users recognise and abide by the legal requirements associated with these

- Users may download and print one copy of any publication from the public portal for the purpose of private study or research.

- You may not further distribute the material or use it for any profit-making activity or commercial gain

If the publication is distributed under the terms of Article $25 \mathrm{fa}$ of the Dutch Copyright Act, indicated by the "Taverne" license above, 


\section{Complex Regional Pain Syndrome Type I}

Measurements and treatment 


\title{
Complex Regional Pain Syndrome Type I
}

Measurements and treatment

\author{
PROEFSCHRIFT
}

Ter verkrijging van de graad van doctor aan de Universiteit Maastricht, op gezag van de Rector Magnificus, Prof. G.P.M.F. Mols

volgens het besluit van het College van Decanen in het openbaar te verdedigen op vrijdag 16 april om 14.00 uur

\section{Door}

Tymour Forouzanfar

Geboren te Teheran-Iran op 22 februari 1973 


\section{Promotor}

Prof. dr. M. van Kleef

\section{Co-promotor}

Dr. W.E.J. Weber

\section{Beoordelingscommissie}

Prof. dr. M. Limburg (voorzitter)

Prof. dr. R.G.T. Geesink

Prof. dr. A.J.J.A. Seherpbier

Dr. J. Patijn

Prof.dr. W.W.A. Zuurmond

\section{Paranymphen}

M. Forouzanfar

L.M.E.G. Smeets

De uitgave van dit proefschrift werd financieel ondersteund door:

Pijn kennis Centrum Maastricht.

\section{Omslag illustratie}

Tymour Forouzanfar 


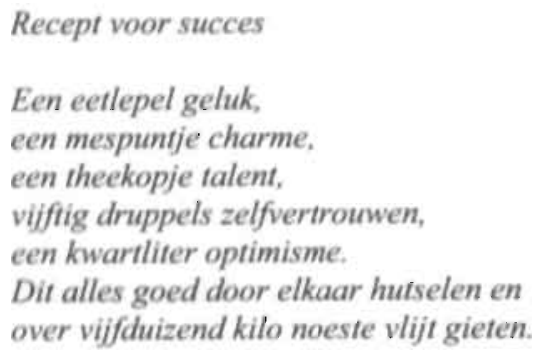

Egon Jakobson 


\section{CONTENTS}

Chapter 1 Introduction

Chapter 2 Treatment of Complex Regional Pain Syndrome Type I:

Review

Chapter 3 What is a meaningful pain reduction in patients with

Complex Regional Pain Syndrome Type I?

Chapter 4 Comparison of multiple against single pain intensity measurements

Complex Regional Pain Syndrome Type I: analysis of 54 patients

Chapter 5 Multi-Frequency Bioelectrical impedance measurements in

Complex Regional Pain Syndrome Type I: Pilot study of 28 patients

Chapter 6 Radiofrequency lesions of the Stellate ganglion in chronic pain Syndromes: Retrospective analysis of clinical efficacy in 86 patients

Chapter 7 Spinal cord stimulation in Complex Regional Pain Syndrome Type I:

Chapter 8 General discussion and conclusion

Chapter 9 Summary

Chapter 10 Samenvatting

Dankwoord

Curriculum Vitae 


\section{CHAPTER 1}

Introduction 


\section{INTRODUCTION}

Weir Mitchell, More house and Keen' reported in 1864 a case of a patient suffering of burning pain accompanied by muscle contracture after gunshot. Sudeck ${ }^{2}$ described in 1900 a complex syndrome characterised by burning pain, edema and decreased limb function. These symptoms occurred after a trauma of the limb ${ }^{2}$. Since then, the term "Sudeck's dystrophy" was introduced. Until now 175 different names in different languages are found 3 . The names are mostly related to supposed pathogenesis, clinical signs, diagnostic findings or inciting event $^{3}$.

A consensus conference, held in 1993, introduced the purely descriptive "Complex Regional Pain Syndrome", now the official name for several years ${ }^{4}$. CRPS I is a posttraumatic syndrome that presents with spontaneous pain, which is not related to the territory of a single nerve and is disproportionate to the inciting event ${ }^{4}$.

Sudden or progressive pain is the most disabling feature of CRPS I. The pain is often accompanied by a complex combination of negative symptoms or sensory deficits, such as partial or complete loss of sensation, and positive symptoms that include dysesthesia and paresthesiae ${ }^{5-10}$. Trophic changes often occur in CRPS I. These include all structures from skin to bone. Nails may become brittle and hair loss or increased hair growth may occur. The skin may have a scleroderma-like appearance. Red, warm and edematous skin with vasodilatation in the affected extremity reflects an inflammatory reaction ${ }^{5-10}$. However, the skin may also be cold and mottled due to vasoconstriction with livedo reticularis, cold intolerance and induration $5-10$.

Veldman et all' demonstrated that CRPS I is often associated with motor impairments. In their prospective study of 829 CRPS I patients, tremor in the affected arm was present in $49 \%$ and muscular incoordination in $54 \%$ of the patients. Muscle spasms were present in $25 \%$ and $16 \%$ of the patients suffered. from such severe weakness that no movements of the limbs were possible ${ }^{11}$. According to Schwartzman ${ }^{12}$ the movement impairments may spread to other body parts e.g. in mirror-like distribution at the contralateral side.

Treatment modalities for CRPS I are generally disappointing 13, 14. Patients with CRPS I often don't respond to non-steroidal anti-inflammatory drugs. Resistance or insensitivity to opiates is common. Adjuvant analgesics as antidepressants and anticonvulsants have limited efficacy and undesirable side effects ${ }^{15}$. Local anaesthetic blocks targeted at peripheral nerves, plexi, dorsal roots, and the sympathetic nervous system have limited effects; longer lasting invasive treatments like nerve blocks by phenol injection or cryotherapy risk irreversible functional impairment and have not been tested in placebo-controlled trials ${ }^{16-19}$. The efficacy 
of chronic epidural administration of drugs such as clonidine, steroids, opioids, or midazolam has not been adequately assessed ${ }^{13}$.

\section{PATHOGENESIS}

Although various underlying mechanisms have been described, the pathophysiology of CRPS 1 remains poorly understood. Multiple components most likely play roles in the generation and maintenance of CRPS $17,8,20,21$ including immunologically, neuropathic and psychological mechanisms $7,8,20-22$,

\section{Immunological mechanisms}

Mailis et al investigated the correlation of HLA class I and II expression in 15 patients with poor treatment outcome. Their study demonstrated elevated levels of both types HLA antigens in $80 \%$ of treatment resistant patients 22 . Several investigators demonstrated an association with $\mathrm{HLA}^{23,24}$. High expression of heritable antigens has also been reported in murine model of neuropathic pain 25 .

Despite the clinical symptoms, which resemble an inflammatory response, a humoral or cellular immune activation could never be proved. However, the coincidence of signs of inflammation with trophic changes and mechanical hyperalgesia in CRPS I strongly resembles neurogenic inflammation. Activation of primary afferents leads to the release of calcitonin gene-related peptide (CGRP) and substance P (SP) from nerve endings, Release of CGRP' leads to an increase in peripheral blood flow (vasodilatation) by an action on the arterioles, whereas release of substance $\mathrm{P}$, in addition, induces plasma protein extravasation from venules ${ }^{3,26,27}$. In CRPS I Weber et al. ${ }^{28}$ were able to show that the excitability of primary afferents and thereby the release of neuropeptides is increased. In the acute stage this may explain increased skin temperature, edema and trophic changes (increased hair- and nail growth). It is assumed that neuropeptides are mainly released from the so-called 'sleeping' mechano-insensitive nociceptors, which are sensitised by the initial trauma and the resulting processes of regeneration. Recruitment of 'sleeping' nociceptors predominantly leads to mechanical hyperalgesia, another marked sign in CRPS $1^{9}$. However, one has to bear in mind that neuropeptides are released not only in the periphery, but also from the central endings of the primary afferents. After nerve trauma, the SP receptor (NKI-R) will be up-regulated in dorsal horn neurones of the spinal cord, and thereby SP will initiate sensitisation of central pain transmission neurones, a distinctive mechanism leading to pain chronicity. Acutely after 
trauma, in inflammatory processes or triggered by ischemia and reperfusion, oxygen-derived free radicals are produced in the affected tissues. Animal models with intra-arterial infusion of tert-butylhydroperoxide, a free radical donor, strongly resemble clinical symptoms of acute CRPS I: edema, increased skin temperature, impaired function and pain behaviour 7,8 .

\section{Neuropathic mechanism}

Increased skin temperature and increased sweating which are often seen in CRPS I patients are caused by vasoconstrictor hypo-activity and sudomotor hyperactivity. According to Wasner et al ${ }^{29}$ this impaired sympathetic output function must be due to functional alterations. of the central nervous system.

Rommel et al ${ }^{30}$ also support the central mechanisms. In their prospective study they reported sensory deficits extending beyond the painful area of the affected limb ${ }^{30}$. They noted a significant increased frequency of mechanical allodynia and movement disorders in patients with hemisensory impairment or sensory deficits in the upper quadrant compared to those with impairment limited to the affected limb. Similar significant increase were also noted for motor impairment and correlated with allodynia/hyperalgesia. In conclusion they report that functional alterations in cewtral processing might result in motonlsensory imparment in CRPS. I patients.

These assumptions are supported by ladarora et al. ${ }^{31}$ Positron Emission Tomography (PET) performed in patients with chronic posttraumatic neuropathic pain or neuralgia demonstrated a significant decreased level of thalamic activity contralateral to the symptomatic side compared to normal controls.

\section{Psychological aspects}

The majority of patients with chronic pain, regardless of the cause and origin, experience some psychologic symptoms in the course of their illness ${ }^{32}$. From a behavioural point of view, Fordyce and Vlaeyen described that, when pain becomes chronic, the relationship between organic pathology and pain experience becomes less direct ${ }^{33}$. 34 . In the biomedical model, nociception is controlled by somatic factors; a nociceptive stimulus is followed by a so-called respondent pain reaction. The value of the biomedical model becomes limited in the case of chronic pain. At this point, the relationship between a nociceptive stimuli and pain behaviour attenuates because an operant pain reaction has developed. The behaviour is not directly related with a nociceptive stimulus ${ }^{33}, 34$. 
In patients with CRPS I the behaviour is said to be unproportionate to a known onganic cause $^{35}$. It is demonstrated that compared to patients with localised neuropathic pain and chronic back pain patients, CRPS I do not display an unique or unusual pattern in terms of their symptom reporting, anxiety symptoms, pain related dysfunction, illness behaviour, and psychological distress ${ }^{35}$. However, other studies show that CRPS I patients display higher emotional distress, i.e. somatisation and phobic anxiety, than non-CRPS 1 patients ${ }^{36-38}$, Although, the possibility of a psychopathological aetiology of CRPS I continues to receive support, it is still unclear whether CRPS I patients differ from non-CRPS I patients on a cognitive level.

\section{CLINICAL PRESENTATION}

\section{Sensory symptoms}

Pain and hyperesthesia are the predominant sensory symptoms. The pain is often described as aching, burning, pricking or shooting. It is localised deep in the tissue. Abnormal sensations to mechanical- and thermal stimuli or upon joint movement are frequently presented.

Allodynia is often described. Sensory deficits are common in CRPS I patients $5,30,39,40$,

\section{Autonomic symptoms}

Autonomic signs include swelling, colour and temperature changes, and sweating abnormalities. The swelling is often aggravated by physical activities, painful stimuli, environmental and local temperature changes, and hydrostatic pressure $3,29,41,42$.

\section{Motor- and dystrophic symptoms}

Mụscle weakness, tremor, dystonia, myoclonus and decreased range of motion often accompany CRPS I. Range of motion is decreased by joint effusion early in the disease and by contraction and fibrosis later in the disease $\mathrm{e}^{3,26}$. Decreased grip strength is observed in $78 \%$ of the patients ${ }^{43}$. Tremor has been reported in $24 \%$ to $60 \%$ of the patients $9,41,44$.

Change in nail and hair growth in affected extremity is frequently reported in patients. suffering of CRPS I. These symptoms are often accompanies with skin changes including fibrosis, hyperkeratosis and thin glossy skin ${ }^{6}$. 


\section{Diagnostic criteria systems}

Like other neuropathic pain syndromes the main symptom of CRPS I is local, often burning, pain. Accompanying symptoms are allodynia, edema, hyperhidrosis, hypertrichosis, colouring of the skin, motor disturbances and in time atrophy of the involved tissue (skin, muscle, bone). The symptoms are often disproportionate to the inciting event ${ }^{45}$.

To improve clinical recognition of this disorder, and facilitate selection of more generalizable samples for treatment outcome and basic science research the International Association for the Study of Pain (IASP) introduced a standardised CRPS I criteria ${ }^{46}$. According to the IASP the diagnosis of CRPS I should be based on the following criteria:

1. The presence of an initiating noxious event, or a cause of immobilisation.

2. Continuing pain, allodynia, or hyperalgesia with which the pain is disproportionate to any inciting event.

3. Evidence at some time of edema, changes in skin blood flow, or abnormal sudomotor activity in the region of pain.

4. This diagnosis is excluded by the existence of conditions that would otherwise account forsberdgreern faninanatuystúnenón:

These criteria are easy to handle and sufficient for clinical use. However, for scientific research they are too circumstantial and lack specificity. The external validity of the IASP criteria used as currently written may result in the over-diagnosis of CRPS I ${ }^{47,48}$. As suggested by Bruebi and co-workers a more restricted definition, which combines the symptoms should be used for scientific studies ${ }^{47}$. They proposed the following modified research diagnostic criteria for CRPS I:

1. Continuing pain which is disproportionate to any inciting event.

2. Must report at least one symptom in each of the four following categories Sensory: reports of hyperesthesia.

Vasomotor: reports of temperature asymmetry and/or skin colour changes and/or skin colour asymmetry.

Sudomotor/edema: reports of edema and/or sweating changes and/or sweating asymmetry.

Motor/trophic: reports of decreased range of motion and/or motor dysfunction (weakness, tremor, dystonia) and/or trophic changes (hair, nail, skin). 
3. Must display at least one sign in two or more of the following categories

Sensory: evidence of hyperalgesia (to pinprick) and/or allodynia (to light touch).

Vasomotor: evidence of temperature asymmetry and/or skin colour changes and/or asymmetry.

Sudomotor/edema: evidence of edema and/or sweating changes and/or sweating asymmetry.

Motor/trophic: evidence of decreased range of motion and/or motor dysfunction (weakness, tremor, dystonia) and/or trophic changes (hair, nail, skin).

These modifications, based upon results of their factor analysis research 47 appears to be more specific than current IASP criteria, and may substantially improve the ability to discriminate accurately between CRPS I and other types of neuropathic pain.

\section{EPIDEMIOLOGY}

The mean age of CRPS I (I and II) patients ranges from 36 to 42 years with a predominant for women ( $60 \%$ to $81 \%$ ). The upper extremities are more often affected than the lower extremity. As mentioned before the aetiology of CRPS Is typically an injury: 16\% after fracture, $10 \%-29 \%$ after sprain, $3 \%$ to $24 \%$ post-surgery, $2 \%$ o $17 \%$ other causes, or of unknown aetiology 44,49 .

Veldman et al reported that the recurrence or 'spread' to involve another extremity or region to be $10 \%$. He estimated the incidence of recurrence at $1.8 \%$ a year ${ }^{50}$. In a prospective study Maleki et al demonstrated that the mean onset of contiguous spread was 78 days; independent and mirror image spread was longer; 2.6 and 2.5 years respectively ${ }^{49}$.

\section{MEASUREMENT}

\section{Pain assessment}

Pain intensity is the most common pain dimension measured in both clinical work and treatment outcome research ${ }^{36}$. Normally pain ratings are assessed using a $100 \mathrm{~mm}$ Visual Analogue Scale (VAS), which is anchored by 2 extremes of pain; "no pain" on the left and "the worst possible pain" on the right. A single rating of pain intensity is mostly used. however it is unlikely that a single rating is a reliable or valid indicant of average pain ${ }^{51}$. One way to increase the validity of assessment of average pain is to increase the number of 
assessments $^{52}$. In chronic pain patients a single pain intensity rating is the least reliable and valid, while 3 measures of pain intensity a day over the course of 4 days has excellent internal consistency and validity $52-54$. It is articulated that patient may be able to assess their own average pain levels over a period of time simply by asking them to rate their pain "on average" at a single-point in time $\mathrm{e}^{55}$. In back pain patients it has been shown that a single rating of pain "on average" is an accurate estimate of "actual average" pain intensity measured over a course of 7 days $^{56}$. It is not clear whether this is also the case for CRPS I patients.

\section{Sensory and motor tests}

Hypoesthesia and allodynia are frequently present in CRPS I patients, and are among the diagnostic criteria ${ }^{30,41}$. Pin prick, light touch, mechanical and thermal stimulation are used to detect sensory disturbance. However, formal testing of skin thermal thresholds have so far

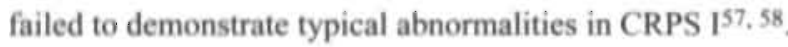

Kemler et al developed a simple device to assess the function of the foot by testing separate tasks for each foot ${ }^{59}$. Range of Motion (ROM) is often used to test the functional state of both the upper and lower extremities 60 . These moasures are huwevel subjective methods and are patient and observer dependant. Therefore, drawing conclusions about the effectiveness of functional state of any given treatment may be questionable.

\section{Skin temperature measurements}

Skin temperature measurements by means of thermistors or thermography demonstrated that the temperature of the affected limbs is changed compared to the non-affected limbs ${ }^{42,61}$. However, the sensitivity and specificity of these tests has never been formally examined.

\section{Radiology}

On the side-comparing $\mathrm{X}$-rays typically spotty osteoporotic changes can be found after 4 to 8 weeks $^{3}$. However, these changes only occur in $40 \%$ of the cases. 


\section{TREATMENT}

\section{Rehabilitation}

Oerlemans et al demonstrated in their prospective controlled study that physical therapy is helpful in the management of pain and mobility restoration in CRPS I patients ${ }^{62}$, In an evaluation of 145 patients physical therapy reduced the pain significantly ${ }^{63}$.

\section{Psychotherapy}

The efficacy of psychotherapy, including cognitive behavioural therapy, stress management, coping skills, relaxation techniques, imagery, self-hypnosis and biofeedback techniques, in patients with chronic pain is documented in several controlled trials 64,65 . Therefore, psychotherapy is proposed for patients with CRPS I to assist in the general rehabilitation of the patients 66 .

\section{Pain management}

Pharmacologic treatment. The agents currently used in the treatment of CRPS I include: tricyclic antidepressants ${ }^{15}$, anticonvulsants ${ }^{15}$, radical scavengers ${ }^{67}$, nonsteroidal antiinflammatory drugs (NSAIDs), calcium regulating drugs, corticosteroids, opioids, calcitonin, adrenoceptor antagonists and agonists, GABA agonists, NMDA-receptor antagonists 14 .

Sympathetic blocks. Sympathetic block is performed by stellate ganglion block ${ }^{36}$, epidural administration of clonidine ${ }^{68}$ and regional intravenous sympathetic blockade (RIS) ${ }^{18}$. Agents used in RIS blockade include phentolamine ${ }^{69}$, reserpine ${ }^{16}$, guanethidine ${ }^{16,} 18$, droperidol 70 and ketanserine 17,71 . Although, there is a lack of prospective studies evaluating sympathetic blocks they are still traditional first line treatments.

Neurostimulation. Spinal cord stimulation (SCS), is widely accepted in the treatment of benign chronic pain ${ }^{72-74}$. Moreover, Kemler et al ${ }^{74}$ demonstrated the six month effectiveness of SCS in CRPS I patients in a randomised study. However, because of the high cost involved in SCS it is of utmost importance to assess the long-term effect of the SCS. Furthermore, follow-up studies on the differences in effect of cervical and lumbar SCS in CRPS I do not exist.

Peripheral nerve stimulation (PNS). Hassenbach et al ${ }^{75}$ reported favourable results in a prospective trial of 32 consecutive patients with CRPS 1. The long-term response 
demonstrated a fair to good pain relief in $63 \%$ of the patients. Further, allodynia and spontaneous pain reduced significantly. Most protocols, techniques, and electrode designs for PNS are far from ideal. However, they are improving. In particular, specific electrode development is needed to improve the nerve-electrode interface, in some areas.

Complementary therapies. Two prospective studies demonstrated positive results in CRPS I patients after acupuncture treatment ${ }^{76,77}$. The efficacy of 40 minutes of Qigong exercises twice a week for 4 weeks was investigated by Wu et al ${ }^{78}$. They noted significant improvement when compared with sham exercises.

\section{Management of dysionia}

In a randomised, double-blinded, placebo-controlled study bolus intrathecal injections of baclofen were given to 7 women with CRPS $\mathrm{I}^{79}$. Of these patients $86 \%$ reported complete or partial resolution of dystonia of the hand. Six subjects crossed over and received continuous intrathecal baclofen. Fifty percent of these patients regained normal hand function, and 33\% also regained their ability to walk.

\section{Preventing CRPS I}

Zollinger et al ${ }^{80}$ demonstrated in their randomised control trial that prophylactic use of ascorbic acid (Vitamin C) reduces the incidence of CRPS I after Colles' fracture significantly.

\section{CURRENT PROBLEMS AND AIMS OF THE PRESENT THESIS}

As mentioned before currently practișed treatments of CRPS 1 include radical scavengers ${ }^{67}$, regional intravenous sympathetic blocks ${ }^{18}$ and neuromodulation ${ }^{74}$. Kingery et al ${ }^{14}$ reviewed existing trials for CRPS management in 1997 and demonstrated that there is limited support for the effectiveness of topical DMSO (dimethylsulfoxyde), epidural clonidine, intravenous regional blocks and intranasal calcitonine. Jadad et al ${ }^{18}$ showed that there is no evidence for the efficacy of regional intravenous sympathetic blockade (RIS). Controversy exists about the effectiveness of therapeutic interventions for the management of CRPS I. In order to ascertain appropriate therapies we conducted a review of existing randomised controlled trials of therapies for this disabling disease. The results are presented in chapter 2 . The review demonstrated several main problems in CRPS I studies. 
In the CRPS I literature most clinical studies use pain ratings as the primary outcome measure. Mostly, in these studies a significant pain reduction after treatment is defined as successful 18, 70, 71, 76, 77. Some authors define a pain reduction of 30 to $50 \%$ as successful $16,19$. 81. However, a clinically relevant pain reduction in patients with CRPS I is still not defined. In chapter 3 we present a study on the degree of pain reduction in patients with CRPS I that can be defined as successful.

In clinical studies with patients suffering from CRPS I, pain is, usually assessed by a single pain rating. This rating is consequently used as the primary outcome measure, assuming that it is equivalent to multiple pain ratings. However, to our knowledge this assumption had never been investigated in CRPS I patients. The study presented in chapter 4 was undertaken to compare the validity of the single pain ratings in patients with CRPS I with multiple pain rating test.

The diagnoses and evaluation of CRPS I is based solely on subjective clinical symptoms that including burning pain, sensory abnormalities, diminished strength, hyperhidrosis, hypertrichosis, skin colouring changes and atrophy of the involved tissue (skin, muscle, bone) 44,47 . There is a clinical need for an objective measure of the severity of the patient's condition. In order to develop an objective measure for CRPS I we performed a pilot study on the use of Bio-electrical Impedance Assessment in patients with CRPS I. The results are demonstrated in chapter 5 .

Stellate Ganglion Block (SGB) ${ }^{82}$ and Spinal Cord Stimulation(SCS) ${ }^{72-74}$ are currently used treatment modalities in the treatment of CRPS I. However, information on the effectiveness of SGB and the long term effect SCS, is scarce. In chapter 6 we retrospectively investigated the use of SGB and prospectively the long-term effect of SCS in patients suffering of CRPS I.

In summery the aims of this thesis were as follow:

1. Review of currently used therapies for CRPS I (chapter 2)

2. To analyze the degree of pain reduction in patients with CRPS I that can be defined as "successful" (Chapter 3).

3. To investigate whether a single pain rating in patients with CRPS I can replace a multiple pain rating test (Chapter 4).

4. To develop an objective laboratory measurement for evaluation of CRPS I (Chapter 5).

5. To analyse the effectiveness of Stellate Ganglion Block and Spinal Cord Stimulation as a treatment for CRPS I (Chapter 6 and 7). 


\section{References}

1. Mitchell S, Morehouse G. Keen W. Gunshot wounds and other injuries of nerves. Philadelphia: J.B. Lippincotr \& Co., 1864:164.

2. Sudeck P. Uber die acute entrundliche knochenatrophie. Anchive der Klinische Chirurgie 1900; 62:147-56.

3 Birklein F, Handwerker HO. Complex regional pain syndrome: how to resolve the complexity? Pain 2001; $94: 1-6$.

4. Menkey H, Bogduk N, Classification of chronic pain. Seattle: LASP Press, 1994

5. Thimineur M, Sood P, Kravitz E, Gudin J, Kitaj M. Central nervous system abnormalities in complex regional pain syndrome (CRPS): clinical and quantitative evidence of medullary dysfunction. Clin J Pain 1998; 14:256-67.

6. Wasner G, Backonja MM, Baron R. Traumatic neuralgias: complex regional pain syndromes (reflex sympathetic dystrophy and causalgia): clinical characteristics, pathophysiological mechanisms and therapy. Neurol Clin 1998; 16:851-68.

7. van der Laan L. Kapitein P. Verhofstad A, Hendriks T, Goris RJ. Clinical signs and symptoms of acute reflex sympathetic dystrophy in one hindlimb of the rat, induced by infusion of a free-radical donor. Acta Orthop Belg 1998; 64:210-7

8. van der Laan L, ter Laak HJ, Gabreels-Festen A, Gabreels F, Goris RJ. Complex regional pain syndrome type I (RSD): pathology of skeletal muscle and peripheral nerve. Neurology 1998; $51: 20-5$.

9. Sieweke N, Birklein F, Riedl B, Neundorfer B, Handwerker HO. Pattems of hyperalgesia in complex regional pain syndrome. Pain 1999; 80:171-7.

10. Harden RN. Complex regional pain syndrome, Br J Anoesth 2001; 87:99-106.

11. Veldman PH, Reynen HM, Amtz IE, Goris RJ. Signs and symptoms of reflex sympathetic dystrophy: prospective study of 829 patients. Lancet 1993; 342:1012-6.

12. Schwartzmann R, Kerrigan 3. The movement disorder of reflex sympathetic dystrophy. Neurology 1990; 40:57-61.

13. Forouzanfar T, Koke AJA, .. van Kleef M, Weber WEJ. Treatment of complex regional pain syndrome type 1. European $J$ ournal of Pain 2002; 6:105-122.

14. Kingery WS. A critical review of controlled clinical trials for peripheral neuropathic pain and complex regional pain syndromes [see comments]. Pain 1997; 73:123-39:

15. Weber WE. [Pharmacotherapy for neuropathic pain caused by injury to the afferent nerve fibers]. Ned Tijdschr Geneeskd 2001: 145:813-7.

16. Blanchard J, Ramamurthy S, Walsh N, Hoffman J. Schoenfeld L. Intravenous regional sympatholysis: a double-blind comparison of guanethidine, reserpine, and normal saline, J Pain Symptom Manage 1990; 5:357-61.

17. Bounameaux HM, Hellemans H, Verhaeghe R. Ketanserin in chronic sympathetic dystrophy. An acute controlled trial [letter]. Clin Rheumato/ 1984; 3:556-7.

18. Jadad AR, Carroll D, Glynn CJ, McQuay HJ. Intravenous regional sympathetic blockade for pain relief in reflex sympathetic dystrophy; a systematic review and a randomized, double-blind crossover study. J Pain Symptom Manage $1995: 10: 13-20$

19. Price DD, Long S, Wilsey B, Rafii A. Analysis of peak magnitude and duration of analgesia produced by local anesthetics injected into sympathetic ganglia of complex regional pain syndrome patients. Clin J Pain 1998; 14:216-226.

20. Stanton-Hicks M. Reflex sympathetic dystrophy; a sympathetically mediated pain syndrome or not? Curr Rev Pain 2000; 4:268-75.

21. Stanton-Hicks M. Complex regional pain syndrome (type 1, RSD; type II, causalgia); controversies. Clin J Pain 2000; 16:\$33-40

22. Mailis A, Wade 3. Profile of Caucasian women with possible genetic predisposition to reflex sympathetic dystrophy: a pilot study. Clin J Pain 1994; 10:210-7. 
23. Kemler MA, van de Vusse AC, van den Berg-Loonen EM, Barendse GA, van Kleef M, Weber WE. HLA-DQI associated with reflex sympathetic dystrophy. Nearology 1999; 53:1350-1.

24. van de Beck WJ, van Hilten J, Roep BO. HLA-DQ1 associated with reflex sympathetic dystrophy, Neurology 2000; $55 \times 457-8$.

25. Devor M. Nerve pathophysiology and mechanisms of pain in causalgia. J Auton Nerv Syst 1983: 7:371-84.

26. Birklein F. Schmelz M, Schifter S. Weber M. The important role of neuropeptides in complex regional pain syndrome. Newrology 2001; 57:2179-84.

27. Birklein F, Kunzel W, Sieweke N. Despite clinical similarities there are significant differences between acute limb trauma and complex regional pain syndrome I (CRPS D). Pain 2001; 93:165-71.

28. Weber M, Birklein F, Neundorfer B, Schmelz M. Facilitated neurogenic inflammation in complex regional pain syndrome. Pain 2001: 91:251-7.

29. Wasner G, Schattschneider J, Heckmann K, Maier C, Baron R. Vascular abnormalities in reflex sympathetic dystrophy (CRPS I): mechanisms and diagnostic value, Brain 2001; 124:587.99.

30. Rommel 0 , Gehling M, Dertwinkel R, et al. Hemisensory impairment in patients with complex regional pain syndrome. Pain 1999; 80-95-101.

31. Iadarola MJ, Max MB, Berman KF, et al. Unilateral decrease in thalamic activity observed with positron emission tomography in patients with chronic neuropathic pain. Pain 1995; 63:55-64.

32. Jamison RN, Rudy TE, Penzien DB, Mosley TH, Jr. Cognitive-behavioral classifications of chronic pain: replication and extension of empirically derived patient profiles. Pain 1994; 57:277-92.

33. Fordyce WE. Behavioral methods for chronic pain and illness. St. Louis: Mosby, 1976.

34. Vlacyen JWS, Groenman NH, Thomassen J, Schuerma JA, Van Eek H A behavioral treaiment for situing and standing. intolerance in a patient with chronic low back pain patient. Clin J Pain 1989; 5:233-7.

35. Ciccone DS, Bandilla EB, Wu W. Psychological dysfunction in patients with reflex sympathetic dystrophy. Pain 1997; $71: 323-33$

36. Geerzzen J, de Bruijn H, Arendzen J. Reflex Sympathetic dystrophy: early treatment and psychological aspects. Arch Phys Med Rehabil 1994; 75:442-6.

37. DeGood DE, Cundiff GW, Adams LE, Shutty MS, Jr. A psychosocial and behavioral comparison of reflex sympathetic dystrophy, low back pain, and headache patients. Pain 1993; 54:317-22.

38. Bruehl S, Husfeldt B, Lubenow TR, Nath H. Ivankovich AD. Psychological differences between reflex sympathetic dystrophy and non-RSD chronic pain patients [see comments]. Pain 1996; 67:107-14.

39. Harden RN. A clinical approach to complex regional pain syndrome. Clin J Pain 2000; 16:S26-32.

40. Galer BS. Hemisensory impairment in patients with complex regional pain syndrome. Pain 2000; 84:113.

41. Birklein F, Sittl R. Spitzer A, Claus D. Neundorfer B, Handwerker HO. Sudomotor function in sympathetic reflex dystrophy. Pain 1997; 69:49-54.

42. Wasner G, Schattschneider J, Baron R. Skin temperature side differences-a diagnostic tool for CRPS? Pain 2002; $98: 19$. 26.

43. Zyluk A. The sequelac of reflex sympathetic dystrophy. $J$ Hand Surg $[\mathrm{Br}]$ 2001:26:151-4.

44. Harden RN, Bruchl S, Galer BS, et al. Complex regional pain syndrome: are the IASP diagnostic criteria valid and sufficiently comprehensive? Pain 1999; 83:211-9.

45. Schurmann M, Gradl G. Andress HJ. Furst H. Schildberg FW. Assessment of peripheral sympathetic nervous function for diagnosing early post-traumatic complex regional pain syndrome type I. Pain 1999; 80:149-59.

46. Stanton-Hicks M, Janig W, Hassenbusch S, Haddox JD, Boas R, Wilson P. Reflex sympathetic dystrophy; changing concepts and taxonomy [sec comments]. Pain 1995; 63:127-33. 
47. BruchI S, Harden RN, Galer BS, et al. External validation of IASP diagnostic criteria for Complex Regional Pain Syndrome and proposed research diagnostic criteria. International Association for the Study of Pain. Pain 1999, 81:147. 54.

48. Galer BS, Bruchl S, Harden RN. IASP diagnostic criteria for complex regional pain syndrome: a preliminary empirical validation study. International Association for the Study of Pain. Clin J Pain 1998; 14:48-54.

49. Maleki J, LeBel AA, Beninett GJ, Schwartzman RU. Patterns of spread in complex regional pain syndrome, type I (reflex sympathetic dystrophy). Pain 2000; 88:259-66.

50. Veldman P, Goris R. Multiple reflex sympathetic dystrophy: which patients are at risk for developing a recurrence of reflex sympathetic dystrophy in the same or another limb. Pain 1996; 64:463-466.

51. Jensen MP, Karoly P, Braver S. The measurement of clinical pain intensity: a comparison of six methods. Pain 1986; 27:117-26.

52. Jensen MP, McFarland CA. Increasing the reliability and validity of pain intensity measurement in chronic pain patients [see commentu]. Pain 1993; 55:195-203.

53. Jensen MP, Turner LR, Turner JA, Romano JM. The use of multiple-item scales for pain intensity measurement in chronic pain patients. Pain 1996; 67:35:40.

54. Jensen MP, Tumer JA, Romano JM. Fisher LD. Comparative reliability and validity of chronic pain intensity measures. Pain 1999; 83:157-62.

55. Dworkin RH, Siegfried RN. Are all those pain ratings necessery? [Letter to the editor]. Pain 1994; $58: 279$.

56. Bolton JE. Accuracy of recall of usual pain intensity in back pain patients. Pain 1999; 83:533-9.

57. Price DD, Long S, Huit C. Sensory testing of pathophysiological mechanisms of pain in patients with reflex sympathetic dystrophy. Pain 1992; 49:163-73.

58. Tahmoush AJ, Schwartzman RJ, Hopp JL, Grothusen JR. Quantitative sensory studies in complex regional pain syndrome type 1/RSD, Clin J Pain 2000; 16:340-4.

59. Kemler MA, De Vet HC. An objective and standardized test of foot function: normative values and validation in patients with reflex sympathetic dystrophy. Arch Phys Med Rehabil 2000; 81:1401-7.

60. Kemler MA, Rijks CP, de Vet HC. Which patients with chronic reflex sympathetic dystrophy are most likely to benefit from physical therapy? J Manipulative Physiol Ther 200I; 24:272-8.

61. Tahmoush AJ, Malley J, Jennings JR. Skin conductance, temperature, and blood flow in causalgie. Neurology 1983: 33:1483-6.

62. Oerlemans HM, Goris JA, de Boo T, Oostendorp RA. Do physical therapy and oceupational therapy reduce the impairment percentage in reflex sympathetic dystrophy? Am J Phys Med Rehabil 1999: 78:533-9.

63. Birk!ein F. Riedl B, Sieweke N, Weber M. Neundorfer B. Neurological, findings in complex regional pain syndromes-analysis of 145 cases. Acta Neurol Scand 2000: 101:262-9.

64. Carlson C. Hoyle R. Efficacy of abbreviated progressive muscle relaxation training: a quantitive review of behavioral medicine rescarch. J Consult Clin Psychol 1993;61:1059-1067.

65. Flor H, Fydrich T, Turk D. Efficacy of multidisciplinary pain treatment centers: a meta-analytic review. Pain 1992; 49:221-230.

66. Stanton-Hicks M. Baron R, Boas R, et al. Complex Regional Pain Syndromes: guidelines for therapy. Clin J Pain 1998; $14: 155-66$.

67. Zuurmond WW, Langendijk PN, Bezemer PD, Brink HE, de Lange JJ, van loenen AC. Treatment of acute reflex sympathetic dystrophy with DMSO $50 \%$ in a fatty cream. Acta Anaesthesiol Scand 1996; 40:364-7.

68. Rauck RL, Eisenach JC, Jackson K, Young LD, Southern J. Epidural clonidine treatment for refractory reflex sympathetic dystrophy [see comments]. Anesthesiology 1993; 79:1163-9; discussion 27A.

69. Verdugo RJ, Campero M, Ochoa JL. Phentolamine sympathetic block in painful polyneuropathies. II. Further questioning of the concept of 'sympathetically maintained pain' [see comments]. Neurology 1994; 44:1010-4. 
70. Ketiler RE, Abram SE. Intravenous regional droperidol in the management of reflex sympathetic dystrophy: a doubleblind, placebo-controlled, crossover study, Amesthesiology 1985; 69:-933-6.

71. Harna MH, Peat SJ, Ketanserin in reflex sympathetic dystrophy. A double-blind placebo controlled cross-over trial. Pain $1989 ; 38: 145-50$.

72. Stanton-Hicks M, Salamon J. Stimulation of the central and peripheral nervous system for the control of pain. $J$ Clin Nearophysiol 1997; 14:46-62.

73. Kemler MA, Barendse GA, Van Kleef M, Van Den Wildenberg FA, Weber WE. Electrical spinal cord stimulation in reflex sympathetic dystrophy: retrospective analysis of 23 patients. $J$ Newroung 1999; 90:79-83.

74. Kemler MA, Barendse GA, van Kleef M, ef al. Spinal cord stimulation in patients with chronic reflex sympathetic dystrophy. N Engl J Med 2000: 343:618-24.

75. Hassenbusch SJ, Stanton-Hicks M, Schoppa D, Walsh JG, Covington EC. Long-term results of peripheral nerve stimulation for reflex sympathetic dystrophy. $J$ Neuronung 1996; 84:415-23.

76. Kho HK. The impect of acupuncture on pain in patients with reflex sympathetic dystrophy. Pain Clin 1995; 8:59-61.

77. Korpan MI, Deru Y, Schneider B, Leitha T. Fialka-Moser V. Acupuncture in the treatment of postraumatic pain syndrome. Acta Orthop Belg 1999; 65:197-201.

78. Wu WH, Bandilla E, Ciecone DS, et al. Effects of qigong on late-stage complex regional pain syndrome. Attern Ther Health Med 1999: 5:45-54.

79. van Hilien BJ, van de Beek WJ, Hoff J, Voormolen JH, Delhaas EM. Intrathecal baclofen for the treatment of dystonia in patients with reflex sympathetic dystrophy. $N$ Engl $J$ Med 2000; 343:625-30.

80. Zollinger PE, Tuinebreijer WE, Kreis RW, Breederveld RS. Effect of vitamin C on frequency of reflex sympathetic dystrophy in wrist fractures: a randomised trial. Lancet 1999; 354:2025-8.

81. Verdugo RJ, Ochoa J.. 'Sympathetically maintained pain.' I. Phentolamine block questions the concept [see comments]. Neurology 1994; 44:1003-10.

82. Bonelli S, Conoscente F, Movilia PG, Restelli L, Francucei B, Grossi E. Regional intravenous guanethidine vs, stellate ganglion block in reflex sympathetic dystrophies: a randomized trial. Pain 1983; 16:297-307. 
$-16$. 


\section{CHAPTER 2}

\section{Treatment of \\ Complex Regional Pain Syndrome Type I. \\ Review}

Tymour Forouzanfar, Albere J. A. Köke,

Maarten van Kleef and Wilhelm E.J. Weber

Published in Eur. J. Pain 2002; 6(2): 105-122. 


\section{ABSTRACT}

Objectives: Reflex Sympathetic Dystrophy (RSD) also known as Complex Regional Pain Syndrome Type I (CRPS I) is a disabling neuropathic pain syndrome. Controversy exists about the effectiveness of therapeutic interventions for the management of RSD/CRPS I. In order to ascertain appropriate therapies we conducted a review of existing randomised controlled trials of therapies for this disabling disease.

Methods: Eligible trials were identified from the Cochrane, Pubmed, Embase and MEDLINE databases from 1966 through June 2000, from references in retrieved reports and from references in review articles.

Results: Twenty-six studies concerning treatment modalities were identified. Eighteen studies were randomised placebo-controlled trials and eight studies were randomised activecontrolled trials. Three independent investigators reviewed articles for inclusion criteria using a 15-item check list. Seventeen of the trials were of high quality according to the 15 -item criteria. There was limited evidence for the effectiveness of these interventions because of the heterogeneity of treatment modalities. The search for trials concerning prevention of RSD/CRPS I resulted in 2 eligible studies. Both were of high quality and dealt with different interventions. There is limited evidence for their preventive effect.

Conclusion: In conclusion there is limited evidence to support the effectiveness of commonly used interventions for treating or preventing RSD or CRPS I. More prospective controlled trials are needed in this field. 


\section{INTRODUCTION}

Complex regional pain syndrome (CRPS) Type I and II are neuropathic pain syndromes accompanied with sudomotor and vasomotor disturbances. CRPS I, which corresponds to the common image of Reflex Sympathetic Dystrophy (RSD) is defined as a painful, disabling syndrome ${ }^{1}$. The Consensus Conference of the International Association for Study of Pain defined CRPS I as a post-traumatic syndrome that presents with spontaneous pain that is not related to the territory of a single nerve and is disproportionate to the inciting event ${ }^{1,2}$. The diagnostic criteria include: (a) pain, allodynia, or hyperalgesia; (b) evidence at some time of edema, vasomotor and sudomotor change in the pain region; and (c) no other conditions that would otherwise account for the degree of pain and dysfunction. CRPS II is a pain syndrome that starts after a nerve injury and is not necessarily limited to the distribution of the injured nerve ${ }^{3,4}$. The diagnostic criteria are the same as that of CRPS L. CRPS is differentiated from other neuropathic pain syndromes by the existence of edema, vasomotor and sudomotor disturbances. Some authors previously used a positive response on sympathetic blockade and diffuse or patchy osteopenia as an important diagnostic criterion for RSD ${ }^{5-7}$. In CRPS I the role of sympathetic block in diagnosis has been minimized. Consequently, each category under the term CRPS could be divided into patients responsive and unresponsive to sympathetic blocks ${ }^{8}$.

Currently practised treatments of RSD/CRPS I include radical scavengers ${ }^{9}$, regional intravenous sympathetic blocks ${ }^{10}$ and neuromodulation ${ }^{11}$. Kingery et al ${ }^{12}$ reviewed existing trials for RSD/CRPS management in 1997 and demonstrated that there is limited support for the effectiveness of topical DMSO (dimethylsulfoxyde), epidural clonidine, intravenous regional blocks and intranasal calcitonine. Jadad et al ${ }^{10}$ showed that there is no evidence for the efficacy of regional intravenous sympathetic blockade (RIS). We conducted a systematic review of published trials for the treatment and prevention of this disease with an emphasis on randomised controlled trials ( $\mathrm{RCT}$ ). 


\section{MATERIAL AND METHODS}

\section{Selection of studies}

A computer assisted search of the Cochrane, Pubmed, Embase and MEDLINE databases from 1966 through June 2000 was conducted using the key words "complex regional pain syndrome type I", "reflex sympathetic dystrophy" in combination with "trial" or "randomised trials" or "random allocation" or "prospective studies" or "double/single blind" and "prevention". Additional reports were identified from reference lists in retrieved reports and in review articles. In 1994 the term Complex Regional Pain syndrome was introduced 1,2. Because of the differences in diagnostic criteria between RSD and currently used CRPS I, studies about RSD and CRPS I were reviewed separately.

Two investigators independently reviewed all identified trials to determine if a study should be included. Studies were included if they were double or single blinded randomised controlled trials with patients suffering from RSD or CRPS I using pain intensity as the main outcome measure. Only studies from the Dutch-, German- and English literature were included. We excluded not-randomised studies. Case reports and clinical observations were also excluded.

\section{Methodological quality of the studies}

Trials concerning ireatment effectiveness were scored using a 15 - item check list ${ }^{13}$ (tabel.1), which included selection and restriction of the study group, treatment allocation, study size, prognostic comparability, drop outs, interventions, extra treatments, blinding procedure, outcome measurements, follow-up period, side effects and analysis and presentation of data. Each criterion was weighted, resulting in a maximum score of 100 for each study. The essence of a good clinical trial is the (statistical) comparability of the different treatment groups. Thus allocation procedure and drop-out rates are key elements in controlled trials. Therefore, these criteria received the highest possible scores in the check, list. Three independent investigators (T. Forouzanfar and W. E. J. Weber reviewed the placebo controlled studies; T. Forouzanfar and A. J. A. Köke reviewed active controlled studies) assessed the methodological quality of the trials. Disagreements were resolved by consensus between the two investigators. If no agreement could be reached a third investigator was consulted. The assessment resulted in a hierarchical list in which higher scores indicate studies with a higher methodological quality. Trials dealing with prevention of RSD or CRPS I. were scored using the same methodology. 
A Selection and Restriction

Seren

I Description of inclusion and exclusion criteria

2 Reatriction lo a homogenoous study population:

\section{B Treatment allecation}

1 Randomication

2 Allocation procedure adryucte

3 Blinded allocation procedure

\section{Stedy sire}

1. Smallest group bieger than 25 subjests

2 Smallest group bieger than 50 subjects

3 Smallest group bigger than 75 subjects

D Pregnostic cemparability

1 Type of diagnesis

2 Baseline scores for outcome measures

Duration of the complaint

$$
\text { Age }
$$

Sex

6. Previous medication

E. Drop ests

I No drop outs OR

2 Number of drop outs given in each group

3 Reasons for withdrawal (of drop outs) given in cach group

4 Drop outs not leading to bias (less than $5 \%$ )

F Interventioes

$\begin{array}{ll}1 & \text { Type of intervention } \\ 2 & \text { Dose } \\ 3 & \text { Treatment frequency } \\ 4 & \text { Duration of treatment } \\ 5 & \text { Compliance presented }\end{array}$

G Intervention

1 Type of intervention

2 Dose

3 Treatment frequency.

4 Duration of treatment

5 Compliance presented

H Extra treatment

I. No co-intervention $\mathbf{O R}$.

2 Co-intervention comparable betwęen groups

I Blinding of patient

I Attempt at blinding

2 Blinding evaluated and successful

I. Blinding of therapist

I. Artempt at blinding

2. Blinding evaluated and successfiul

K Blinding of observer

!. Attempt at blinding

2 Blinding evaluated and successful

L. Outcome measures

I. Pain intensity

2 Global improvement:

Functional status

Medical consumption

Other

Other

M. Timing of measurements

I Timing comparable

2 Measurement just after the last treatment

$\mathrm{N}$ Side effects.

I Description of the side effects in each group

$+i+2$

+4 If yes, then

$+4+10$

$+4$

$+4+4$

$+4+6$

$+4+8$

$4+2$

it 2

$+41$

$+4 \quad 1$

$+4+1$

$4+* \quad 1$

$+12$

$+2$

$+42$

at +8

it +1

$+4$

$+4$

$+4$

$+42$

$+1+1$

$+1+1$

$+1+1$

$+1+1$

$+42$

$4++5$

$+45$

$4+4$

$+42$

$+4+4$

$+4$

$4+4$

$+2$

$4+1$

$+4$

$+14+1$

$2+1$

$+405$

$+40.5$

$4+1$

$4++5$

O Analysis and presention of data

I Frequencys / mean and standard deviation / median and quartiles . . th * 2 Intention to treat analysis $O R$.

Adequate correction for base line differences or drop outs 


\section{Outcome of the studies}

We considered a study to be positive if the pain intensity was significantly reduced by the therapeutic intervention described when compared with placebo or a control group. A study was classified as "negative" if no difference in pain was achieved by the intervention when compared to the placebo. If the therapeutic intervention under study was more effective, but not significant, the study was classified as "positive not significant".

A similar categorisation was used for preventive treatments. These studies were classified positive if RSD/CRPS I was prevented significantly compared with placebo. If no prevention was achieved, then the study was classified as "negative". If the intervention applied in the study prevented the development of RSD/CRPS I more than placebo, but not significantly so, it was classified as "positive not significant".

We also investigated the influence of sponsorship of the reviewed studies on the methodological quality of the selected studies.

\section{Statistics}

Studies with similar interventions were pooled. A study was regarded as relevant if either pain intensity or prevention of CRPS I was the outcome measure. For methodological quality score we used a cut-of point of 50 as mentioned in the study of van Tulder et al ${ }^{14}$. A trial was considered to be of high quality if the methodological score was 50 points or more, and of low quality if the score was less than 50 points. The level of evidence for therapeutic intervention effectiveness was graded into four levels based on the quality, outcome and relevance of the studies 14 . The four levels were: strong evidence, moderate evidence, limited evidence and no evidence. Strong evidence was based on multiple relevant, high quality trials; moderate evidence on one relevant, high quality trial. and one or more relevant low quality trial. Limited evidence was classified as one relevant, high quality trial or multiple relevant, low quality trials whereas no evidence was classified as one relevant, low quality trial, no relevant trials or contradictory outcomes. 


\section{RESULTS}

\section{Methodological naws}

The major methodological flaws in the reviewed studies included poor description of the inclusion and the exclusion criteria, restriction to a homogeneous study population, small study size, lack of details about previous medications and inadequate patient's compliance description (table 2, 4 and 6).

Tabel 2. Hicrarchiccal lis of the quality score of the RCT's with a placeto group

\section{Scores of the quality criteria}

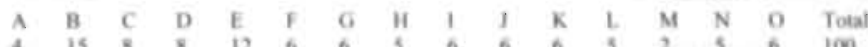

RSD

\begin{tabular}{|c|c|c|c|c|c|c|c|c|c|c|c|c|c|c|c|c|}
\hline Rauck -93 & 4 & 15 & 4 & 4 & 12 & 6 & 6 & 5 & 4 & 4 & 0 & 2 & 2 & 5 & 2 & 77 \\
\hline Ciobelet +92 & 4 & 15 & 4 & 8 & 12 & 4 & 4 & 5 & 4 & 4 & 0 & 3 & 2 & 5 & 2 & 76 \\
\hline Varenna '00 & 4 & 15 & 0. & 8 & 12 & 4 & 4 & 5 & 4 & 4 & 4 & 4 & 2 & 5 & 2 & 75 \\
\hline Adami -97 & 4 & 15 & 0 & 8 & 12 & 6 & 6 & 5 & 4 & 4 & 0 & 15 & 2 & 5 & 2 & 74.5 \\
\hline Zuurmond 96 & 2 & 15 & 0 & 7 & 12 & 3 & 3 & 0 & 4 & 4 & 4 & 15 & 2 & 5 & 2 & 64.5 \\
\hline Verduge .94 & 0 & 5 & 4 & 4 & 12 & 4 & 4 & 5 & 4 & 4 & 4 & 2 & 2 & 5 & 2 & 61 \\
\hline Bickerstaff $\cdot 91$ & 0 & 15 & 0. & 7 & 3 & 4 & 4 & 5 & 4 & o & 0 & 2 & 2 & 5 & 2 & 54 \\
\hline Blanchand '90 & 4 & 0 & 0 & 7 & 12. & 4 & 4 & 5 & 4 & 4 & 0 & 1.5 & $i$ & 5 & 2 & 53.5 \\
\hline Kettier ' 88 & 2 & 5 & 0 & 7 & 4 & 4 & 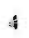 & 5 & 4 & 4 & 4 & z & 1 & 5 & 3 & 53 \\
\hline Jadad '95 & 0 & 15 & 0 & 4 & 12 & 4 & 4 & 5 & 4 & 4 & 0 & 2.5 & 2 & 5 & 2 & 51.5 \\
\hline Christensen ' 82 & 2 & 5 & 0 & 7 & 12 & 4 & 4 & 5 & 0 & 0 & 0 & 3 & 1 & 0 & 2 & 45 \\
\hline $\begin{array}{l}\text { Bounamcatx } \\
-84\end{array}$ & 4 & 0 & 0 & 7 & 12 & 4 & 4 & 0 & 2 & 2 & 0 & 2 & 2 & 0 & 2 & 41 \\
\hline Fialka 93 & 2 & 5 & 0 & 2 & $12:$ & 3 & 3 & 0 & 4 & 0 & 4 & 1 & 0 & 0 & 2 & 38 \\
\hline Hanna -89 & 0 & 0 & 0 & 4 & 0 & 4 & 4 & 5 & 4 & 4 & 0 & 1.5 & 1 & 5 & 2 & 34.5 \\
\hline Kho .95 & 0 & 0 & 0 & 4 & 0 & 4 & 4 & 5 & 4 & 0 & 0 & 15 & 2 & 0 & 2 & 26.5 \\
\hline
\end{tabular}

CRPSI

$\begin{array}{llllllllllllllllll}\text { Price } & -98 & 4 & 5 & 0 & 8 & 12 & 4 & 4 & 5 & 4 & 4 & 4 & 1.5 & 2 & 5 & 2 & 64.5\end{array}$

$\begin{array}{llllllllllllllllll}\text { Wu } & -99 & 4 & 15 & 0 & 2 & 4 & 6 & 6 & 5 & 6 & 0 & 0 & 4 & 2 & 0 & 2 & 59\end{array}$

$\begin{array}{llllllllllllllllll}\text { Korpan } & +99 & 0 & 15 & 0 & 7 & 0 & 4 & 4 & 5 & 0 & 0 & 0 & 2.5 & 2 & 0 & 2 & 41.5\end{array}$ 
In most studies it was not clear whether the therapist or the observer was blinded. Moreover, only one study tested whether the blinding procedure was adequate ${ }^{15}$. In 21 studies the treatment was defined as successful when the pain after intervention was significantly reduced compared with baseline $9-11,15-33$. Only in 5 studies a pain reduction of $30 \%$ or more compared with baseline was defined as a successful treatment ${ }^{34-38}$.

\section{Randomised placebo controlled trials}

A total of 18 articles were included in this review. Tables $3 \mathrm{a}$ and $3 \mathrm{~b}$ list these studies according their quality score. Fifteen studies used RSD criteria. Form these studies 5 were published after $19949,10,18,19,26$. Three studies used the diagnostic criteria for CRPS I 15, 22 , 34. The two investigators managed to resolve disagreements by consensus and the third investigator was never involved. Three trials investigated the effectiveness of acupuncture and used sham acupuncture as placebo. These studies were classified as placebo controlled trials $22,25,26$ because it was not clear whether sham acupuncture was an active control or a placebo.

The quality score of the reviewed papers for RSD ranged from 26.5 to 79 . Ten RCTs had a methodological quality score of 50 point or more $9,10,15,16,18-21,34-36,39$. These articles were considered to be of high quality. Three studies had a cross - over design $10,21,34,36$. The study populations varied between 6 and 66 patients. Treatment modalities included, clonidine $^{16}$, calcitonine 20,39 , clodronate ${ }^{18}$, alendronate ${ }^{19}$, DMSO cream ${ }^{9}$, phentolamine ${ }^{35}$,

phenylephrine ${ }^{35}$, reserpine ${ }^{36}$, guanetidine ${ }^{10,36}$, droperidol ${ }^{21}$, prednisolone ${ }^{37}$, acupuncture 22,24 , 26 and ketanserine 23,25 . 
Table 3a. Hieranchical list of randomined placebo controlled trials of RSD.

\begin{tabular}{|c|c|c|c|c|c|c|c|c|c|c|c|}
\hline Author & Year \& & Score & $\begin{array}{l}\text { Cross- } \\
\text { over }\end{array}$ & PI & Treatment & Treatment & Measurements & Outcome for socoess & $\begin{array}{l}\text { Followup } \\
\text { (month) }\end{array}$ & Resial & Rebual \\
\hline Rauck & 1993 & 77 & No & 26 & Cionidine $700 \mu g$ (epid) & Cionodine $300 \mu g$ (epid) & $\begin{array}{l}\text { VAS, MPQ } \\
\text { pain reduction scale }\end{array}$ & $\begin{array}{l}\text { Significant diflerences in improvement } \\
\text { between groups } \\
\text { (p<0.05) }\end{array}$ & - & $\begin{array}{l}\text { Positve } \\
\text { significant }\end{array}$ & \\
\hline Gobelet & 1992 & 76 & No & 66 & $\begin{array}{l}\text { Calcitonin } 1000 \text { thrice dally } \\
\text { for } 3 \text { weeks (in)" }\end{array}$ & & $\begin{array}{l}\text { Pain scale at rest. } \\
\text { pain scale during } \\
\text { movement } \\
\text { ROM, oodema scale }\end{array}$ & $\begin{array}{l}\text { Significant differences between groups } \\
\qquad(p<0.05)\end{array}$ & 2 & $\begin{array}{l}\text { Posilve } \\
\text { significant }\end{array}$ & - \\
\hline Varenna & 2000 & 75 & No & 32 & $\begin{array}{l}\text { Clodronate } 300 \mathrm{mg} \text { daily } \\
\text { for } 10 \text { days. } \\
\qquad(\mathrm{iv})^{2}\end{array}$ & & $\begin{array}{l}\text { VAS. } \\
\text { global measure of } \\
\text { improvement } \\
\text { giobal assessmet, ROM } \\
\text { Laboratory tests }\end{array}$ & $\begin{array}{l}\text { Significant differences in improvement } \\
\text { between groups } \\
\text { (pre } 0.05)\end{array}$ & 6 & $\begin{array}{l}\text { Positive } \\
\text { significant }\end{array}$ & \\
\hline Adami & 1997 & 74,5 & No & 20 & $\begin{array}{l}\text { Alendronate } 75 \mathrm{mg} / \text { day for } \\
3 \text { days (iv) }\end{array}$ & & $\begin{array}{l}\text { VAS, } \\
\text { motorncore. } \\
\text { DXa }\end{array}$ & $\begin{array}{l}\text { Significant diflerences in improvernert } \\
\text { between groups } \\
\text { (pec0 05) }\end{array}$ & 12 & $\begin{array}{l}\text { Powtive } \\
\text { significant }\end{array}$ & . \\
\hline Zuurmond & 1996 & 64,5 & No. & 32 & $\begin{array}{l}50 \% \text { DMSO cream for } 2 \\
\text { month }\end{array}$ & & $\begin{array}{l}\text { RSD soom } \\
\text { VAS }\end{array}$ & $\begin{array}{l}\text { Significant change of the median } \\
\text { (between baseine and affer } 2 \text { month) } \\
\text { compared between both groups. }\end{array}$ & 2 & Negative & \\
\hline Verdugo & 1994 & 61 & No & 77 & $\begin{array}{l}\text { First phase. iv placebo } \\
\text { followed by, iv } \\
\text { phentolamine } 35 \text { mg for } 30 \\
\text { min }\end{array}$ & $\begin{array}{l}\text { Second phase: iv placebo } \\
\text { was followed by. N } \\
\text { phentolame } 35 \mathrm{mg} \text { or } \\
\text { phemylephrine } 500 \text { ing in } \\
\text { random order }\end{array}$ & 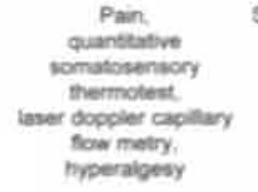 & $\begin{array}{l}\text { Significant improvement within patenta } \\
\text { Change by so\% of more was } \\
\text { considered as significant. }\end{array}$ & - & Negative & Negative \\
\hline Bickentaf & 1991 & 54 & Nọ & 40 & $\begin{array}{l}\text { Caicichonin } 200 \text { IU Iwice } \\
\text { dady for } 4 \text { weeks (IN) }\end{array}$ & & $\begin{array}{l}\text { Chororimetry. } \\
\text { pain questioner, } \\
\text { hand volume, grip } \\
\text { strength. } \\
\text { finger siffines. }\end{array}$ & $\begin{array}{l}\text { Significart difterences in ingrovement } \\
\text { between groups. }\end{array}$ & 3 & Negablve & $*$ \\
\hline
\end{tabular}




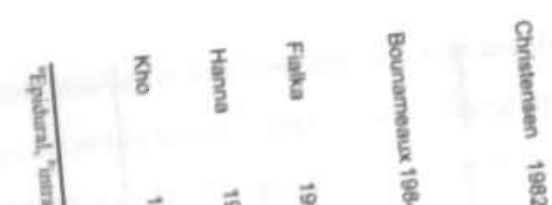

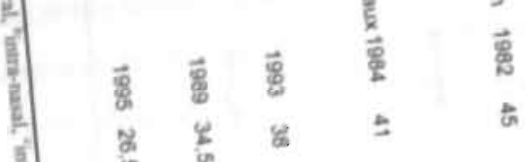

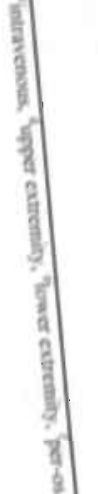

만.

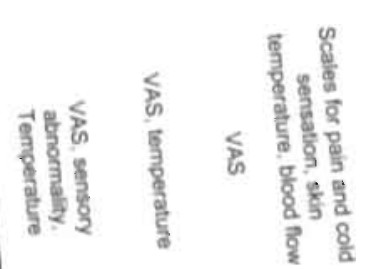

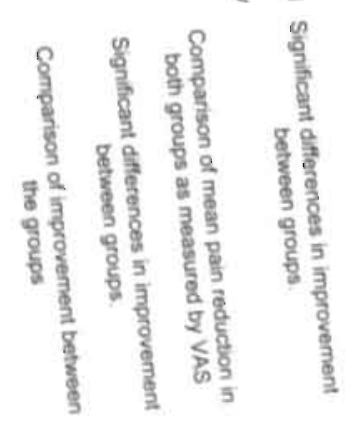

$\therefore$ -

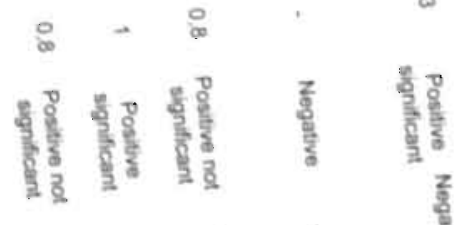

害咅

棌

$\stackrel{9}{\square}$

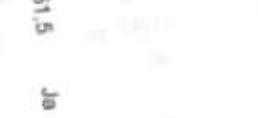

ब
罯

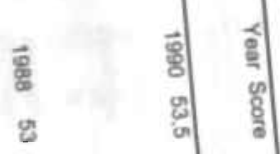

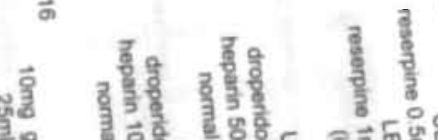

3ㅎำ

1EN

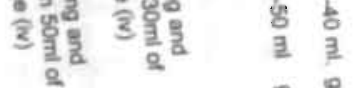

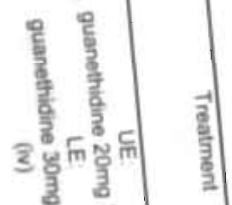

항

等整

홍

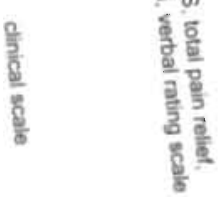

整高

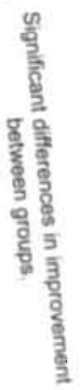

意

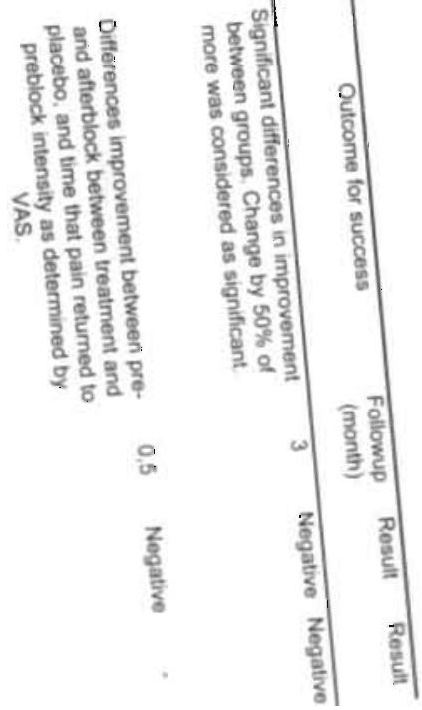




\begin{tabular}{|c|c|c|c|c|c|c|c|c|c|c|c|}
\hline Author & Year & Scone & $\begin{array}{l}\text { Cross } \\
\text { over }\end{array}$ & $P I$ & Treatment & Treatment & Measurnments & Outcome for success & $\begin{array}{l}\text { Followup } \\
\text { (month) }\end{array}$ & Resuit & Resuit \\
\hline Price & 1998 & 64.5 & Yes & 7 & $\begin{array}{l}\text { Sympathetic ganglion block by } \\
1 \% \text { lidociane }\end{array}$ & & $\begin{array}{c}\text { VAS, } \\
\text { Allodynia }\end{array}$ & $\begin{array}{l}\text { Significant diflerences between groups in peak } \\
\text { anaigesic eflect and biock duration. (peak } \\
\text { anaigesic effect = VAS differences between } \\
\text { buseline and the lowbet VAS in the first hour of } \\
\text { the biock; biock duration = fime that the pain } \\
\text { intensity returned to } 50 \text { of of the difference } \\
\text { between baseline and peak analgesic eflect. }\end{array}$ & 0.5 & $\begin{array}{l}\text { Posilive not } \\
\text { significant }\end{array}$ & 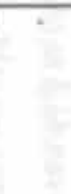 \\
\hline Wu & 1999 & 59 & No & 26 & $\begin{array}{c}\text { Qigong } 40 \text { minutes twice a week } \\
\text { for } 3 \text { weeks and } 7 \text { woeks at } \\
\text { home }\end{array}$ & & $\begin{array}{l}\text { VAS, } \\
\text { medication uaage. } \\
\text { SCL90, Behaviour } \\
\text { Bonescan }\end{array}$ & $\begin{array}{l}\text { Significant differences in improvernent between } \\
\text { groups }\end{array}$ & 2.5 & $\begin{array}{l}\text { Positive } \\
\text { sipnificant }\end{array}$ & - \\
\hline Korpan & 1999 & 41,5 & No & 14 & $\begin{array}{l}\text { Acupunture } 5 \text { times a week for } 3 \\
\text { woeks }\end{array}$ & Sham & $\begin{array}{l}\text { VAS, functional impaiment. } \\
\text { volumetric mreasurement. } \\
\text { goniometry, Temperature }\end{array}$ & $\begin{array}{l}\text { Significant differences in improvement between } \\
\text { groups }\end{array}$ & 6 & Negative. & \\
\hline
\end{tabular}

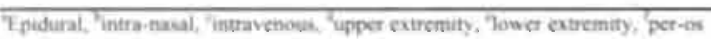


The methodological quality score of the CRPS I studies ranged between 41.5 to 64.5 and the study population between 7 and 26 patients $15,22,34$. The study of Price et al ${ }^{34}$ and Wu et al 15 had a score of 64.5 and 59 respectively. These studies were considered to be of high quality. The treatment modalities included: sympathetic ganglion blocks ${ }^{34}$, Qigong ${ }^{15}$, and acupuncture 22 .

Tabel 4. Hierarchiecal list of the qualify score of randomised active controlled trials.

\begin{tabular}{|c|c|c|c|c|c|c|c|c|c|c|c|c|c|c|c|c|}
\hline & \multicolumn{14}{|c|}{ Soores of the quality criteria } & \multirow[b]{2}{*}{$\begin{array}{l}0 \\
6\end{array}$} & \multirow[b]{2}{*}{$\begin{array}{l}\text { Total } \\
100\end{array}$} \\
\hline & $\hat{4}$ & $\begin{array}{l}\text { B } \\
\text { is }\end{array}$ & $\begin{array}{c}c \\
B\end{array}$ & $\underset{x}{D}$ & $\begin{array}{l}E \\
12\end{array}$ & $\begin{array}{l}F \\
6\end{array}$ & $\begin{array}{l}0 \\
6\end{array}$ & $\begin{array}{l}\mathrm{H} \\
5\end{array}$ & $\begin{array}{l}1 \\
6\end{array}$ & $\begin{array}{l}3 \\
6\end{array}$ & $\begin{array}{l}K \\
6\end{array}$ & $\frac{L}{5}$ & $\begin{array}{l}M \\
2\end{array}$ & $\begin{array}{l}N \\
5\end{array}$ & & \\
\hline \multicolumn{17}{|l|}{$R S D$} \\
\hline Hord ' 92 & 2 & 15 & 0 & 8 & 4 & 4 & 4 & 5 & 4 & 0 & 4 & 2 & 1 & 5 & 2 & 60 \\
\hline Oerlemans '00 & 4 & 15 & 4 & 7 & 10 & 4 & 4 & 0 & in & 8 & 0 & 4.5 & 1 & 0 & 6 & 595 \\
\hline Ramamurthy '95. & 4 & is & 0 & $s$ & 12 & 4 & 4 & 0 & 2 & 0 & 2 & 3 & 2 & 0 & 2 & 58 \\
\hline Rose ' $\$ 9$ & 4 & is & 0 & s & 0 & 4 & 4 & b & 2 & 2 & 0 & 1.5 & 2 & 5 & 0 & 47.5 \\
\hline Bonelli ' 83 & 4 & 0 & 0 & 4 & 12 & 4 & 4 & 0 & 0 & 0 & 0 & 2 & 2 & 0 & 4 & 36 \\
\hline Geertzen '94 & 2 & 0 & 0 & 6 & 12 & 4 & 4 & 0 & 0 & 0 & 0 & 0.5 & 2 & 5 & 0 & 35 \\
\hline \multicolumn{17}{|l|}{ CRPSI } \\
\hline Uher '00 & 2 & 15 & 0 & 5 & 12 & $\varepsilon$ & 5 & 5 & 0 & 0 & 0 & 2 & 2 & 0 & 2 & 55 \\
\hline Wallace '00 & 0 & 0 & 0 & 8 & 12 & 6 & 6 & 5 & 2 & 0 & 2 & 1.5 & 2 & 5 & 2 & 49.5 \\
\hline
\end{tabular}

RSD

Sympathetic block.

The study, performed by Rauck et al ${ }^{16}$, was classified as high quality. Epidural clonidine 700 $\mu \mathrm{g}$ and $300 \mu \mathrm{g}$ both decreased pain significantly more than placebo.

The high quality study of Verdugo ${ }^{35}$ demonstrated that neither intravenous. phentolamine $35 \mathrm{mg}$ nor phenylephrine $500 \mu \mathrm{g}$ given to achieve regional sympathetic block were effective for the treatment of RSD.

One study ${ }^{36}$ tested intravenous reserpine $(0.5 \mathrm{mg}$ for the upper extremity; $1 \mathrm{mg}$ for the lower extremity) and intravenous guanethidine ( $20 \mathrm{mg}$ for the upper extremity; $30 \mathrm{mg}$ for the lower extremity). One further trial ${ }^{10}$ on RSD investigated only intravenous guanethadine (10 $\mathrm{mg}$ and $30 \mathrm{mg}$ for the upper extremity; $20 \mathrm{mg}$ and $30 \mathrm{mg}$ for the lower extremity). Both articles were of high quality and did not find any improvement compared with placebo. 
The high quality study of Kettler ${ }^{21}$ showed that administration of intravenous droperidol $(2.5 \mathrm{mg}$ in $30 \mathrm{ml}$ saline for the upper extremity and $2.5 \mathrm{mg}$ in $50 \mathrm{ml}$ saline for the lower extremity) did not result in any improvement in RSD patients.

Intravenous ketanserine was investigated in two studies 23,25 . Bounameaux et al 23 administered ketanserine $10 \mathrm{mg}$ in one bolus. There was no significant improvement in pain intensity. Hanna et al ${ }^{25}$ did the same. However they found significant improvement by Ketanserine compared with placebo.

\section{Calcium regulating drugs.}

Varenna et al ${ }^{18}$ investigated the efficacy of intravenous clodronate $300 \mathrm{mg}$ given for 10 days. Their trial was of high quality and resulted in a significant improvement in pain reduction in those patients given clodronate compared with the placebo group. Thus there is limited evidence for the efficacy of clodronate. Adami et al ${ }^{19}$ administered intravenous alendronate $7.5 \mathrm{mg}$ or placebo daily for 3 days. This was a high quality trial with a positive significant result.

Two articles 20,39 were identified using calcitonine (intranasal) as a therapeutic intervention. Both articles were of high quality: In the study ${ }^{39}$ with the highest quality score (76), performed by Gobelet et al, significant improvement in pain intensity was achieved after intra nasal calcitonine 100 IU thrice daily for three weeks. Whereas in the trial of Bickerstaff ${ }^{20}$, no improvement was found after administering of calcitonine 200 IU intra nasally twice daily for 4 weeks.

\section{Radical scavenging.}

Topical DMSO was tested by Zuurmond et al $^{9}$ in a high quality study which did not show significant pain reduction.

\section{Corticosteroids.}

We found one trial ${ }^{37}$ that investigated the efficacy of prednisolone $10 \mathrm{mg}$ thrice daily for a maximum period of 12 weeks. The investigators, Christensen et al ${ }^{37}$ found a significant improvement after administering prednisolone. However this trial was of low quality. 


\section{Complementary therapies.}

Two trials $22,25,26$ studied the efficacy of acupuncture 5 times a week for 3 weeks in patients with RSD. They found an improvement compared with sham acupuncture 25,26 . However this improvement was not significant. Both articles were of low quality.

\section{CRPS I}

\section{Sympathetic block.}

Sympathetic ganglion block in CRPS I patients by $1 \%$ lidocaine was tested in one high quality study performed by Price et al ${ }^{34}$. The results demonstrated that there was a slight improvement after lidocaine, but this improvement was not significant compared with saline.

\section{Complementary therapies.}

The efficacy of 40 minutes of Qigong exercises twice a week for 4 weeks was investigated by Wu et al ${ }^{15}$ in a high quality study and with significant improvement was noted when compared with sham exercises.

One low quality trail investigated the efficacy of acupuncture 5 times a week for 3 weeks on CRPS I patients and did not tind any improvement ${ }^{2}$ ?

\section{Randomised active controlled trials}

Eight studies were identified investigating the effectiveness of the treatment modalities by comparing different treatment interventions. The results are shown in tables $5 \mathrm{a}$ and $5 \mathrm{~b}$. In 6 studies RSD diagnostic criteria were used. Two of these studies were published after 199427. 40. Two studies were identified performing the CRPS I diagnostic criteria $28,29$.

The quality score of the RSD studies ranged between 35 and 65.5 . Three studies proved to be of high quality. The interventions consisted of regional intravenous sympathetic blocks $^{27}, 30,31,38$, physical therapy ${ }^{33}$, Stellate ganglion block ${ }^{31}$ and DMSO application ${ }^{32}$.

The methodological quality sçore of the studies on CRPS I were 55 and 49.5 28, 29. The studies investigated the efficacy of lymph drainage 28 and intravenous lidocaine ${ }^{29}$, respectively. 
Table 5a. Hierarchical liat of randomised active controlled trials on RSI

\begin{tabular}{|c|c|c|c|c|c|c|c|c|c|c|c|}
\hline Author & Year : & Score & $\begin{array}{l}\text { Cross- } \\
\text { over }\end{array}$ & $P t$ & Treatment & Treatment & Treatment. & Measurement & Dutcome for succoss & $\begin{array}{l}\text { Folicow-up } \\
\text { (month) }\end{array}$ & Result \\
\hline Hord & 1992 & 60 & Yest & 12 & $\begin{array}{l}\text { RiS block by } 1.5 \mathrm{mg} / \mathrm{kg} \\
\text { bretylum and } 0.5 \mathrm{~s} \\
\text { lidocain }\end{array}$ & $\begin{array}{l}\text { RIS block by } 40-60 \mathrm{ml} \\
\text { of } 0.5 \% \text { lidocaine }\end{array}$ & & $\begin{array}{l}\text { VAS, Vitai signa, skin } \\
\text { temperature }\end{array}$ & $\begin{array}{l}\text { Pain reduction of mors } \\
\text { than } 30 \% \text { was } \\
\text { considered as signilicant }\end{array}$ & $\underset{3.5}{\text { Maximai }}$ & $\begin{array}{l}\text { bretylum and lidocaine } \\
\text { resulted in sonificant } \\
\text { better improvement then } \\
\text { ldocaine abene }\end{array}$ \\
\hline Oerlemans & 1999 & 595 & No & 135 & Physical therapy & Occupational therapy & $\begin{array}{l}\text { Social work } \\
\text { (no therapy) }\end{array}$ & $\begin{array}{l}\text { VAS, MPQ. AROM, skin } \\
\text { temperature. Volumetrie }\end{array}$ & $\begin{array}{l}\text { Differences between } \\
\text { baseline and } \\
\text { subsequent } \\
\text { observations for each } \\
\text { group and within groups } \\
\text { (p<0.05) }\end{array}$ & 12 & $\begin{array}{l}\text { Significant improvement } \\
\text { compared to baseline } \\
\text { and control group }\end{array}$ \\
\hline Ramamurthy & 1995 & 58. & Yes & 60 & $\begin{array}{l}\text { UE } \\
20 \mathrm{mg} \text { guanothidine (iv) } \\
\text { LE } \\
40 \mathrm{mg} \text { guanethidine (iv) }\end{array}$ & $\begin{array}{c}\text { UE: } \\
2 \mathrm{~mL} \text { saline in } 0.5 \% \\
30-50 \mathrm{~mL} \text { idocaine } \\
\text { LE } \\
4 \mathrm{~mL} \text { saline in } 0.5 \% \\
40-75 \mathrm{~mL} \text { idocaine }\end{array}$ & & $\begin{array}{l}\text { MPQ, Giobal evaluation } \\
\text { scale, ROM, Skin } \\
\text { Iemperature }\end{array}$ & $\begin{array}{c}\text { The primary efficacy } \\
\text { variatie was the pain } \\
\text { rating index of the MPQ } \\
\text { between placebo and } \\
\text { treatment }\end{array}$ & 6 & $\begin{array}{l}\text { No significant } \\
\text { improvement }\end{array}$ \\
\hline Rocco & 1989 & 47.5 & Yes. & 12 & $\begin{array}{l}\text { RIS block by } 20 \mathrm{mg} \\
\text { guanethidine in } 50 \mathrm{mil} 0.5 \text {, } \\
\text { S fidocaine }\end{array}$ & $\begin{array}{l}\text { RIS block by } 1.25 \mathrm{mg} \\
\text { roserpine in } 50 \mathrm{ml} 0.5 \\
\text { Sh lidocame }\end{array}$ & $\begin{array}{l}50 \mathrm{mil} 0.5 \mathrm{~s} \\
\text { lodocaine }\end{array}$ & $\begin{array}{l}\text { VAS, NRS, pain diary. } \\
\text { Stain temperature }\end{array}$ & $\begin{array}{l}\text { Difliersinces betwean } \\
\text { baseline and } \\
\text { subsecquent } \\
\text { observations for each } \\
\text { group and within groups }\end{array}$ & 24 & $\begin{array}{l}\text { No Significart } \\
\text { improvement }\end{array}$ \\
\hline Bonelth & 1983 & 36 & No & 19 & $\begin{array}{l}\text { Stellate ganglion block } \\
\text { with bupivacaine } 0.5 \% \text {. } 15 \\
\text { mil it a lotal of } 8 \text { block }\end{array}$ & $\begin{array}{l}20 \text { mg guanethidine } \\
\text { (iv), every } 4 \text { days bo a } \\
\text { btal of } 4 \text { blocks }\end{array}$ & & $\begin{array}{l}\text { VAS, shin temperature. } \\
\text { skin plethymography }\end{array}$ & $\begin{array}{l}\text { Ooflenances between } \\
\text { baseline and } \\
\text { mubsequent } \\
\text { observations for each } \\
\text { group and wehin groups } \\
\text { (por 05) }\end{array}$ & 3 & $\begin{array}{l}\text { Significant improvement } \\
\text { compared to baseline. } \\
\text { no differences between } \\
\text { grougs }\end{array}$ \\
\hline Geertzen & 1994 & 35 & No & 26 & $\begin{array}{l}\text { DMSO } 50 \mathrm{H} \text { in water, } 4 \text {. } \\
\text { limes a day for } 3 \text { weeks }\end{array}$ & $\begin{array}{l}\text { RiS block twice a: } \\
\text { week for } 3 \text { woeks }\end{array}$ & & $\begin{array}{l}\text { VAS, daly activity. } \\
\text { Edema, discolorition, } \\
\text { ROMe. finger function. } \\
\text { psycholosical atpects }\end{array}$ & 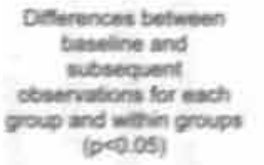 & 3 & $\begin{array}{c}\text { Sonifcart improvement } \\
\text { compared io baseline. } \\
\text { no dillerences between } \\
\text { groups }\end{array}$ \\
\hline
\end{tabular}




\begin{tabular}{|c|c|c|c|c|c|c|c|c|c|c|}
\hline Author & Year Score & $\begin{array}{l}\text { Cross- } \\
\text { over }\end{array}$ & $P 1$ & Treatment & Treatment. & Treatment & Measurement & Outcome for succes & $\begin{array}{l}\text { Followup } \\
\text { (month) }\end{array}$ & Lentimorovement \\
\hline Wher & $2000 \quad 55$ & No & 35 & $\begin{array}{l}\text { Exercise in combination. } \\
\text { with manual lymph } \\
\text { drainage three limes a } \\
\text { week for } 6 \text { weeks }\end{array}$ & $\begin{array}{l}\text { Exercise three times a } \\
\text { week for } 6 \text { weeks }\end{array}$ & & $\begin{array}{l}\text { VRS, ROM, skin } \\
\text { temperature, volumetry, } \\
\text { sintigraphy }\end{array}$ & $\begin{array}{l}\text { Differences belween } \\
\text { baseline and subsequent } \\
\text { observations for each } \\
\text { group and within groups } \\
(p<0.05)\end{array}$ & 15 & $\begin{array}{l}\text { Significant improvernent } \\
\text { compared to baseline, no } \\
\text { differences between groups }\end{array}$ \\
\hline Wallace & 200049.5 & Yes & 16 & $\begin{array}{l}\text { Piasma concentrabon of } 1 \text {. } \\
2 \text { and } 3 \text { ugiml lidocaine } \\
\text { were targeted and } \\
\text { maintained for } 20 \mathrm{~min} \text { intrs: }\end{array}$ & Diphentydramine & & $\begin{array}{l}\text { VAS, allodynia. } \\
\text { neurosensory testing }\end{array}$ & $\begin{array}{l}\text { Differences between } \\
\text { baseline and subsequent } \\
\text { observations for each } \\
\text { group and within groups } \\
\qquad(p<0.05 \text { ) }\end{array}$ & 0.25 & $\begin{array}{l}\text { Significant decreased } \\
\text { response to stroking and } \\
\text { cool stimuli. and } \\
\text { spontaneous pain at high } \\
\text { fidocaine plasma level }\end{array}$ \\
\hline
\end{tabular}


Sympathetic block.

Three cross-over studies have investigated the effectiveness of sympathetic blockade. Hord et $\mathrm{al}^{38}$ administered bretylium $1.5 \mathrm{mg} / \mathrm{kg}$ together with $0.5 \%$ lidocaine or only $0.5 \%$ lidocaine with out bretylium. They defined a pain reduction of more than $30 \%$ compared with baseline as significant. This high quality study demonstrated that the combination of both treatments resulted in significant pain reduction.

Ramamurthy et $\mathrm{al}^{27}$ compared the effectiveness guanethidine in a high quality trial . The patients were enrolled to receive four intravenous regional blocks at 4-day intervals with either guanethidine or $0.5 \%$ lidocaine. Each patient was randomised to receive either I guanethidine and 3 lidocaine blocks, 2 guanethidine and 2 lidocaine blocks, or 4 guanethidine blocks without any lidocaine block. The sympathetic blocks for the upper extremity were done with either $2 \mathrm{ml}(20 \mathrm{mg})$ guanethidine or $0.5 \%$ lidocaine 30 to $50 \mathrm{~mL}$. For the lower extremity the blocks were performed with $4 \mathrm{ml}(40 \mathrm{mg})$ guanethidine or $0.5 \%$ lidocaine 40 to $75 \mathrm{ml}$. The results did not demonstrate any significant differences between the interventions. In addition, Rocco et al ${ }^{30}$, in a low quality randomised cross-over study, investigated the effectiveness of guanethidine and reserpine. All patients successively received $20 \mathrm{mg}$ guanethidine in $50 \mathrm{ml} 0.5 \%$ lidocaine, $1.25 \mathrm{mg}$ reserpine in $50 \mathrm{ml} 0.5 \%$ lidocaine and $50 \mathrm{ml}$ $0.5 \%$ lidocaine with a 1 -week interval between medications. No significant reduction in pain was found with either combination therapy.

Stellate ganglion block using $15 \mathrm{ml} 0.5 \%$ bupivacaine was compared to regional intravenous sympathetic block using guanethidine $20 \mathrm{mg}$ every four days to a total of 4 blocks ${ }^{31}$ in a low quality study. This study, performed by Bonelli et al ${ }^{31}$, did not demonstrate any differences between these treatments.

Radical scavenging vs. Sympathetic block.

Geertzen et al ${ }^{32}$ compared in a low quality study the effectiveness of dermal application of DMSO $50 \%$ four times daily for 3 weeks with regional intravenous sympathetic blockade trice weekly for 3 weeks. No differences were found between these interventions.

\section{CRPS I}

Sympathetic block.

Wallace et al ${ }^{29}$ administered lidocaine and compared its effectiveness with diphenhydramine. Plasma lidocaine concentration steps of $1 \mu \mathrm{g} / \mathrm{ml}, 2 \mu \mathrm{g} / \mathrm{ml}$ and $3 \mu \mathrm{g} / \mathrm{ml}$ were targeted and 
maintained for 20 minutes. In this low quality study lidocaine proved to achieve significant improvement.

\section{Complementary therapies.}

In a study by Uher et $\mathrm{al}^{28}$ the effectiveness of lymph drainage combined with exercise was compared with exercise alone. This high quality study did not show any differences between these interventions.

\section{Prevention of CRPS I}

The search for relevant studies concerned with prevention of RSD/CRPS I resulted in 2 randomised placebo controlled studies ${ }^{41,42}$, that describe preventive modalities in RSD patients (tables 6 and 7). Both articles were of high quality. In the first article ${ }^{41}$ either placebo or Vitamin C $500 \mathrm{mg}$ was administered daily for 50 days in patients with RSD after a Colles' fracture. At one year the incidence of RSD in those patients given Vitamin C was significantly less than those in the placebo group. In the second study ${ }^{42}$ either saline or intravenous guanethidine $20 \mathrm{mg}$ was administered in patients undergoing faciectomy for Duputyren's disease. They concluded that it is not possible to prevent RSD giving intravenous guanethidine pre-operatively.

Tabel 6. Hieranchiecal list of RCTs on the prevention of RSD

Scores of the quality criteria

\begin{tabular}{llllllllllllllll}
\hline $\mathrm{A}$ & $\mathrm{B}$ & $\mathrm{C}$ & $\mathrm{D}$ & $\mathrm{E}$ & $\mathrm{F}$ & $\mathrm{G}$ & $\mathrm{H}$ & $\mathrm{I}$ & $\mathrm{J}$ & $\mathrm{K}$ & $\mathrm{L}$ & $\mathrm{M}$ & $\mathrm{N}$ & $\mathrm{O}$ & Total \\
4 & 15 & 8 & 8 & 12 & 6 & 6 & 5 & 6 & 6 & 6 & 5 & 2 & 5 & 6 & 100
\end{tabular}

\begin{tabular}{lllllllllllllllllll}
\hline Zollinger 99 & 4 & 15 & 6 & 7 & 12 & 4 & 4 & 0 & 4 & 4 & 4 & 3 & 2 & 5 & 2 & 76 & \\
Gichwind 95 & 4 & is & 4 & 7 & 12 & 4 & 4 & 5 & 4 & 4 & 0 & 3 & 2 & 0 & 2 & 70 & 3 \\
\hline
\end{tabular}

Tabel 7. Hierarchiecal list of RCTs on the prevention of RSD

\begin{tabular}{|c|c|c|c|c|c|c|c|c|c|}
\hline Author & Year & Score & $\begin{array}{l}\text { Cross- } \\
\text { over }\end{array}$ & $\mathrm{Pt}$ & Treatment & Treatment & Outcome. & $\begin{array}{l}\text { Followup } \\
\text { (month) }\end{array}$ & Result \\
\hline Zollinger & 1999 & 76 & No & 123 & $\begin{array}{c}\text { Vitamin C, } 500 \mathrm{mg} \text { for } 50 \\
\text { day }\end{array}$ & Placebo & RSD-criteria & 12 & $\begin{array}{c}\text { Significant less } \\
\text { incidence of RSD with } \\
\text { Vit } C\end{array}$ \\
\hline Gschwind & 1995 & 70 & No & 71 & Guanathidine $20 \mathrm{mg}$ iv & Placebo & RSD-criteria & 15 & Negative \\
\hline
\end{tabular}




\section{The influence of sponsorship on methodological quality}

To investigate the influence of sponsorship on the quality of the selected studies we combined all studies of treatment modalities to one study population. Seven studies of 26 studies were funded $16,17,20,27,35,38,40$. The mean methodological quality of the funded studies was significantly higher than the other studies ( $t$-test; $p<0.02$ ).

\section{DISCUSSION}

We designed the present review to prevail a consensus in the treatment or prevention of RSD or CRPS I. Randomised controlled trials that have examined the effectiveness of treatments and prevention of this disabling disease were reviewed.

Generally, the value of a review of the literature depends on the success in obtaining the results of all studies that have been conducted on the subject at issue. Reviews are subject to bias caused by the outcomes of published and unpublished studies differing (publication: bias). Although we put much effort into obtaining all the available studies, we may have missed important published and unpublished trials. Furthermore, we were not blinded for the outcomes of the publications in this review, which means that some degree of reviewer bias cannot be excluded. Any, reader however, can check our point assignment and apply different weights to different criteria.

We identified 27 randomised trials, of which 18 were placebo controlled ${ }^{9}, 10,15-26,34$ 37. The heterogeneity of the studies and the small sample sizes precluded the drawing of firm. conclusions about the efficacy or effectiveness of any of the interventions studied on RSD or CRPS I patients. On basis of our review we conclude that there is limited to no evidence for efficacy of sympathetic blocks (Stellate ganglion block or RIS block), radical scavenging, prednisolone administration, acupuncture and manual lymph drainage. Calcium regulating drugs and Qigong exercises seem to be promising treatment modalities. However, further high quality studies are required before the place of these treatments in pain therapy can be established. Further, it is demonstrated that funded studies have better methodological quality than not funded studies.

The search for eligible trials about prevention resulted in 2 high quality randomised placebo controlled studies in which vitamin $\mathrm{C}$ and intravenous guanethidine were investigated on RSD patients 41,42 . Vitamin C prevented RSD while guanethidine did not prevent the development of RSD. Both studies had small sample sizes and no other randomised placebo 
controlled studies were identified. Therefore there is limited evidence whether any interventions can significantly prevent RSD.

The major methodological flaws in the reviewed studies included poor description of the inclusion and the exclusion criteria, restriction to a homogeneous study population, small study size, lack of details about previous medications and inadequate patient's compliance description. Mostly, it was not clear whether the therapist or the observer was blinded and only one study ${ }^{15}$ tested whether the blinding procedure was adequate. Except of 5 studies $^{34-38}$ in all studies the treatment was defined as successful when the pain after intervention was significantly reduced compared with baseline and the control ${ }^{9-11}, 15-33$. In these studies it is not clear whether a significant pain reduction is classified as improvement according the patients. Therefore the results of these studies are questionable. Furthermore, after the introduction of the CRPS I diagnostic criteria in $1994{ }^{1}$ only 5 studies $15,22,28,29,34$ of the 14 studies $9,10,15,18,19,22,26,28,29,33,34,41-43$ performed after 1994, used these criteria.

In conclusion there is limited evidence to support the effectiveness of commonly used interventions for treating or preventing RSD or CRPS I. More prospective controlled trials are needed in this field. 


\section{References}

1. Merskey KR, Bogduck N. Classification of Chronic Pain: Descriptions of Chronic Pain Syndromes and Difinitions of Pain Term. Seattle, WA: LASP Press, 1994

2. Schurmann M, Gradl G, Andress H, Furst H, Schildberg FW. Assessment of peripheral sympathetic nervous function for diagnosing early post-traumatic complex regional pain syndrome type L. Pain 1999, 80:149-59.

3. Baron R. Peripheral neuropathic pain: from mechanisms to symptoms. Clin J Pain 2000; 16:\$12.20.

4. Woolf CJ, Mannion RJ. Neuropathic pain: actiology, symptoms, mechanisms, and management. Lancet 1999, 353:1959. 64.

5. Davidoff G, Werner R, Cremer S, Jackson MD, Ventocilla C. Wolf L. Predictive value of the three-phase iechnetium bone scan in diagnosis of reflex sympathetic dystrophy syndrome. Arch Phos Med Rehabil 1989; 70:135-7.

6. Kozin F, Soin JS, Ryan LM, Carrera GF, Wortmann RL. Bone scintigraphy in the reflex sympathetic dystrophy syndrome. Radiology 1981: 138:437-43.

7. Schwartaman RJ, McLellan TL Reflex sympathetic dystrophy. A review. Arch Neurol 1987; 44:555-61.

8. Stanton-Hicks M, Janig W, Hassenbusch S, Haddox JD, Boas R, Wilson P. Reflex sympathetic dystrophy: changing concepts and taxonomy. Pain 1995; 63:127-33.

9. Zuurmond WW, Langendijk PN, Bezemer PD, Brink HE, de Lange J, van loenen AC. Treatment of acute reflex sympathetic dystrophy with DMSO $50 \%$ in a fatty cream. Acta Anacrthesiol Scand 1996; 40:364-7.

10. Jadad AR, Carroll D, Glynn CJ, McQuay HJ. Intravenous regional sympathetic blockade for pain relief in reflex sympathetic dystrophy; a systematic review and a randomired, double-blind crossover study. J Pain Simplom Mamage 1995: 10:13-20.

11. Kemler MA, Barendse GA, van Kleef M, et al. Spinal cord stimulation in patients with chronic reflex sympathetic dystrophy [see comments]. N Engl J Med 2000; 343:618-24.

12. Kingery WS. A critical review of controlled elinical trials for peripheral neuropathic pain and complex regional pain. syndromes [see comments]. Pain 1997; 73:123-39.

13. de Vet HCW, deBie RA, G. vdHGJM, Verhagen AP, Sijpkes P, Knipschild PG. Systematic reviews on the basis of methodological criteria. Physiotherapy 1997; 83:284-9!

14. van Tulder MW, Koes BW, Bouter LM. Conservative treatment of acute and chronic nonspecific low back pain. A systematic review of randomized controlled trials of the most common interventions. Spine 1997:22:2128-56.

15. Wu WH, Bandilla E, Ciecone DS, et ali. Effects of qigong on late-stage complex regional pain syndrome. Altern Ther Health Med 1999; 5:45-54.

16. Rauck RL, Eisenach, JC, Jackson K, Young LD, Southern J. Epidural elonidine treatment for refractory reflex sympathetic dystrophy [see comments]. Anesthesiology 1993; 79:1163-9; discussion 27A.

17. Gobeler C, Waldburger M, Meier Jl L. The effect of adding calicitonin to physical treatment on reflex sympathetic dystrophy, Pain 1992; 48:171-5.

18. Varenna M, Zucchi F, Ghiringhelli D, et al. Intravenous clodronate in the treatment of reflex sympathetic dystrophy syndrome. A randomized, double blind, placebo controlled study. $J$ Rheumatol 2000; 27:1477-83

19. Adami S. Fossaluzza V. Garti D. Fracassi E, Braga V. Bisphosphonate therapy of reflex sympathetic dystrophy syndrome. Ann Rheum Dis 1997; 56:201-4

20. Bickerstaff. DR, Kanis JA. The use of nasal calcitonin in the treatment of post-traumatic algodystrophy (see comments] Br J Rheumatol 1991, 30:291-4.

21. Kettler RE, Abram SE. Intravenous regional dropendol in the management of reflex sympathetic dystrophy: a doubleblind, placebo-controlled, crossover study. Anesthesiology 1988; 69-933-6. 
22. Korpan MI, Dexw Y, Schneider B, Leitha T, Fialka-Moser V. Acupuncture in the treatment of posttraumatic pain syndrome. Acta Orthop Belg 1999; 65:197-201.

23. Bounameaux HM, Hellemans H, Verhacghe R. Ketanserin in chronic sympathetic dystrophy, An acute controlled trial [letter], Clin Rheumatol 1984: 3:556-7.

24. Fialka V, Resch KL, Ritter-Dietrich D, et al. Acupuncture for reflex sympathetic dystrophy [letter]. Arch Intern Med $1993 ; 153: 661,665$.

25. Hanna MH, Pẹt SJ. Ketanserin in reflex sympathetic dystrophy. A double-blind placebo controlled cross-over trial. Pain $1989 ; 38: 145-50$.

26. Kho HK. The impect of acupuncture on pain in patients with reflex sympathetic dystrophy, Pain Clin 1995; 8:59-61.

27. Ramamurthy S, Hoffman J. Intravenous regional guanethidine in the treatment of reflex sympathetic dystrophy/causalgia: a randomized, double-blind study, Guanethidine Study Group. Anesth Analg 1995; 81:718-23.

28. Uher EM, Vacariu G, Schneider B, Fialla. V. [Comparison of manual lymph drainage with physical therapy in complex regional pain syndrome, type I. A companative randomized controlled therapy study]. Wien Klin Wochenschr 2000; $112: 133.7$.

29. Wallace MS, Ridgeway BM. Leung AY, Gerayli A, Yaksh TL. Concentration-effect relationship of intravenous lidocaine on the allodynia of complex regional pain syndrome types f and II. Anesthesiology 2000; 92:75-83.

30. Roceo AG, Kaul AF, Reisman RM, Gallo JP. Lief PA. A comparison of regional intravenous guanethidine and reserpine in reflex sympathetic dystrophy. A controlled, randomized, double-blind crossover study. Clin J Pain 1989; 5:205-9.

31. Boneli S, Conoscente F, Movilia PG, Restelli L. Francucci B, Grossi E. Regional intravenous guanethidine vs, stellate ganylion block in reflex sympathetic dystrophies: a randomired trial. Pain 1983; 16:297-307.

32. Geertzen JH, de Bruijn H, de Bruijn-Kofman AT, Arendzen JH. Reflex sympathetic dystrophy: early treatment and. psychological aspects. Arch Phys Med Rehabil 1994; 75:442-6.

33. Derlemans HM, Goris JA, de Boo T, Oostendorp RA. Do physical therapy and occupational therapy reduce the impairment percentage in reflex sympathetic dystrophy? Am I Phys Med Rehabil 1999: 78:533-9.

34. Price DD, Long S, Wilsey B, Rafii A. Analysis of peak magnitude and duration of analgesia produced by local anesthetics injected into sympathetic ganglia of complex regional pain syndrome patients. Clin J Pain 1998: 14:216-226.

35. Verdugo RJ, Ochoa JL. 'Sympathetically maintained pain.' I. Phentolamine block questions the concept [see comments]. Neurology 1994: 44:1003-10

36. Blạchard J, Ramamurthy S, Walsh N, Hoffman I!. Schoenfẹid L. Intravenous regional sympatholysis: a doụble-blind comparison of guanethidine, reserpine, and normal saline. J Pain Symptom Manage 1990: 5:357-61.

37. Christensen K, Jensen EM. Noer I. The reflex dystrophy syndrome response to treatment with systemic corticosteroids. Acta Chir Scand 1982: 148:653-5.

38. Hord AH, Rooks MD, Stephens BO, Rogers HG, Fleming LL. Intravenous regional bretylium and lidocaine for treatment of reflex sympathetic dystrophy: a randomized, double-blind study. Anesth Analg 1992; 74:818-21.

39. Gobelet C. Meier J, Schaffner W. Bischof-Delaloye A, Gerster JC, Burckhardt P. Calcitonin and reflex sympathetic dystrophy syndrome. Clin Rhenumatol 1986; 5:382-8.

40. Oerlemans HM. Oostendorp RA, de Boo T, van der Laan L. Severens J., Goris JA. Adjuvant physical therapy versus occupational therapy in patients with reffex sympathetic dystrophy/complex regional pain syndrome type I. Arch Plys Mod Rehabil 2000; $81: 49-56$

41. Zollinger PE, Tuinebreijer WE, Kreis RW, Breederveld RS. Effect of vitamin C on frequency of reflex sympathetic dystrophy in wrist fractures: a randomised trial. Lancet 1999; 354:2025-8

42. Gischwind C, Fricker R, Lacher G, Jung M. Does peri-operative guanethidine prevent reflex sympathetic dystrophy? $J$ Hand Sing / Br/ !995; 20:773-5

43. Verdugo RJ, Ochoa Л. Reversal of hypoaesthesia by nerve block, or placebo: a psychologically mediated sign in chronic pseudoneuropathic pain patients. J Nearol Neurosarg Psychiatry 1998; 65:196-203. 


\section{CHAPTER 3}

What is a meaningful pain reduction in patients with Complex Regional Pain Syndrome Type I?

Tymour Forouzanfar, Wilhelm E.J. Weber, Marius Kemler and Maarten van Kleef

Published in Clin. J. Pain 2003; 19(5): 281-285 


\section{ABSTRACT}

Objectives: The aim of the present study was to investigate the degree of pain reduction in patients with CRPS I that can be defined as "successful".

Design: All patients rated their pain on a Visual Analogue Scale (VAS, 0-10) before treatment and on three occasions after treatment at 6 months, 1 year and 2 years. Patients also rated a Global Perceived Effect (GPE) for their pain relief at the same time periods. The GPE items were classified as "successful" or "unsuccessful". The mean absolute and relative pain reduction (VAS) was calculated for both "successful" and "unsuccessful" GPE classifications for each time period. Sensitivity and specificity analyses were performed.

Patients: Sixty-one CRPS I patients.

Results: The patients defined a relative pain reduction of $58 \%$ (s.d.: 23.4 ) or more as "successful", whereas in both "successful" and "unsuccessful" patients the pain was reduced significantly on the VAS. Furthermore, sensitivity and specificity analyses demonstrated that a cut-off point of $50 \%$ relative pain reduction and a $3 \mathrm{~cm}$ absolute pain reduction on VAS have the highest likelihood that patients report "successful" on the GPE.

Conclusion: Relative pain reduction of $50 \%$ or more and an absolute pain reduction of at least $3 \mathrm{~cm}$ on VAS are accurate in predicting a successful pain reduction after a given treatment. 


\section{INTRODUCTION}

Complex Regional Pain Syndrome type I (CRPS I), formerly known as Reflex. Sympathetic Dystrophy, is a post-traumatic syndrome with pain that is not related to the territory of a single nerve and is disproportionate to the inciting event ${ }^{1}$. No specific test is currently available to diagnose this syndrome, and the diagnosis of CRPS I has to be based solely on subjective measurements of clinical symptoms. In clinical studies on CRPS I, pain assessment is a crucial measurement. The Visual Analogue Scale (VAS) is normally used to assess the pain intensity. A treatment is defined as successful when the pain after intervention is significantly reduced compared with baseline and/or control group measures $2 \cdot 7$. Farrar et $\mathrm{al}^{8}$ showed that a percentage pain intensity difference of more than $33 \%$ is an accurate cut-off point in reflecting clinically important improvement for patients treating for breakthrough cancer pain. Furthermore, in rheumatoid arthritis a $36 \%$ overall improvement should be considered as clinically important ${ }^{9}$.

In CRPS I studies a pain reduction of 30 to $50 \%$ has been claimed to demonstrate that a treatment is successful ${ }^{10-13}$. To our knowledge, however, it is still not clear what degree of pain reduction is clinical relevant for CRPS I patients. We undertook the present study to investigate the clinical relevant pain reduction in patients suffering from CRPS I.

\section{METHODS}

\section{Subjects}

The data for this study consisted of the pain intensity assessments in 52 CRPS I patients participating in a previously reported randomized trial on the effectiveness of spinal cord stimulation ${ }^{14}$. Furthermore, 9 patients, who were treated with spinal cord stimulation but whot did not participate in the trial were included in this study. The diagnostic criteria for CRPS I, developed by the International Association for the Study of Pain ${ }^{15}$, were used for all patients. In addition, patients had to show impaired function and extension of symptoms outside the area of trauma.

\section{Procedure}

All patients were asked to score their pain on a VAS $(0-10 \mathrm{~cm}) 3$ times a day over a course of 4 days. The VAS was anchored by 2 extremes of pain: "no pain" on the left and "the worst possible pain" on the right end. In addition, all patients rated the Global Perceived Effect 
(GPE) on a seven-point scale (1, worst ever; 2, much worse; 3, a little worse; 4 , not changed; 5, a little improved; 6, much improved; and 7, best ever). The GPE was translated from English in to Dutch ${ }^{14}$. These VAS and GPE measurements were made pre-treatment and at 6 month, I year and 2 year follow-up.

\section{Statistics}

Global Perceived Effect scores of 6 and 7 were classified as "successful" and GPE scores of 1-5 were defined as "unsuccessful". For both "successful" and "unsuccessful" the mean absolute and relative pain reduction was calculated for the pain intensity (VAS) for each consecutive follow-up periods. Parametric data were analysed using t-tests.

We used $2 \times 2$ tables to calculate the sensitivity, specificity and accuracy values for different cut-off points in absolute and relative pain intensity reduction ${ }^{8}$. These pain intensity reductions were compared with the GPE classifications(i.e. "successful" and "unsuccessful"). Table I demonstrates the definition of sensitivity, specificity and accuracy as used in the present study.

Table 1. Calculation of sensitivity, specificity and aceuracy

\begin{tabular}{lcc}
\hline Pain reduction & "Successful" patients according to & "Unsuccessful" patients according \\
& the GPE & to the GPE \\
\hline $50 \%$ & a & b \\
$<50 \%$ & c & d
\end{tabular}

Sensitivity, $a /(a+c)$; specificity, $d /(b+d)$; accuracy, $(a+d) /$ patient population

The best cut-off point was selected by 2 authors (T. F. and W.E.J.W.) and was defined as one with the highest overall accuracy coupled with the best balance of sensitivity and specificity. When similar levels of accuracy occurred, the cut-off point with a reasonable value for both sensitivity and specificity was chosen.

\section{RESUITS}

There were no significant differences between the groups with regard to mean pre treatment VAS and mean age ( $t$-test; $p>0,1$ ). Therefore, both groups were combined to one study population. Patient demographics are listed in table 2. The study population consisted of 19 males and 42 females. The mean pretreatment VAS was 7.1 and the mean age 43 years. 
Table 2. Patient demographics.

\begin{tabular}{lc}
\hline Gender & 19 \\
Male & 42 \\
Female & $43.1 \pm 10.6$ \\
Age $($ mean \pm s.d.) & $7.1 \pm 1.5$ \\
VAS (mean \pm s.d.)
\end{tabular}

The pain scores for each consecutive follow-up period are listed using the classification "successful" and "unsuccessful" (table 3). The GPE level "best ever" was never selected by the patients. The overall pain reduction according to all levels of the GPE is listed in table 4. Of the 2-year follow-up the results of 5 patients. were missing. The absolute pain reduction of both "successful" and "unsuccessful" patients was decreased significantly during the follow-up assessments ( $\mathrm{p}<0.05$ ). A relative pain reduction between $58 \%$ (s.d: 23.4 ) and $71 \%$ (s.d.: 16.3) and an absolute pain reduction between 4.2 (s.d.: 2.0 ) and 4.8 (s.d.: 1.6) was scored as "successful" by the patients, whereas a relative pain reduction of $13 \%$ (s.d.: 35.2 ) or less was noted as "unsuccessful". An absolute pain reduction of 1.1 (s.d.: 2.4) was defined as "unsuccessful",

Table 3. The absolute and relative pain reduction (mean \pm s.d.) according the classification "successful" and "unsuccessful" ("Successful" is defined as "much improved" and "best ever" according the GPE; "unsuccessful" is defined as " a little improved", "not changed", "a little worse", "much worst" and "worst ever")

\begin{tabular}{|c|c|c|c|c|}
\hline \multirow[b]{2}{*}{ Period } & \multicolumn{2}{|c|}{ Successful } & \multicolumn{2}{|c|}{ Unsuccessful } \\
\hline & $\begin{array}{c}\text { Absolute pain } \\
\text { reduction }\end{array}$ & $\begin{array}{l}\text { Relative pain } \\
\text { reduction }(\%)\end{array}$ & $\begin{array}{l}\text { Absolute pain } \\
\text { reduction }\end{array}$ & $\begin{array}{l}\text { Relative pain } \\
\text { reduction (\%) }\end{array}$ \\
\hline $\begin{array}{l}6 \text { month follow-up } \\
\qquad(\mathrm{N}=61)\end{array}$ & $\begin{array}{c}4.8( \pm 1.6) \\
(\mathrm{N}=16)\end{array}$ & $71.1( \pm 16.3)$ & $\begin{array}{c}1.1( \pm 2.4) \\
(\mathrm{N}=45)\end{array}$ & $13.7( \pm 35.2)$ \\
\hline $\begin{array}{l}\text { Eyear follow-up } \\
\qquad(\mathrm{N}=61)\end{array}$ & $\begin{array}{c}4.4( \pm 1.9) \\
(\mathrm{N}=21)\end{array}$ & $63.3( \pm 25.4)$ & $\begin{array}{c}0.7( \pm 2.0) \\
(\mathrm{N}-40)\end{array}$ & $7.5( \pm 30.8)$ \\
\hline $\begin{array}{l}2 \text { year follow-up } \\
\qquad(\mathrm{N}=56)\end{array}$ & $\begin{array}{c}4.2( \pm 2.0) \\
(\mathrm{N}=18)\end{array}$ & $58.2( \pm 23.4)$ & $\begin{array}{c}0.7( \pm 2.2) \\
(\mathrm{N}=38)\end{array}$ & $8.4( \pm 32.1)$ \\
\hline
\end{tabular}

For both "successful" and "unsuccessful" patients the absolute pain was reduced significantly in all follow-up periods $(P<0.05)$. 
Table 4. Relative pain reduction (mean \pm s.d.) according the levels of the GPE.

\begin{tabular}{|c|c|c|c|}
\hline & & & \multirow[b]{2}{*}{2 year follow-up } \\
\hline & 6 month follow-up & I year follow-up & \\
\hline Worst ever & $-41,8( \pm 45,4)$ & $-38.6( \pm 21.4)$ & $-25.4( \pm 13.6)$ \\
\hline Much worst & $-24.5( \pm 17.4)$ & $-26.9( \pm 14.2)$ & $-8.8( \pm 18.7)$ \\
\hline A little worst & $-11.2( \pm 9.6)$ & $4.3( \pm 25.1)$ & $4.8( \pm 33.6)$ \\
\hline Not changed & $22.9( \pm 28.6)$ & $13.9( \pm 26.0)$ & $16.4( \pm 26.1)$ \\
\hline A little improved & $30.2( \pm 16.3)$ & $26.4( \pm 27.7)$ & $30.7( \pm 40.1)$ \\
\hline Much improved & $71.1( \pm 16.3)$ & $63.3( \pm 25.4)$ & $58.2( \pm 23.4)$ \\
\hline Best ever & . & . & - \\
\hline
\end{tabular}

None of the patients reported "best ever" on the GPE

The frequency distribution of VAS scores associated with "successful" and "unsuccessful" is demonstrated in fig 1 . The ranges of $\%$ improvement in VAS are: $<0$ (increase in pain compared with baseline), $0<20,20<40,40<60,60<80$ and $80-100$. At 6 month follow-up al patients reported a pain reduction of $40 \%$ or more. At the 1 year and 2 year follow-up $90.5 \%$ respectively $72.2 \%$ of the patients reported a pain reduction of at least $40 \%$. 
Figure 1. The frequency distribution of VAS scores associated with "successful" and "unsuccessful" according the GPE.

6 month follow-up $(\mathrm{N}=6 \mathrm{I})$

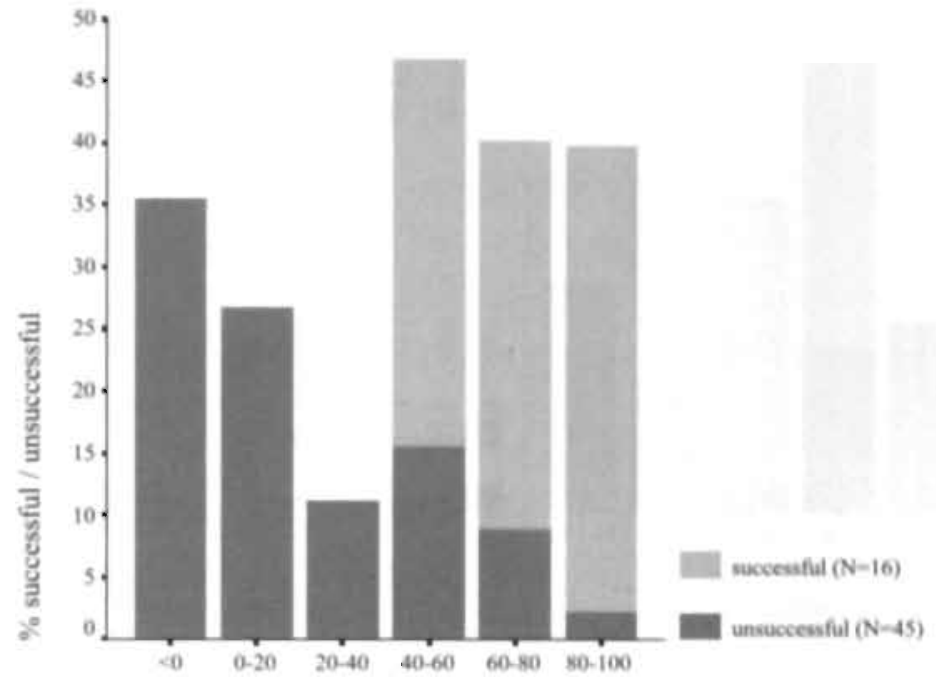

$\%$ improvement according the VAS

I' year follow-up $(\mathrm{N}=61)$

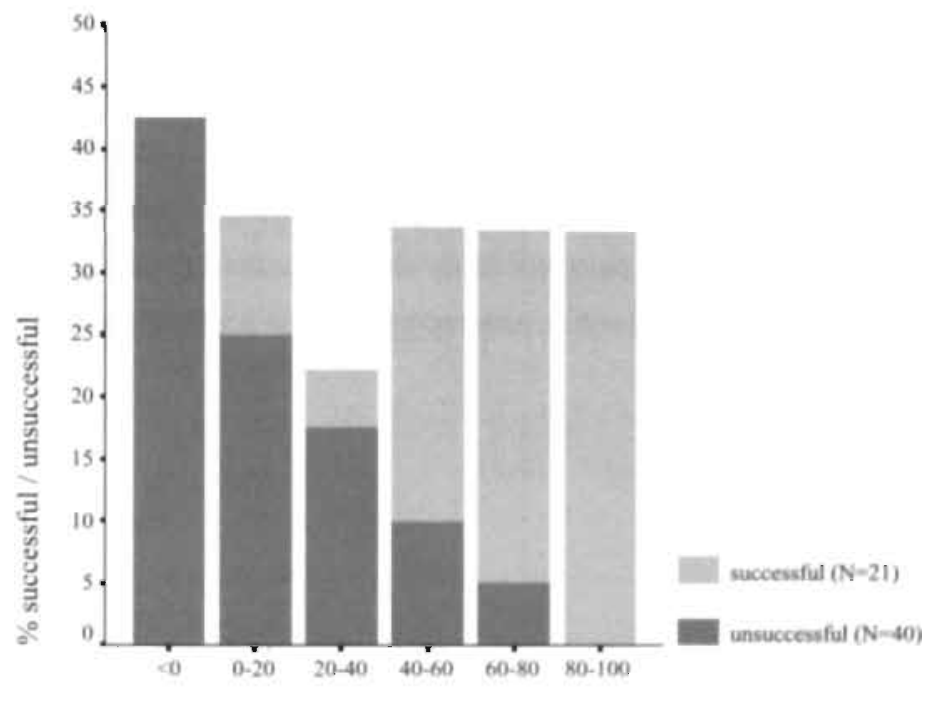

$\%$ improvement according the VAS 


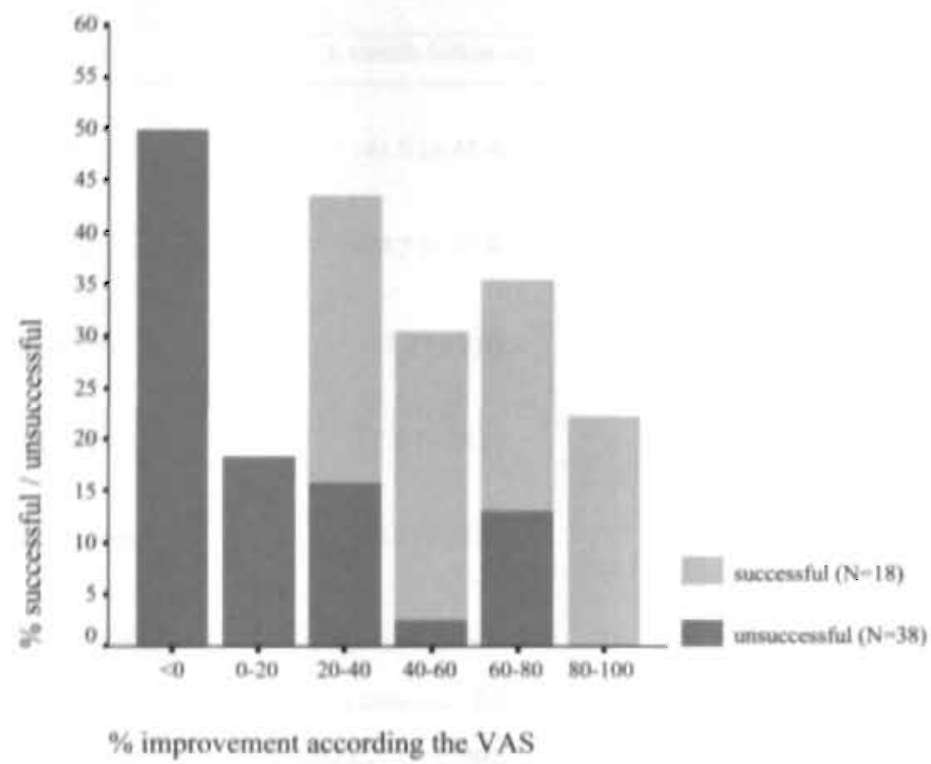

Table 5 shows the calculated sensitivity, specificity and accuracy values at various cut- offs. A cut-off point of $\geq 50 \%$ relative pain reduction showed the highest accuracy with the best balance of sensitivity and specificity. In the 6 month follow-up this cut-off point resulted in a sensitivity of $93.8 \%$ and a specificity of $80.0 \%$ with an accuracy of $83.6 \%$. In other words, "successful" patients on the GPE are associated with a $93.8 \%$ likelihood reporting a relative pain intensity reduction of $\geq 50 \%$, whereas "unsuccessful" patients have a $80.0 \%$ likelihood reporting $<50 \%$ relative pain reduction. The calculations for the absolute pain reduction showed that a VAS $\geq 3 \mathrm{~cm}$ absolute pain reduction as an accurate cut-off point. 
Table 5. Sensitivity, specificity and accuracy of various cur-off points of the relative (\%) and absolute pain reduction compared with the GPE.

\begin{tabular}{|c|c|c|c|c|c|c|c|c|c|c|c|c|c|c|c|c|c|c|}
\hline \multirow[b]{2}{*}{ Relative pain reduction } & \multicolumn{6}{|c|}{6 month follow-up } & \multicolumn{6}{|c|}{ I year follow-up } & \multicolumn{6}{|c|}{2 year follow-up } \\
\hline & $\geq 20$ & $\geq 30$ & $\geq 40$ & $\geq 50$ & $\geq 60$ & $\geq 70$ & $\geq 20$ & $\geq 30$ & 240 & $\geq 50$ & $\geq 60$ & 270 & $\geqslant 20$ & $\geq 30$ & $\geq 40$ & 250 & 360 & $\geq 70$ \\
\hline Sensitivity (\%) & 100 & 100 & 100 & 93.8 & 68.7 & 43.8 & 90.5 & 90.5 & 85.7 & 85.7 & 61.9 & 42.8 & 100 & 94,4 & 72.2 & 61.1 & 50.0 & 44.4 \\
\hline Specificity $(\%)$ & 62.2 & 66.7 & 73.3 & 80.0 & 88.8 & 97.8 & 67.5 & 72.5 & 85.0 & 87.5 & 95.0 & 100 & 68.4 & 76.3 & 84.2 & 86.8 & 86.8 & 97.4 \\
\hline Accuracy (86) & 72.1 & 75.4 & 80.3 & 83.6 & 83.6 & 83.6 & 75,4 & 78.7 & 85,3 & 86.9 & 83.6 & 80.3 & 78.6 & 821 & 80.3 & 78.6 & 75,0 & 80.4 \\
\hline Absolute pain reduction & & $\geq 1$ & $\geq 2$ & $\geq 3$ & $\geq 4$ & $\geq 5$ & & $\geq 1$ & $\geq 2$ & $\geq 3$ & $\geq 4$ & $\geq 5$ & & $\geq 1$ & $\geq 2$ & $\geq 3$ & $\geq 4$ & $\geq 5$ \\
\hline Sensitivin $7 \mathrm{Ca}$ & & 100 & 100 & 87.5 & 68.7 & 37.5 & & 90.5 & 85.7 & 85.7 & 57,1 & 38.1 & & 88.3 & 84.2 & 83.3 & 55.0 & 38.9 \\
\hline Specificity $\%$ & & 55.6 & 64.4 & 75.6 & 80.0 & 95.5 & & 57.5 & 72.5 & 85.0 & 92.0 & 95.0 & & 60.5 & 73.7 & 84.2 & 86.8 & 99.0 \\
\hline Accuracy $(9 \omega)$ & & 67.2 & 73.8 & 78.7 & 77.1 & 80 & & 68.9 & 77.1 & 85.2 & 80.3 & 75.0 & & 67.9 & 76.8 & 75.0 & 76.8 & 80.4 \\
\hline
\end{tabular}




\section{DISCUSSION}

In the CRPS I literature most clinical studies use pain ratings as the primary outcome measure. Mostly, in these studies a significant pain reduction after treatment is defined as successful $2-7$. Some authors define a pain reduction of 30 to $50 \%$ as successful ${ }^{10-13}$. However, a clinically relevant pain reduction in patients with CRPS 1 is still not defined.

In the present study we have shown that CRPS I patients define a relative pain reduction of $58 \%$ or more as "successful". In both "successful" and "unsuccessful" patients the pain was reduced significantly. Furthermore, a relative pain reduction of $50 \%$ and more as cut-off point proved to be the most accurate point with the best sensitivity and specificity. For the absolute pain reduction, $3 \mathrm{~cm}$ on VAS could be defined as an accurate cut-off point.

In our study we compared the GPE with the VAS. The GPE was used as the "gold standard" in this comparison, which may be questionable. The VAS measures patient's pain intensity. Pain assessment using a VAS score before and after a given treatment will only demonstrate a decrease or increase of the pain intensity. It gives less information about the degree of success of a treatment according the patients. Therefore, using a VAS to define a treatment successful or not, would be physician based rather then patient based. The GPE on the other hand, has the advantage to assess the degree of treatment success according the patient, which makes any statement patients based.

A relative pain reduction of 30 to $50 \%$, has often been used in the definition of a positive outcome in analgesic studies ${ }^{10-13}$. In defining cut-off points several authors have used different outcomes - additional dose of rescue medication ${ }^{8}$, experts' opinion 9.16 and a seven point Likert scale 17, 18 for instance - as the gold standard to evaluate the effectiveness of the study intervention. These standards have potential limitations, which must be considered. In using the additional dose of rescue medication as standard, for example, one must consider the factors other than pain that may play a role in the patient's decision to take a rescue dose ${ }^{8}$. Regarding experts' opinion, the inaccuracy of observers in assessing patients' pain or psychosocial state has been described by several studies ${ }^{19-23}$; comparison of the experts' opinion with patients' pain may bias the results. In de use of the Likert scale, the comparison of that scale with a quality-of-life measurement or pain intensity assessment is a comparison of two subjective scales, and the results may be biased by the patient's sense of what the interviewer want to hear or what the patient thought the answer ought to be. The patients (using a Likert scale) may report satisfaction to please the doctor, because they were seen quickly, or simply because the patient's mood has improved. In contrast, in using the VAS in 
a clinical setting, the patients may report less pain after treatment because reporting otherwise would be too cognitively dissonant to be acceptable.

We compared two subjective measurements to identify a meaningful pain reduction in patients with CRPS I. Therefore, the limitations as mentioned before must be considered in the present study. Further, for our study the GPE was translated into Dutch. Therefore, the words used may affect our results. We used the words "best ever" instead of "very much improved". The level, "best ever" may be interpreted as the maximal improvement that can be achieved after treatment, which could explain that none of our patients reported, "best ever" at the follow-up periods.

Despite these shortcomings we hypothesize that, in CRPS I patients, a significant pain reduction after treatment, as measured by the VAS, does not necessarily imply that the patient defines the treatment as successful. Furthermore, a relative pain reduction of $50 \%$ or more and an absolute pain reduction of at least $3 \mathrm{~cm}$ on VAS are accurate in predicting a successful pain reduction after a given treatment.

To support these hypotheses prospective studies are indispensable. Furthermore, we emphasize that, in future clinical studies on CRPS I, the VAS and a GPE scale should be used side by side, to measure patients' pain and the degree of improvement according the patients. If only a VAS is used, it is preferable for the patients as well as for the investigators, to define clearly beforehand the degree of pain reduction that is deemed successful. 


\section{References}

1. Schurmann M, Gradl G. Andress HJ, Furst H, Schildberg FW. Assessment of peripheral sympathetic nervous function for diagnosing early post-traumatic complex regional pain syndrome type L. Pain 1999; 80:149-59.

2. Hanna MH, Peat SJ. Ketanserin in reflex sympathetic dystrophy. A double-blind placebo controlled cross-over trial. Pain 1989: 38:145-50.

3. Kho HK. The impect of acupuncture on pain in patients with reflex symputhetic dystrophy. Pain Clin 1995: 8:59-61.

4. Kettler RE, Abram SE. Intravenous regional droperidol in the management of reflex sympathetic dystrophy: a doubleblind, placebo-controlled, crossover study. Anesthesiology 1988; 69:933-6.

5. Jadad AR, Carroll D, Glynn CJ, McQuay HJ. Intravenous regional sympathetic blockade for pain relief in reflex sympathetic dystrophy: a systematic review and a randomized, double-blind crossover study. J Pain Symptom Manage 1995; 10:13-20.

6. Korpan MI, Dezu Y, Schneider B, Leitha T, Fialka-Moser V. Acupuncture in the treatment of posttraumatic pain syndrome Acta Orthop Belg 1999; 65:197-201.

7. Zuurmond WW, Langendijk PN, Beremer PD, Brink HF, de Lange JJ, van loenen AC. Treatment of acute reflex sympathetic dyatrophy with DMSO $50 \%$ in a fatty cream. Acta Anaesthesiol Scand 1996; 40:364-7.

8. Farrar J, Portenoy RK, Berlin JA, Kinman JL, Strom BL. Defining the clinically important difference in pain outcome measures. Pain 2000; 88:287.94.

9. Goldsmith CH, Boers M, Bombardier C, Tugwell P. Criteria for clinically important changes in outcomes: development. scoring and evaluation of rheumatoid arthritis patient and trial profiles. OMERACT Committec. J Rheumatol 1993; $20-561-5$

10. Blanchard J, Ramamurthy S, Walsh N, Hoffman J, Schoenfeld L. Intravenous regional sympatholysis: a double-blind comparison of guanethidine, reserpine, and normal saline, J Pain Symptom Manage 1990; 5:357-61.

11. Price DD, Long S, Wilsey B, Rafi, A. Analysis of peak magnitude and duration of analgesia produced by local anesthetics injected into sympathetic ganglia of complex regional pain syndrome patients. Clin J Pain 1998; 14:216-226.

12. Verdugo RJ, Ochoa JL. 'Sympathetically maintained pain.' I'. Phentolamine block questions the concept. Neurology 1994; $44: 1003-10$.

13. Hord AH, Rooks MD, Stephens BO, Rogers HG, Fleming LL. Intravenous regional bretylium and lidocaine for treatment of reflex sympathetic dystrophy: a randomized, double-blind study. Anesth Analg 1992; 74:818-21.

14. Kemler MA, Barendse GA, van Kleef M, et al. Spinal cord stimulation in patients with chronic reflex sympathetic dystrophy. N Eingl I Med 2000; 343:618-24.

15. Merskey KR, Bogduck N. Classification of Chronic Pain: Descriptions of Chronic Pain Syndromes and Difinitions of Pain Term. Seattle, WA: IASP Press, 1994.

16. Todd KH, Funk JP. The minimum clinically important difference in physician-assigned visual analog pain scores. Acad Eimerg Med 1996; 3:142-6.

17. Juniper EF, Guyatt GH, Willan A, Griffith LE. Determining a minimal important change in a disease-specific Quality of Life Questionnaire. J Clin Epidemiol 1994: 47:81-7.

18. Redelmeier DA, Guyau GH. Goldstein RS. Assessing the minimal important difference in symptoms: a comparison of two rechniques. J Clin Epidemiol 1996: 49:1215-9.

19. Gulbrandsen P. Hjortdahl P. Fugelli P. General practitioners' knowledge of their patients' psychosocial problems: multipractice questionnaire survey. Bmy 1997: 314:1014-8.

20. Eastwood MR. Screening for psychiatric disorder. Psychol Med 1971: 1:197-208,

21. Oakley ME, MeCreary CP. Flack VF, Clark GT. Solberg WK. Pullinger AG. Dentists' ability to detect psychological problems in patients with temporomandibular disorders and chronic pain. J Am Dent Assoc 1989; 118:727-30.

22. Stewan MA, Buck CW. Physicians' knowledge of and Response to Patients' Problems. Medical Care 1977; 15:578-585. 
23. Grosuman SA, Sheidler VR, Swedeen K. Mucenski J, Piantadosi S. Correlation of patient and caregiver ratings of cancer pain. I Pain Symptom Manage 1991: 6:53-7. 
$-52$. 


\section{CHAPTER 4}

Comparison of multiple against single pain intensity measurements in Complex Regional Pain Syndrome Type I: analysis of 54 patients

Tymour Forouzanfar, Marius Kemler, Alfons G.H. Kessels, Albere J.A. Köke, Maarten van Kleef, and Wilhelm E.J. Weber.

Published in Clin. J. Pain 2002; 18(4): 234-237 


\section{ABSTRACT}

Objective: The present paper describes comparison of multiple and single pain ratings in patients with CRPS I.

Design: Correlation, agreement and reliability analyses were performed between the average pain intensity measured 3 times a day over a course of 4 days and one single pain rating (designated as "recalled average" pain by the patient) before treatment and 1-, 3- and 6 month after treatment.

Patients: The patient population consisted of 54 patients suffering from CRPS I in a randomized trial.

Results: The results show that both measurements correlate and agree excellently . Furthermore, both ratings measure significant pain reduction after treatment, however "recalled average" pain reflects greater change in pain intensity.

Conclusion: In patients with CRPS I a single pain rating is an accurate predictor of the average pain measured by a multiple pain rating test. Moreover, both assessments are accurate enough to determine changes in pain over time with an effective treatment. 


\section{INTRODUCTION}

Complex regional pain syndrome type I (CRPS I), formerly known as Reflex Sympathetic Dystrophy, is defined as a post-traumatic syndrome with pain, not related to the territory of a single nerve and disproportionate to the inciting event ${ }^{1}$. At present no specific test is available to diagnose this syndrome. Therefore the diagnosis of CRPS I has to be based solely on subjective measurements of the clinical symptoms including sensory abnormalities, diminished strength, hyperhidrosis, skin colouring changes and pain ${ }^{2}$. In clinical studies on CRPS I, pain assessment is a crucial measurement. In most of these studies a single pain rating is used as the primary outcome measure, assuming that this is equivalent to multiple ratings ${ }^{3-9}$.

In the assessment of pain, pain reports tend to change over time, even during the course of a day ${ }^{10-12}$. Jensen et al ${ }^{13,14}$ have shown that in chronic pain patients a single pain intensity rating was the least reliable, while 3 measures of pain intensity a day over the course of 4 days showed excellent internal consistency and validity. Because multiple assessments are impractical both in the clinical and research setting. Dworkin et al's suggested that patients may be able to assess their own average pain levels over a period of time simply by asking them to rate their pain "on average" at a single-point in time. For patients suffering from back pain a single rating of pain "on average" is an accurate estimate of "actual average" pain intensity measured over a course of 7 days ${ }^{16}$. There are different methods to compare clinical measurements. According to Bland and Altman 17, 18 such a comparison should be based on the differences between the two measurements performed on the same subject. The mean differences would be the estimated bias, the systematic difference between measurements, and the standard deviation (s.d.) of the differences would measure random fluctuations around this mean. In addition, the $95 \%$ limits of agreement (mean differences plus or minus $1.96 \mathrm{~s} . \mathrm{ds}$ ) can be used to determine how far apart measurement by the two assessment are likely to be for most individuals ${ }^{17}, 18$.

The present study was designed to investigate whether a single pain rating in patients with CRPS I can replace a multiple pain rating test. For this purpose, we performed correlation and agreement analyses according Bland and Altman 17, 18 between the average pain intensity measured 3 times a day over a course of 4 days and one single pain measurement of pain "on average" in 54 patients suffering from CRPS I. Then we analyzed the accuracy of both measurements in assessing changes in pain ratings to determine the efficacy of pain treatment ${ }^{19}$. 


\section{METHODS}

\section{Patients}

The data for this study consisted of the pain intensity assessments measured in 54 CRPS I patients, 17 males and 37 females with a mean age of 39 years and a mean CRPS I duration of 38 month (table 1).

Table 1. Patient characteristics

\begin{tabular}{lc}
\hline Patients & 54 \\
Age (years) & $39 \pm 10$ \\
Sex & 17 \\
Male & 27 \\
Female & $38 \pm 25$ \\
Duration (month) & \\
\hline
\end{tabular}

The patients were included in a randomized trial in which spinal cord stimulation plus physical therapy was compared with physical therapy alone. The results of this trial were described elsewhere ${ }^{20}$. Diagnostic criteria for CRPS I developed by the International Association for the Study of Pain were used ${ }^{21}$. In addition to these, patients had to show impaired function and extension of symptoms outside the area of trauma.

\section{Procedure}

All patients were asked to score 3 times a day over a course of 4 . days their pain on a $100 \mathrm{~mm}$ Visual Analogue Seale (VAS), which was anchored by 2 extremes of pain; "no pain" on the left and "the worst possible pain" on the right end. At the end of the $4^{\text {th }}$ day they were asked to note their average pain of the last week using a Visual Analogue Scale with the same extremes as the above-mentioned scale. The patients rated their pain before treatment and one month, three month and six month after treatment.

\section{Statistics}

The pain intensity measured with the single VAS is further mentioned as "recalled average" pain, whereas the calculated average pain intensity noted over 4 days is the "actual average" pain. For comparison of these two entities, the equivalent statistic, Pearson's R, was used. Correlation coefficients (R.) were defined as follow: 0.5-0.6, moderate; $0.6-0.8$, well; $0.8-0.10$, excellent. To assess the agreement between the two measurements we compared the 
difference of these two pain measurements for each patient with the average of both measurements for each follow-up period, as described by Bland and Altman ${ }^{17}$. The limit of agreement ( $95 \%$ confidence level) is defined as the mean differences of two measurements plus or minus 1.96 s.d. $(M \pm 1.96$ s.d.). In assessing the accuracy of pain assessments in measuring treatment effects, the t-values of the student t-test from pre-treatment to each follow-up was examined (e.g. a larger t- value or lower p value as indicating greater accuracy).

\section{RESULTS}

\section{"Recalled average" pain vs. "actual average" pain}

In table 2 the correlation coefficients and the entities of the agreement are listed for each follow-up period. The "recalled average" pain correlated excellently with the "actual average" pain with correlation coefficients $0.81,0.94,0.95$ and 0.95 for pre-treatment period, 1-, 3- and. respectively 6 month follow-up.

Table 2. Correlation and agreement between "recalled average" pain and "actual average" pain.

\begin{tabular}{ccccc}
\cline { 3 - 4 } \multicolumn{1}{c}{} & & \multicolumn{3}{c}{ Agreement } \\
\hline Period & Correlation R & Mean difference & Standard deviation & $95 \%$ confidence level \\
\hline Pre-treatment & 0.81 & 0.14 & 0.88 & $0.14 \pm 1.73$ \\
I-month follow-up & 0.94 & -0.02 & 0.67 & $-0.02 \pm 1.31$ \\
3-month follow-up & 0.95 & 0.03 & 0.96 & $0.03 \pm 1.88$ \\
6-month follow-up & 0.95 & -0.13 & 0.92 & $-0.13 \pm 1.80$ \\
\hline
\end{tabular}

The plot presented in fig. 1 shows the correlation between "recalled average "pain and "actual average" pain. Because the plots of pre-treatment, 1-,3-and 6-month follow-up are similar, only the plot of 1-month follow-up is presented.

Because of the similarities of the results of the agreement analysis, only the analysis of the 1-month follow-up will be discussed. This analysis demonstrated a mean difference, "recalled average" pain minus "actual average" pain, of -0.02 and a SD of 0.67 . The lower $95 \%$ limit is $-0.02-(1.96 \times 0.67)=-1.33$ and the upper limit is $-0.02+(1.96 \times 0.67)=1.29$. In other words, for $95 \%$ of the subjects "recalled average" pain will be between 1.33 below the "actual average" pain and 1.29 above it, as shown in fig.2. Thus, there is a "high degree" of agreement between both measurements. 
Figure 1. The "recalled average" pain plotted against "actual average" pain for 1-month follow-up.

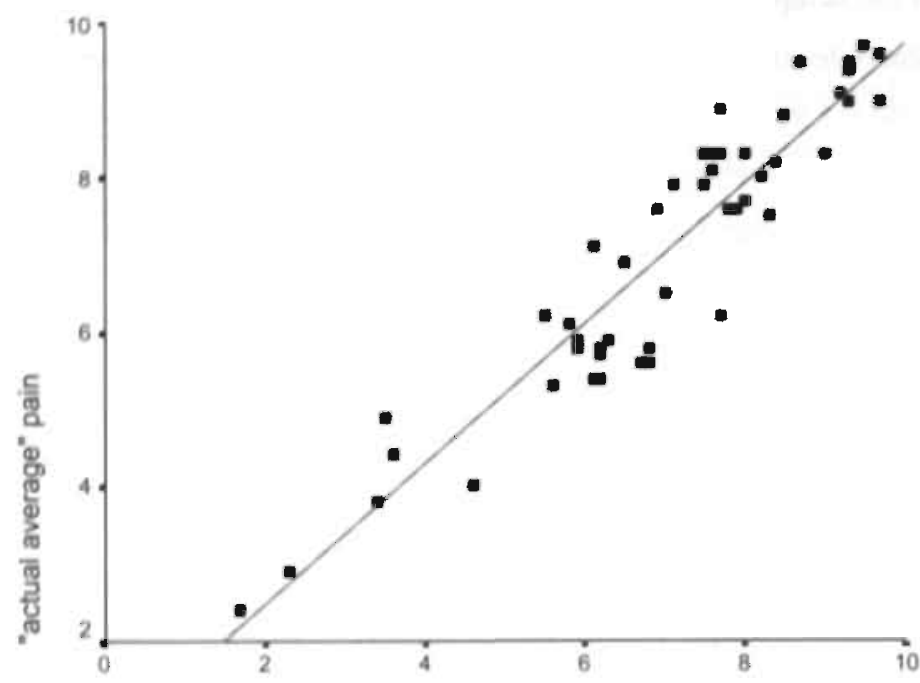

"recalled average" pain

Figure 2. Differences between "recalled average" pain and "actual average" pain plotted against their mean rating for 1-month follow-up; the horizontal lines are the mean differences and the limits of agreement.

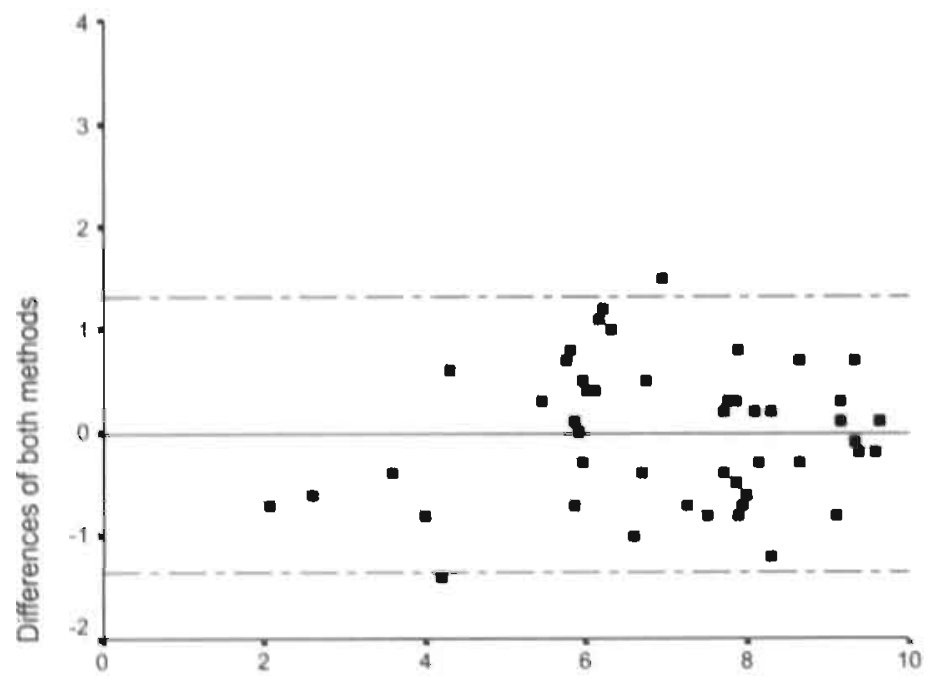

Mean of both methods 


\section{Accuracy in assessing treatment effects}

In table 3 the pain intensity for the pre-treatment and the follow-up periods according the measurement is listed. There were no significant differences between "actual average" and "recalled average" pain assessed on each measurement period. In addition, both measurements show pain intensity reduction during the follow-up periods.

Table 4 demonstrates the $\mathrm{t}$ - and $\mathrm{P}$ values from pre-treatment to each follow-up. The analysis showed a significant t-value (all p < 0.001 ) on 3- and 6-month follow-up. Based on the size of the t-value, the "recalled average" pain tended to reflect greater change than the "actual average" pain.

Table 3. The mean pain intensity for pre-treatment and the follow-up periods.

\begin{tabular}{lcccc}
\hline & Pre- & I-month & 3-month & 6-month. \\
& treatment & follow-up & follow-up & follow-up \\
\hline Actual average (mean \pm SD) & $6.9 \pm 1.4$ & $6.8 \pm 1.9$ & $5.5 \pm 2.9$ & $5.2 \pm 2.9$ \\
Recalled average (mean \pm SD) & $7.0 \pm 1.4$ & $6.8 \pm 1.9$ & $5.5 \pm 3.1$ & $5.1 \pm 3.0$ \\
\hline
\end{tabular}

Table 4. T-values for change in pain intensity from pre-treatment to cach follow-up.

\begin{tabular}{lccc}
\hline & $\begin{array}{c}\text { Pre treatment to } \\
\text { 1-month follow-up } \\
\text { ( } p \text { values) }\end{array}$ & $\begin{array}{c}\text { Pre treatment to } \\
\text { 3-month follow-up } \\
\text { ( } p \text { values) }\end{array}$ & $\begin{array}{c}\text { Pre treatment to } \\
6 \text {-month follow-up } \\
\text { (p values) }\end{array}$ \\
\hline $\begin{array}{l}\text { Actual average } \\
\text { Recallied average }\end{array}$ & $1.10(p=0.26)$ & $4.0(p<0.001)$ & $4.8(p<0.001)$ \\
\hline
\end{tabular}

\section{DISCUSSION}

In clinical studies with patients suffering from CRPS I, pain is usually assessed by a single pain rating. This rating is consequently used as the primary outcome measure, assuming that it is equivalent to multiple pain ratings. However to oụr knowledge this assumption has never been investigated in CRPS I patients. The present study was undertaken to compare the validity of the single pain ratings in patients with CRPS I with multiple pain rating test. To this end we first analysed whether a single pain rating ("recalled average" pain) can replace multiple pain ratings ("actual average" pain) in a group of patients suffering from CRPS I. Next, we investigated the accuracy of both ratings measuring a treatment outcome. Further, the reliability (defined as stability over time) of both assessments was investigated. 
The results show that both measurements correlate excellently. There is a "high degree" of agreement between both methods. Furthermore, both ratings measure significant pain reduction after treatment, however "recalled average" pain reflects greater change in pain intensity.

The presented study has several shortcomings. First, our patient population consisted only of 54 patients. Secondly, the two pain rating are not as equivalent in their time frame as they should be. The patients were asked to provide a rating of their average pain over the preceding week. This measure was compared to the actual average pain of the preceding 4 days. However, Jensen et al ${ }^{13}$ demonstrated that increasing the number of assessments beyond 3 times daily for 4 consecutive days provides only minimal improvement in the psychometric properties of the measurement.

Having in mind that multiple measurements in outcome studies are impractical, Dworkin and Siegfried suggested that patients may be able to measure their average pain intensity over a period of time simply by asking them to rate their pain on average at a singlepoint time ${ }^{15}$. When asking patients to rate their pain on average over the previous week one assumes that patients can in fact recall their pain levels over this period of time with a high degree of accuracy. Several investigators have studied the accuracy of recall of pain intensity in chronic pain patients. This has yielded conflicting results ranging from high levels of accuracy ${ }^{10}$ and no effect of current pain intensity on memory for past pain ${ }^{22}$, to over- or underestimated pain levels depending on pain status at the time of recalli ${ }^{23}$. All studies have relied on correlation and prediction statistics in analysing the relationship between actual pain levels and recall of pain. According to Bolton et al correlation or regression statistics do not provide a real assessment of accuracy ${ }^{16}$. These authors used both agreement statistic (Intraclass Correlation Coefficient) and correlation statistic to investigate the accuracy of recalled pain in patients with back pain ${ }^{16}$. The results of their study show that a single rating of pain "on average" is an accurate estimate of "actual average" pain intensity over recording interval of 7 days ${ }^{16}$.

Our results are in line with the results of Bolton et al ${ }^{16}$. Despite the short-comings of the present study we conclude that as in back pain patients, a single rating of pain "on average" ("recalled average" pain) is an accurate predictor of the actual "average pain" in patients suffering of CRPS I. Moreover, both pain ratings proved to be accurate enough to determine reliable changes in pain over time. 


\section{References}

1. Schurmann M, Gradl G, Andress HJ, Furst H, Schildberg FW. Assessment of peripheral sympathetic nervous function for diagnosing early post-traumatic complex regional pain syndrome type I. Pain 1999; 80:149-59

2. Ochoa JL. Pain mechanisms in neuropathy [see comments], Carr Opin Nearol 1994; 7:407-14.

3. Geertzen JH, de Bruijn H, de Brujin-Kofman AT, Arendren JH, Reflex sympathetic dystrophy: early treatment and psychological aspects. Arch Phys Med Rehabil 1994; 75:442-6.

4. Hamamci N, Dursun E, Unal C, Cakei A. Calcitonin treatment is reflex sympathetic dystrophy? a preliminary study, Br J Clin Pract 1996; 50-373-5,

5. Adami S, Fossalurza V, Gatti D, Fracassi E, Braga V. Bisphosphonate therapy of reflex sympathetic dystrophy syndrome, Ann Rheum Dis 1997; 56:201-4.

6. Blanchard J, Ramamurthy S, Walsh N, Hoffman J, Schocnfeld L. Intravenous regional sympatholysix: a double-blind comparison of guanethidine, reserpine, and normal saline. J Pain Symptom Manage 1990; 5:357-61.

7. Oerlemans HM, Oostendorp RA, de Boo T, Goris RJ. Pain and reduced mobility in complex regional pain syndrome L: outcome of a prospective randomised controlled clinical trial of adjuvant physical therapy versus occupational therapy. Pain 1999, 83:77-83.

8. Zuurmond WW, Langendijk PN, Bezemer PD, Brink HE, de Lange H, van loenen AC. Treatment of acute reflex sympathetic dystrophy with DMSO $50 \%$ in a fatty cream. Acfa Anovsthesio/ Scand 1996; 40:364-7.

4. Wu WH. Bandilla E, Ciccone DS, et al. Effects of qigong on late-stage complex regional pain syndrome. Altern Ther Health Med 1999; 5:45-54.

10. Jamison RN, Brown GK. Validation of hourly pain intensity profiles with chronic pain patients. Pain 1991; 45:123-8.

11. Folkard S, Monk TH, Lobban MC. Towards a predictive test of adjustment to shif work. Ergonomics 1979; $22: 79-91$.

12. Craig KD, Weiss SM. Vicarious influences on pain-threshold determinations. J Pers Soc Psychol 1971; 19:53-9.

13. Jensen MP. McF arland CA. Increasing the reliability and validity of pain intensity measurement in chronic pain patients [see comments]. Pain 1993; 55:195-203.

14. Jensen MP, Turner LR, Turner JA, Romano JM. The use of multiple-item scales for pain intensity measurement in chronic pain patients. Pain 1996; 67:35-40.

15. Dworkin RH, Siegfried RN. Are all those pain ratings necessery? [Letter to the editor]. Pain 1994; 58:279.

16. Bolton JE. Accuracy of recall of usual pain intensity in back pain patients. Pain 1999; 83:533-9.

17. Bland JM, Aftman DG. Statistica! methods for assessing agreenent between two methods of clinicat measurement. Lancet 1986; 1:307-10:

18. Bland JM, Altman DG. Comparing methods of measurement: why plotting difference against standard method is misleading. Lancet 1995; 346:1085-7.

19. Jensen MP, Turner JA, Romano JM, Fisher LD. Comparative reliability and validity of chronic pain intensity measures. Pain 1999; 83:157-62.

20. Kemler MA, Barendse GA, van Kleef M, et al. Spinal cord stimulation in patients with chronic reflex sympathetic dystrophy [see comments]. N Engl J Med 2000; 343:618-24.

21. Merskey KR, Bogduck N. Classification of Chronic Pain: Descriptions of Chronic Pain Syndromes and Difinitions of Pain Term. Seattle, WA: IASP Press, 1994

22. de Wit R, van Dam F, Hanneman M, et al, Evaluation of the use of a pain diary in chronic cancer pain patients at home. Pain 1999; 79:89-99.

23. Linton SJ. Melin L. The accuracy of remembering chronic pain. Pain 1982; 13:281-5. 
.62. 


\section{CHAPTER 5}

Multi-Frequency Bioelectrical impedance measurement in Complex

Regional Pain Syndrome Type 1

Pilot study of 28 patients

Tymour Forouzanfar, Alfons G.H. Kessels, Maarten van Kleef, Wilhelm E.J. Weber, and Bernard. K. van Kreel.

Published in Pain Clinic 2002; 13(2): 211-222 


\begin{abstract}
Objectives: To evaluate the value of Multi-Frequency Bioelectrical Impedance Analysis (MFBIA) in patients suffering from Complex Regional Pain Syndrome Type I (CRPS1). We hypothesised that, patients with CRPS I have altered tissue properties in the affected limbs compared with the non-affected limbs and with limbs from unaffected individuals (control limbs).
\end{abstract}

Participants: 28 patients suffering from CRPS I and in 18 healthy right-handed.

Methods: Receiver operating characteristic (ROC) analyses and areas under the curve (AUC) were performed to analyse the sensitivity and specificity of the MFBIA to detect CRPS I.

Results: Our data showed the phase angle $(\Phi)$, which is defined as the relation between the resistance (ability of an medium to conduct an alternating electrical current) and the reactance (resistive effect due to capacitance produced by tissue interface and cell membrane) was decreased in the CRPS I limbs compared with both the contralateral side ( $\mathrm{p}=$ $0.004)$ and limbs $(p=0.02)$ from unaffected individuals. The MFBIA frequency $\left(\omega_{0}\right)$ at which the reactance and the phase angle are maximal was increased in CRPS I limbs compared with both the contralateral side $(p=0.02)$ and the control limbs $(p=0.01)$. The sensitivity and specificity of $\omega_{0}$ for detecting CRPS $I$ in the lower limb were 0.91 and 0.85 compared with lower limbs in unaffected individuals. In the upper limb, however, sensitivity and specificity were best when the right hand in unaffected individuals was used as the control. The sensitivity and specificity of $\omega_{0} 0.75$ and 0.82 compared with right arm controls. The $\Phi$ values were 0.82 and 0.70 compared with the right arm controls.

Conclusion: The tissue properties are changed in the affected limb according the MFBIA. 


\section{INTRODUCTION}

Complex Regional Pain Syndrome is a painful neuropathic, disabling syndrome' ${ }^{1}$ It is defined as a post-traumatic syndrome that presents with spontaneous pain that is not related to the territory of a single nerve and is disproportionate to the inciting event ${ }^{2}$. At present there is no single objective test or blood value that can prove or exclude this syndrome. Consequently, the diagnoses of CRPS I is based solely on subjective clinical symptoms that including burning pain, sensory abnormalities, diminished strength, hyperhidrosis, hypertrichosis, skin colouring changes and atrophy of the involved tissue (skin, muscle, bone) ${ }^{3}$. There is a clinical need for an objective measure of the severity of the patient's condition.

Bioelectrical impedance (BLA) has been used to analyse numerous aspects of human body composition, including total body water, the intra - and extra-cellular fluid volumes, fat free mass, body cell mass and body fat. The principle behind BIA is that an electrical signal changes as it passes through different body components. Fat and bone act as insulators, whereas lean tissues and electrolytic fluids conduct electricity: an electrical current passes through only lean tissues (muscles) and electric fluid (blood and lymph). In addition, each muscle cell has a membrane that separates intracellular fluid from the extra cellular space. This membrane acts as a capacitance.

Both extra- and intracellular fluids are accounted for in the equivalent circuit model as shown in figure 1. The extra cellular resistivity $\left(R_{e}\right)$ is arrayed in parallel with the intracellular resistivity $\left(\mathrm{R}_{\mathrm{i}}\right)$ and the capacitance of the cell membrane $\left(\mathrm{C}_{\mathrm{m}}\right)$. In this model low frequency alternating current is unable to be conducted across a cell membrane. It passes only through highly conductive extra cellular fluid. However at high frequencies such a current passes though both intra and extra cellular fluid, thereby enabling measurement of total fluid

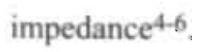


Figure i. Circuit equivalent diagram for impedance in tissue. $\mathrm{C}_{\mathrm{m}}$, capacitance of the cell membrane; $\mathrm{R}_{\mathrm{i}}$.

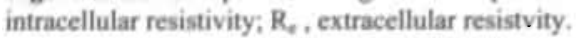

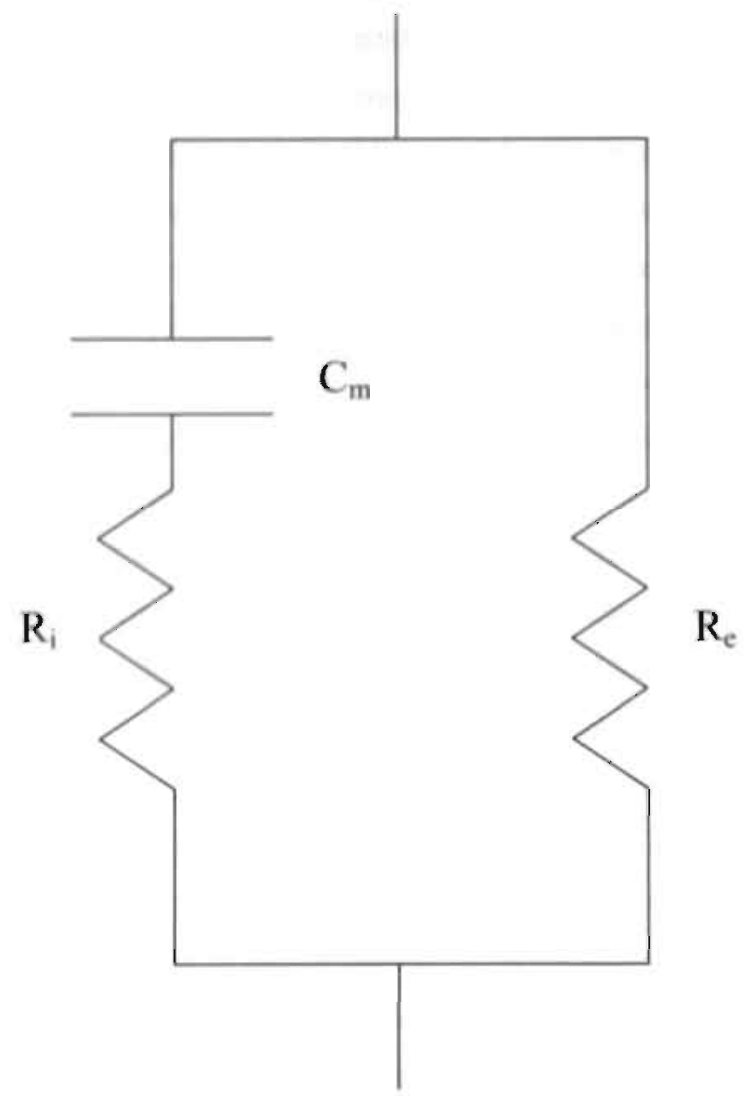

Mathematically, the bioelectrical impedance $(Z)$ is the square root of the sum of the squares of resistance $(R)$ and reactance $(X)$. Bioelectric resistance is the opposition of a biological conductor to the flow of an alternating electric current, whereas reactance is the resistive effect due to capacitance produced by tissue interface and cell membranes. Capacitance, or the storage of electric charge by a condenser, causes the current to lag behind the voltage, creating a phase shift. This shift, also called the phase angle $(\Phi)$, is a linear method of measuring the relationship between resistance $(R)$ and reactance $(X)$ in series or parallel circuits $5,7,8$. Baumgartner $\mathrm{et}^{\mathrm{al}^{7}}$ have shown that the phase angle is positively associated with the reactance and negatively with the resistance. Therefore, variation among phase angles can be interpreted, to some extend, from the associations between resistance and 
reactance within and between body segments. MFBIA can be used to estimate indirectly the intracellular fluid, extra cellular fluid and cell mass in each body segment ${ }^{8-10}$.

We present a pilot study on the use of the MFBIA in patients with CRPS I. We hypothesised that patients suffering from CRPS I have decreased reactance and increased resistance in affected limbs. Consequently the phase angle will be decreased and the frequency at which the maximal reactance and phase angle is reached will be increased.

\section{PATIENTS AND METHODS}

\section{Study population}

The study population consisted of 18 healthy volunteers who were employee's of the department of anesthesiology and pain management and employee's of the department of Clinical chemistry of and 28 patients suffering from CRPS I in one limb, who were consecutively admitted to the Pain Management and Research Centre of the University Hospital Maastricht, The Netherlands. Diagnostic criteria for CRPS I developed by the International Association for the Study of Pain were used "1. The volunteers were employee's of the department of anaesthesiology and pain management and employee's of the department of Clinical chemistry of the University Hospital Maastricht. For the study they were chosen at random.

\section{Bioelectrical impedance}

In our study a Xitron MFBIA (Model 4000B; Xitron, Technologies, Inc., Sandiago, CA, USA) was used. This device uses a four-electrode arrangement that eliminates electrode polarisation. Instead of placing the electrodes on one hand and one foot, the surface electrodes were only placed on the affected side. After the procedure the contra lateral side was measured. The Xitron system delivers a constant current at different frequencies with a range of $5 \mathrm{kHz}$ to $1 \mathrm{MHz}$, which is passed between two outer electrodes. The voltage drop between the two inner electrodes is measured by a high input impedance amplifier.

The BIA measurements were performed as follows: the subjects were sitting on a comfortable chair. If the affected limb was an arm, the current electrodes were placed on the acromion and the wrist on the dorsal side. The detecting electrodes were placed $5 \mathrm{~cm}$ below the acromion and $5 \mathrm{~cm}$ above wrist. To investigate the best position for the measurements of the arm we first measured the MFBIA in two controls in three different arm positions. In the first position the arm was against the body resting on the knee, in the second position the arm 
was lifted in a pronated position and in the third position the arm was lifted and was in contact with an iron standard (see figure 3). The current electrodes were placed on the trochanter and on the ankle on the lateral side in the lower limb. The detecting electrodes were attached $5 \mathrm{~cm}$ below the trochanter and $5 \mathrm{~cm}$ above the ankle. In order to find the best assessment position, the MFBIA was measured in two control subjects while lying on the examination table and while sitting on a chair with the thighs and knees in 90-degree flexion.

\section{Calculations}

The data obtained are values of $\mathrm{R}, \mathrm{X}, \mathrm{Z}, \Phi$ and $\omega$ at frequencies from $1 \mathrm{kHz}$ to $1 \mathrm{MHz}(\mathrm{R}$ : resistance; $\mathrm{X}$ : reactance; $\mathrm{Z}$ : impedance; $\Phi$ : phase angle and $\omega$ : frequency). It is assumed that the plot of $\mathrm{R}$ against $\mathrm{X}$ will give a semi circular are in the complex impedance plane (equation. $I$ and fig. 2).

$$
Z=R_{\infty}+\left(R_{0}-R_{\infty}\right) /\left[1+\left(j \omega / \omega_{0}\right)^{a}\right] \quad(j=\sqrt{ }-1)
$$

Where $R_{0}$ and $R_{6}$ are the resistances at the frequencies $\omega=0$ and $\omega=\infty$, respectively, $\omega_{0}$ is the critical or characteristic angular frequency at which $\mathrm{X}$ and $\Phi$ are maximal and is a specific electrical trait of the conducting medium. The $\alpha$ is a measure of semi circular arc's depression below the real axis. The values of $\alpha$ and $\omega_{0}$ are obtained by equation 2 .

$\log \left[\left(R_{0}-R_{\omega}\right)^{2}+X_{\omega}^{2} /\left(R_{\omega}-R_{\infty}\right)^{2}+X_{\infty}^{2}\right]=2 \alpha \log \omega-2 \alpha \log \omega_{0}$

The real value of $Z$ (resistance; $R_{\oplus}$ ) and the imaginary value of $Z$ (reactance; $X_{\oplus}$ ) are calculated according the equation 3,4 and 5 .

$$
\begin{aligned}
& R_{01}=\left[\left(1+\left(\omega / \omega_{0}\right) \cdot \cos (\alpha \cdot \pi / 2)\right)^{a} \cdot\left(R_{0}-R_{\infty}\right)\right] / N \\
& X_{00}=\left[\left(\omega / \omega_{0}\right)^{a} \cdot \sin (\alpha, \pi / 2) \cdot\left(R_{0}-R_{\infty}\right)\right] / N \\
& N=1+2\left(\omega / \omega_{0}\right)^{a} \cdot \cos (\alpha \cdot \pi / 2)+\left(\omega / \omega_{0}\right)^{2 a}
\end{aligned}
$$


Figure 2. The complex impedance plane. The semi circular figure represents the impadance at different frequencies. The frequency increases from the right sight to the left side of the figure. Reand $R_{6}$ are the resistances at the frequencies $\omega=0$ and $\omega=\infty$, respectively, $\omega_{0}$ is the critical or characteristic angular frequency at which $\mathrm{X}$ and $\Phi$ (phase angle) are maximal and is a specific electrical trait of the conducting medium. The $\mathrm{a}$ is a measure of semi circular are's depression below the real axis.

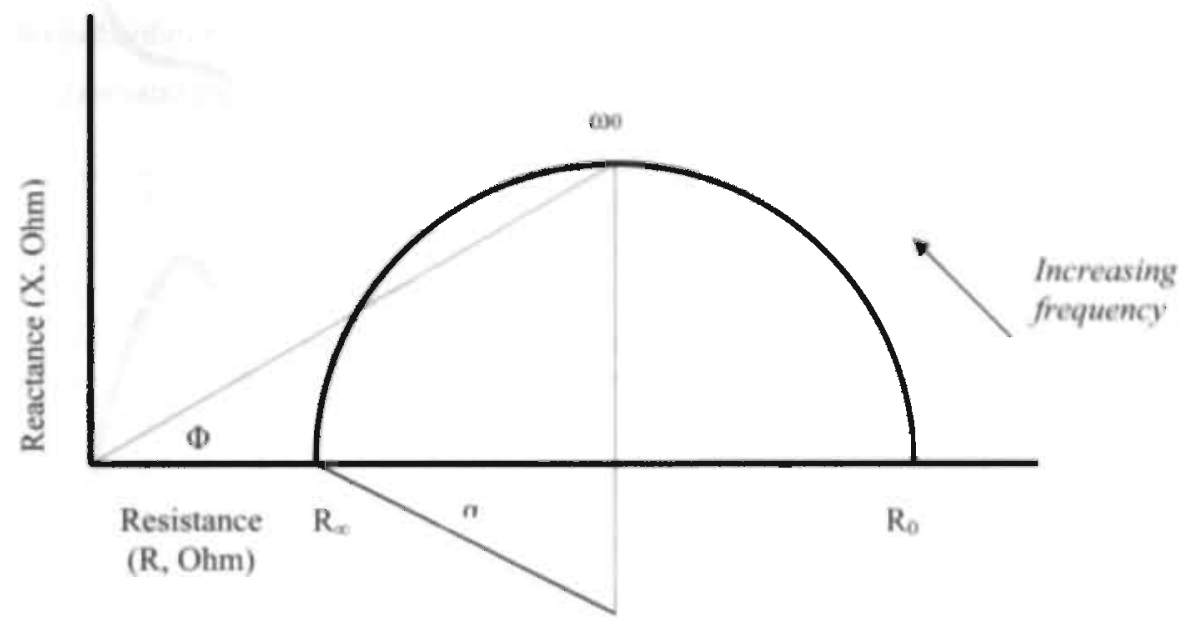

\section{Statistics}

Comparative measures between groups were assessed using paired-t tests. Receiver operating characteristic (ROC) analyses and areas under the curve (AUC) were performed to investigate the specificity and the sensitivity of the MFBIA. MFBIA values of the affected limbs were compared with both the left and right limbs of the unaffected individuals in the control group. The arbitrary guideline based on Swets et al ${ }^{12}$ were used to distinguish between noninformative $(\mathrm{AUC}=0.5)$, less accurate $(0.5<\mathrm{AUC} \leq 0.7)$, moderately accurate $(0.7<\mathrm{AUC} \leq$ $0.9)$, highly accurate $(0.9<\mathrm{AUC}<1)$ and perfect test $(\mathrm{AUC}=1)$. The best cut-off point of the sensitivity and specificity was defined as one with the best balance between both. 


\section{RESULTS}

\section{Patients}

All patients fulfilled the IASP diagnostic criteria" ${ }^{11}$. In addition, all patients had impaired function and extension of symptoms outside the area of trauma. Patient demographic data are shown in table $\mathrm{I}$. The patient population group was older than the unaffected individuals in the control group $(50.0 \pm 15.6$ vs. $38.9 \pm 10.5 ; \mathrm{p}=0.03)$ and the male : female ratio was lower. In all patients and controls the right hand was the dominant hand.

Table 1. Patient's and control characteristics.

$\begin{array}{ccc}\text { CRPS I in the leg } & \text { CRPS I in the arm } & \text { Control } \\ (\mathrm{N}=11) & (\mathrm{N}=17) & (\mathrm{N}=18)\end{array}$

\begin{tabular}{lccc} 
Sex & & & \\
Male & 1 & 4 & 7 \\
Female & 10 & 13 & 11 \\
Mean age $( \pm$ s.d.) & $50.4 \pm 14.2$ & $46.8 \pm 20.4$ & $38.9 \pm 10.5$ \\
Mean duration $( \pm$ s.d.) & $2.7 \pm 2.3$ & $1.9 \pm 1.8$ & - \\
\hline
\end{tabular}

\section{Arm and leg positions for the MFBIA measurement}

Figure 3 shows MFBIA plots for different arm positions. Each point represents a measurement at a different frequency, beginning on the right side with $5 \mathrm{kHz}$ and ending at the left side with I MHz. The horizontal axis indicates the real part of the impedance (resistance) and the vertical axis indicates the imaginary part of the impedance (reactance). The plots demonstrate that lifting the arm in a pronated position was the best position for measuring MFBIA in the arm and it was this position that was used in the subsequent assessments. There were no differences between the lying and sitting position for MFBIA measurement in the leg. These results are not shown. 
Figure 3. MFBIA plots for different arm position.

$R$, resistance, $X$, reactance. Am in the lifted position resulted in the best complex impedance plane.
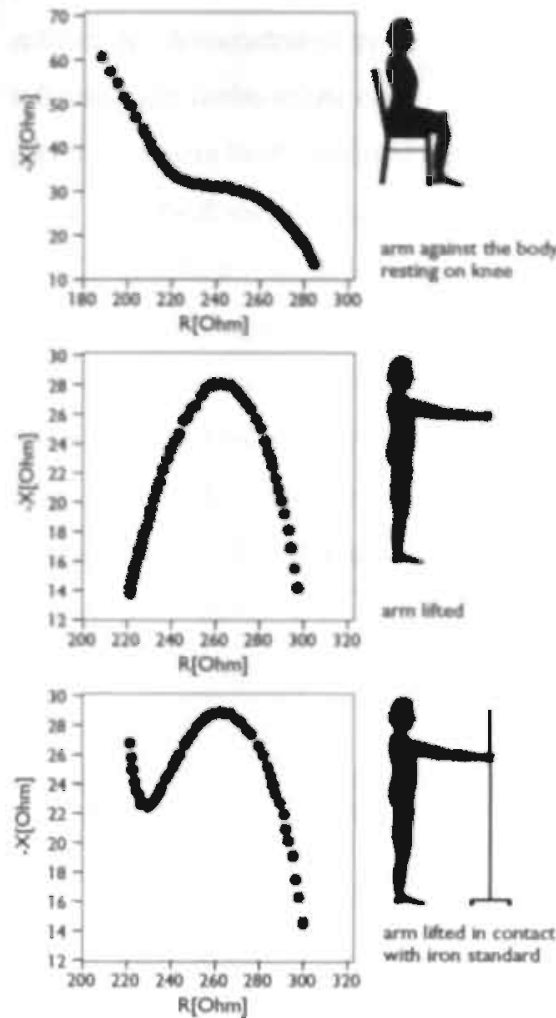

\section{The MFBIA parameters in the control group}

The MFBIA parameters of the left and right limbs in the lower limbs did not differ significantly. However in the upper limbs $\omega_{0}$ of the right arm was decreased compared with the left $\operatorname{arm}(p=0.02)$ and the $\Phi$ of the right arm was increased compared with the left side ( $p$ $=0.02$ ). The other parameters did not differ significantly.

\section{The MFBIA parameters in patients with CRPS i}

The parameter estimates for $\mathrm{X}, \omega_{0}, \Phi$ and $\mathrm{R}$ of each limb are listed in tables $2 \mathrm{a}$ and $2 \mathrm{~b}$. In the upper limb the parameters $\Phi$ and $X$ were decreased in the CRPSI limbs (t-test: $p=0.004, p=$ 0.03 respectively) and $\omega_{0}$ and $R$ were increased $(p=0.02, p=0.03)$ compared with the normal limbs (tab. 2a.). These results were similar when affected limbs were compared with limbs in the control group, but $\mathrm{X}$ did not show any significant changes. There were no 
significant differences between the non-affected limbs and the control group. These results show that $\Phi$ is decreased as a consequence of increased $R$ and that decreased $X$ at $\omega_{0}$ is in the affected limbs.

Table 2a. MFBIA correlation between patients with CRPS I in the leg and the control group.

\begin{tabular}{lccccc}
\hline MFBIA & $\begin{array}{c}\text { Affected limb } \\
\text { (Mean } \pm \text { s.d.) }\end{array}$ & $\begin{array}{c}\text { Normal limb } \\
(\text { Mean } \pm \text { s.d.) }\end{array}$ & $P$ & $\begin{array}{c}\text { Control group } \\
(\text { Mean } \pm \text { s.d.) }\end{array}$ & P \\
\hline $\mathrm{X}^{\prime}$ & $25.4 \pm 7.9$ & $29.7 \pm 6.9$ & 0.03 & $32.51 \pm 0.96$ & $\mathrm{Ns}^{5}$ \\
$\omega_{0}{ }^{2}$ & $57.6 \pm 17.8$ & $43.3 \pm 7.0$ & 0.02 & $40.75 \pm 1.11$ & 0.01 \\
$\Phi^{3}$ & $6.0 \pm 1.6$ & $7.2 \pm 1.9$ & 0.004 & $7.93 \pm 0.24$ & 0.02 \\
$\mathrm{R}^{4}$ & $252.0 \pm 53.8$ & $230.4 \pm 49.0$ & 0.03 & $234.94 \pm 5.53$ & 0.05
\end{tabular}

\footnotetext{
Thypothetical analogue to the conductance or the intra cellular fluid, ${ }^{2}$ frequency at the maximal value of $X$, phase angle at this frequency, ${ }^{4}$ resistivity at $\omega_{0},{ }^{3}$ not significant.
}

Table 2b. MFBIA correlation between patients with CRPS I in the arm and the control group.

\begin{tabular}{lccccc}
\hline MFBIA & $\begin{array}{c}\text { Affected limb } \\
\text { (Mean } \pm \text { s.d.) }\end{array}$ & $\begin{array}{c}\text { Normal limb } \\
\text { (Mean } \pm \text { s.d.) }\end{array}$ & $P$ & $\begin{array}{c}\text { Control group } \\
\text { (Mean } \pm \text { s.d.) }\end{array}$ & $P$ \\
\hline$X^{\prime}$ & $25.8 \pm 4.0$ & $26.8 \pm 5.4$ & $\mathrm{Ns}^{5}$ & $27.75 \pm 0.68$ & Ns \\
$\omega_{0}^{2}$ & $53.8 \pm 10.8$ & $45.5 \pm 9.4$ & 0.002 & $48.85 \pm 1.35$ & 0.02 \\
$\Phi^{3}$ & $5.4 \pm 0.8$ & $6.0 \pm 0.8$ & 0.001 & $6.28 \pm 0.13$ & 0.001 \\
$\mathrm{R}^{4}$ & $277.7 \pm 44.6$ & $261.7 \pm 40.3$ & 0.006 & $254.25 \pm 0.68$ & 0.01
\end{tabular}

\footnotetext{
Thypothetical analogue to the conductance or the intra cellular fluid, ${ }^{2}$ frequency at the maximal value of $\mathrm{X},{ }^{3}$ phase angle at this frequency, ${ }^{4}$ resistivity at $\omega_{0},{ }^{5}$ not significant.
}

The affected limbs in patients suffering of CRPS I in the arm showed decreases in $\Phi$ $(p=0.001)$ and increases in $\omega_{0}(p=0.002)$ and $R(p=0.006)$, compared with the normal limbs (tab. 2b.). There were also differences when compared with the control group; $\Phi$ was decreased $(p=0.001)$ and $\omega_{0}(p=0.02)$ and $R(p=0.01)$ were increased in the CRPS I limbs. As in patients with CRPS I in the leg, patients with CRPS I in the arm showed no significant differences between non-affected limbs and the control group. The $\Phi$ of the affected arms is decreased as a consequence of the significant increase of the $R$ without changes of the $X$ parameter. 


\section{Specificity and sensitivity of the MFBIA}

The ROC curves and the AUC for the lower and upper limbs demonstrated that the $\omega_{0}$ and the $\Phi$ were the most accurate parameters of the MFBIA, therefore only the ROC curves of these entities are demonstrated in figures $4 \mathrm{a}$ and $4 \mathrm{~b}$. The affected limbs were compared with both left and right limbs of the control group. The cut-off values at which the sensitivity and the specificity were both maximal are listed below.

For both $\omega_{0}$ and $\Phi$ of the affected lower limbs the AUC were moderately accurate $(A U C=0.878 ; p=0.001)$. There were no differences of these values compared with the left or right leg of the unaffected control group (see figure $4 \mathrm{a}$ )

The $\omega_{0}$ of the affected upper limbs compared with the left arm of the control group resulted in an AUC of $0.654(p=0.1$; less accurate). Comparison with the right arm of the control group demonstrated an AUC of $0.787(\mathrm{p}=0.005$; moderately accurate). The ROC analyses for the $\Phi$ resulted in an AUC of $0.724(p=0.03$; moderately accurate) for the comparison with the left control arm and an AUC of $0.818(\mathrm{p}=0.002$; moderately accurate) for the right control arm (figure $4 \mathrm{~b}$ ).

Figure 4a. ROC Curves and AUC of the Omega (W) and phase angle for the leg compared with the right and left leg of the control group.

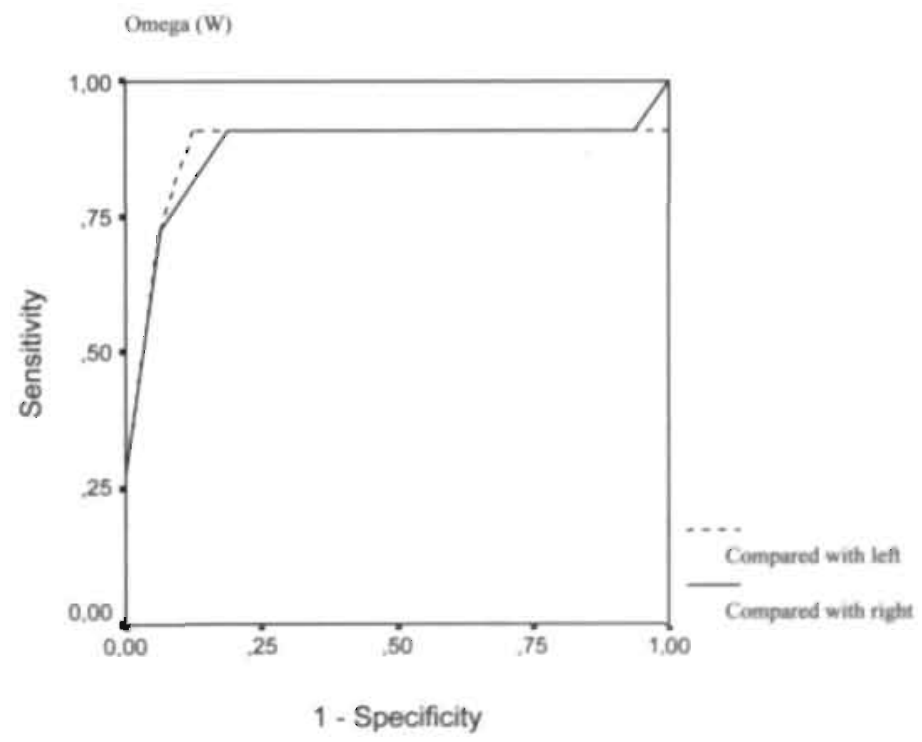


Sensitivity

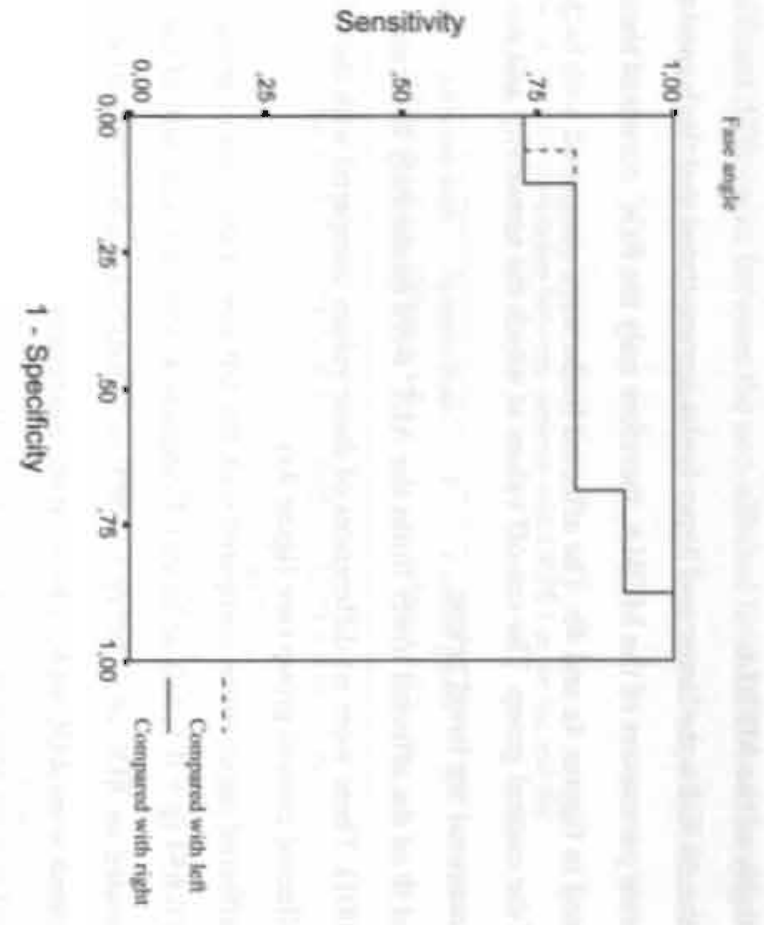


Figure 4b. ROC Curves and AUC of the Omega (W) and phase angle for the arm compared with the right and left arm of the control group.
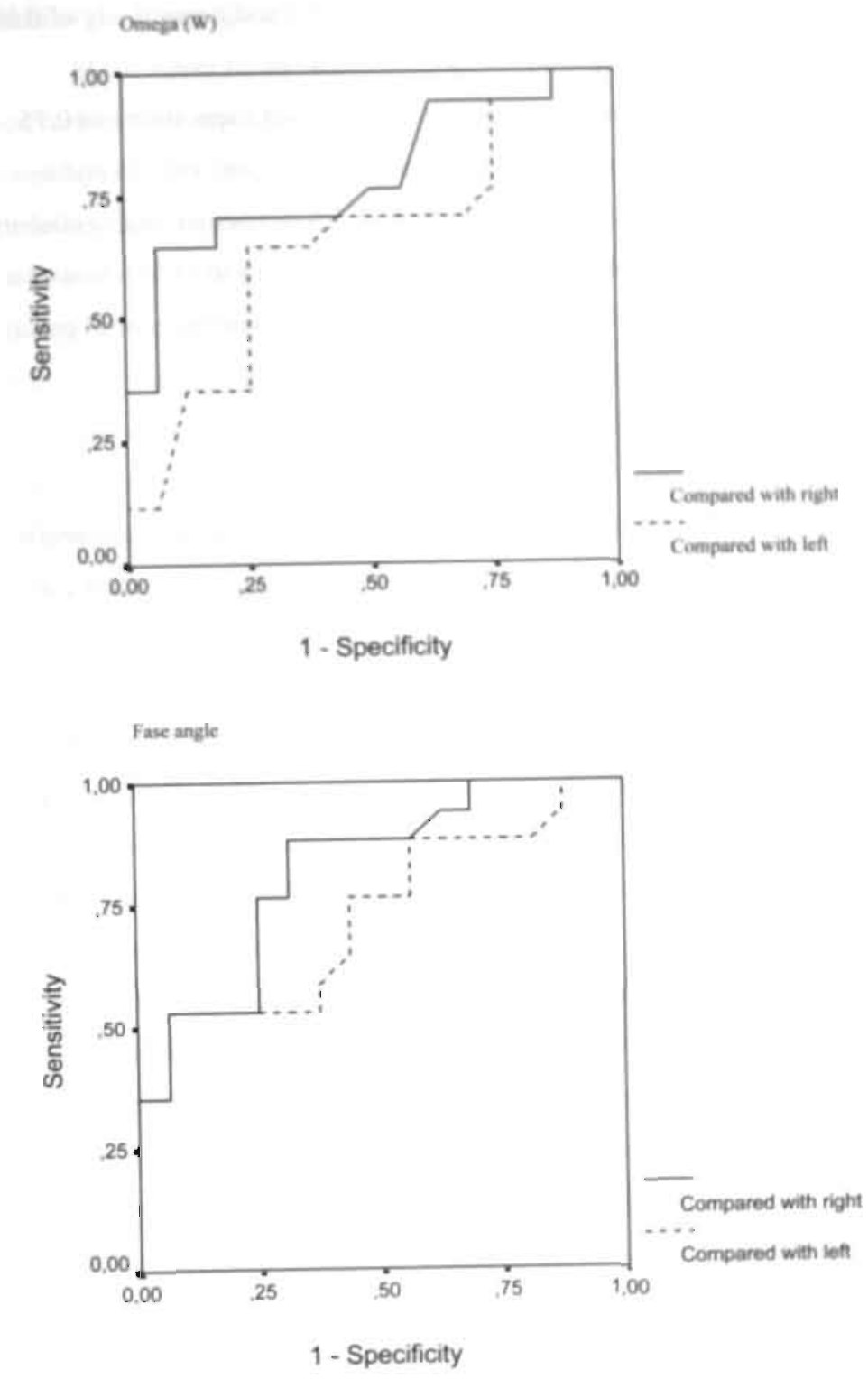
The sensitivity and the specificity analysis of the $\omega_{0}$ and the $\Phi$ demonstrated that for the lower limbs a $\omega_{0}$ of 46.5 had a sensitivity of 0.91 and a specificity of 0.88 compared with the right and left control leg. A $\Phi$ of 6.9 showed a sensitivity of 0.82 and a specificity of 0.88 compared with the left leg as well as the right leg of the control group.

For the upper limbs a $\omega_{0}$ of 53 showed a sensitivity of 0.65 and a specificity of 0.75 compared with the left control arm. A $\omega_{0}$ of 48.5 demonstrated a sensitivity of 0.75 and a specificity of 0.82 compared with the right control arm. A $\Phi$ of 5.5 demonstrated a sensitivity of 0.50 and a specificity of 0.94 compared with the left control arm and a $\Phi$ of 6.0 showed a sensitivity of 0.82 and a specificity of 0.70 compared with the right arm of the control group.

\section{DISCUSSION}

Awareness amongst clinicians of the incidence and severity of CRPS I has been persistently clouded by the lack of simple qualitative and quantitative measures. The present study was designed to investigate the multifrequency bioelectrical impedance as an objective measure of the severity of affected limbs in CRPS I patients. MFBIA, a non-invasive electrical assessment, is accepted for measuring body cell mass and has been shown to be valid in meastring the intra and extra cellular fluid volume in each body segment ${ }^{8-10}$. The usefulness of MFBIA has been investigated in several conditions. Ward et al investigated MFBIA measurements in the diagnosis and management of lymphoedema ${ }^{13}$. They concluded that this measurement is a quantitative and causally-related measure of fluid accumulation and that it represents an advance in the assessment of lymphoedema. Furthermore, several iongitudinal studies have shown a strong ability of the phase angle to predict survival and clinical progression in HIV-infected patients. It is a useful parameter for monitoring disease progression $^{14-17}$ :

Our data demonstrate that the impedance spectrum of the affected limbs in CRPS I patients is altered compared to the contra lateral side and to limbs in a control group. The phase angle in the affected limbs was significantly less than in normal limbs and this could indicate significant change in intra- and extra cellular fluid ratios. In addition, the MFBIA measured a significant increase of $\omega_{0}$ in the affected limbs of CRPS I patients compared with the contralateral limb and the control group and the resistance $(R)$ and $\omega_{0}$ were also increased in affected limbs. The decrease of the phase angle was mainly caused by the increase in resistance (R), which is defined as the ability of a medium to conduct electrical current and not due to changes in the resistive effect produced by tissue interface and cell membrane 
(reactance). Further the entities $\omega_{0}$ and phase angle of the MFBIA. proved to be moderate sensitive and specific for CRPS I in the lower limbs compared with either the left or the right limbs of the control group.

In the upper limbs, however, MFBIA demonstrated less sensitivity and specificity. The best results were seen when the affected limbs were compared with the right limbs of the control group. We assume that this phenomenon can be partly explained by the dominance of the left or right arm in patients and controls. If we hypothesis that a dominant arm would be more developed, the differences of a dominant arm with a CRPS I arm, which is often disused, would be more definite than differences between a not dominant arm with a CRPS I arm. In this current study all unaffected controls were right handed. In our study we presented the cut-off value with maximal sensitivity and specificity. However, because there is less consensus about treatment of CRPS I it is preferable to exclude are "false positive" patients. Therefore it is possible to use cut-off values at which the specificity is maximal.

We were unable to correlate these results obtained with MFBIA with other measures in this current study. No volumetric or functional tests were performed. However Ward et al ${ }^{13}$ demonstrated in patients with lymphoedema that this technique produced quantitative agreement with the currently used measure (limb volume calculated from circumferential measurements) of limb size. Further our control group was significantly younger than the patient population and this could contribute to bias. However, the MFBIA entities of the control group never differed significantly from the normal limbs of the patients suggesting that the control group was satisfactory.

MFBIA measurement proved to be a promising assessment for measuring tissue properties in effected limbs of CRPS 1 patients when compared with the contralateral side and compared to limbs in a control group. The relation of the impedance to these properties is indirect and has not been completely defined. Further, the MFBIA measures the tissue resistivity, which is affected by relative volumes and electrolytic balances between the intraand extra cellular fluids and these factors vary among individuals. We hope to develop MFBIA into an objective measure that can be used to evaluate the severity of CRPS I and that can also be used as a prognostic marker in CRPS I patients. 


\section{References}

1. Veldman PH, Reynen HM, Amtz IE, Goris RJ. Signs and symptoms of reflex sympathetic dystrophy: prospective study of 829 patients, Lancet 1993; 342:1012-6.

2. Schurmann M, Gradl G, Andress H, Furst H, Schildberg FW. Assessment of peripheral sympathetic nervous function for diagnosing early post-traumatic complex regional pain syndrome type I. Pain 1999; 80:149-59.

3. Ochoa Л, Verdugo RJ. Reflex sympathetic dystrophy. A common clinical avenue for somatoform expression. Neurol Clin 1995; 13:351-63.

4. Bedogni G, Merlini L. Ballestrami A, Severi S, Battistini N. Multifrequency bioelectric impedance measurements for predicting body water compartments in duchenne muscular dystrophy. Neuromuscul Disord 1996; 6:55-60.

5. Mikes DM, Cha BA, Dym CL, et al. Bioelectrical impedance analysis revisited. Lymphology 1999; 32:157-65.

6. Schoeller DA. Bioelectrical impedance analysis. What does it measure? [In Process Citation]. Ann N Y Acad Sci 2000; 904:159-62.

7. Baumgartner RN, Chumlea WC, Roche AF. Bioclectric impedance phase angle and body composition. Am J Clin Nutr $1988 ; 48: 16-23$.

8. Baumgartner RN, Chumlea WC. Roche AF. Estimation of body composition from bioelectric impedance of body segments. Am J Clin Nutr 1989; 50:221-6.

9. Van Kreel BK, Cox-Reyven N, Soeters P. Determination of total body water by multifrequency bio-electric impedance: development of several models. Med. Biol. Eng. Comput. 1998; 36:337-345.

10. Sasser DC, Gerth WA, Wu YC. Monitoring of segmental intra- and extracellular volume changes using electrical impedance spectroscopy. J Appl Physiol 1993; 74:2180-7.

11. Merskey KR, Bogduck N, Classification of Chronic Pain: Descriptions of Chronic Pain Syndromes and Difinitions of Pain Term. Seatle, WA: IASP' Press, 1994.

12. Sweis JA. Measuring the accuracy of diagnostic systems. Science 1988; 240:1285-93.

13. Ward LC, Bunce IH. Comish BH, Mirolo BR. Thomas BJ, Jones LC. Multi-frequency bioelectrical impedance augments the diagnosis and management of lymphoedema in post-mastectomy patients. Eur J Clin Invest 1992; 22:751-4.

14. Ot M, Fischer H, Polat H, el al. Bioelectrical impedance analysis as a predictor of survival in patients with human immunodeficiency virus infection. J Acquir Immune Defic Syndr Hum Retrovirol 1995: 9:20-5.

15. Earthman CP. Matthie JR, Reid PM, Harper IT, Ravussin E, Howell WH. A comparison of bioimpedance methods for detection of body cell mass change in HIV infection. I Appl Physiol 2000; 88:944-56.

16. Sehwenk A, Eschner W, Kremer G, Ward LC. Assessment, of intracellular water by whole body bioelectrical impedance and lotal body potassium in HIV-positive patients. Clin Nutr 2000; 19:109-13.

17. Schwenk A. Beisenherz A, Romer K, Kremer G, Salzberger B, Elia M. Phase angle from bioelectrical impedance analysis remains an inđependent predictive marker in HIV-infected patients in the era of highly active antiretroviral treatment. Am J Clin Nutr 2000; 72:496-501. 


\section{CHAPTER 6}

Radiofrequency lesions of the Stellate ganglion in chronic pain syndromes

Retrospective analysis of clinical efficacy in 86 patients

Tymour Forouzanfar, Maarten van Kleef, and Wilhelm E.J. Weber.

Published in Clin. J. Pain 2000; 16(2): 164-8 


\section{ABSTRACT}

Background: Stellate ganglia (SG) blockades are used for treatment of chronic pain syndromes in which the sympathetic nervous system is hypothesised to be involved.

A possible treatment modality to achieve long term pain reduction is blockade of the SG by means of radiofrequency lesion (RF-SG)

Objectives: To evaluate the outcome of RF-SG as a therapy for different chronic pain syndromes, we reviewed 86 RF stellate ganglion procedure.

Method: Medical records containing treatment informations were reviewed systematically. A systematic literature review search in MEDLINE on SG blockades was also performed.

Results: In our clinic, $39,5 \%$ of 226 patients who received a prognostic SG block subsequently underwent RF-SG. Of these patients $40,7 \%$ noted more then $50 \%$ reduction of pain, $54,7 \%$ had no effect on pain and $4,7 \%$ showed worsening of pain. Mean follow-up was 52 weeks. The computer assisted literature search resulted in thirty-one studies, twelve about complications and nineteen about the efficacy of stellate ganglia block. A meta-analysis of these studies showed a partial pain relief in $41,3 \%$ of patients, complete pain relief in $37,8 \%$ and no pain relief in $20,9 \%$.

Conclusion: The efficacy of the RF-SG blockade appears to be in line with other SG block procedures reported in the literature. Our retrospective study shows that a RF-SGi block is most likely to be of benefit for patients suffering from CRPS2, ischemic pain, cervicobrachialgia, or post-1horacotomy pain. However, clinical efficacy remains to be proven in a randomised controlled trial. 


\section{INTRODUCTION}

The cervicothoracic (Stellate) ganglion, which is formed by a fusion of the lower two cervical and first thoracic segmental ganglia, lies on lateral border of the longus collis muscle between the base of the seventh cervical transverse process and the neck of the first rib. The stellate ganglion is a relay station between the paravertebral sympathetic chain and the cervical trunks of the brachial plexus. The main functions of the ganglion contribute to sensorimotor processing of sympathetic impulses of the upper extremities, the neck and the face $^{1-4}$.

Historically blockade of the stellate ganglion has been used as a treatment for a wide variety of conditions such as glaucoma, neuritis of the optic nerve, tinnitus, angina pectoris, arrhythmia, coronary occlusion, pulmonary embolism and thrombophlebitis 1, 5. Presently it is a widely used method in the treatment of chronic pain syndromes in the facial and cervicobrachial region, and also in non painful conditions 5,6 , e.g. hyperhidrosis.

There are several methods to block the stellate ganglion, but mostly the anterior paratracheal approach is used. Usually local anesthetic solutions such as bupivacaine, procaine and Lidocaine are used. In routine clinical procedures the first diagnostic blockade with a local anaesthetic is followed by more blockades if the pain syndrome appears respond to the treatment ${ }^{6-9}$

Since 1992 we have used radiofrequency induced lesions ${ }^{10}$ to block the SG. Patients were selected for this procedure when they reported at least $50 \%$ pain relief after a SG blockade with a local anaesthetic solution. RF lesions were used because of their controllability, they are well tolerated and they have few adverse effects 11,12 . Although their effects may be partial or temporary ${ }^{11}, 12$, they may promote better conditions for rehabilitation.

In this retrospective study we reviewed 237 SG blockades which were performed in The Pain Management and Research Centre, Dept. of Anesthesiology, University Hospital Maastricht, The Netherlands, between I992 and 1998. For comparative purposes we also reviewed existing literature on the efficacy and complications of stellate ganglion blockades.

\section{METHODS}

For the first part of this study all patients treated with stellate ganglia blockade in The Pain Management and Research Centre between 1992 and 1998 were identified using the hospital 
database containing treatment information. The selected medical records were claimed and reviewed. To review systematically the medical records the following standard set of data was obtained: age, sex, duration of pain, diagnoses, Visual Analogue Scale, number of policlinic consultations without any diagnoses, effect of the blockade on the pain, appearance of Horner's syndrome, effect of the blockade on the skin temperature, effect of the definitive blockade on the pain, time between the diagnostic and definitive blockade, number of blockades and side effects.

\section{Technique of prognostic and RF SG blockade}

The patient is placed on the operating table in the supine position. For a stellate ganglion block, the cervicothoracic spine is visualised in an AP projection. The carotid artery is kept aside while a $60 \mathrm{~mm} 24 \mathrm{G}$ needle (Pole Needle-RC Cotop, Amsterdam, The Netherlands) is introduced to make contact with the $\mathrm{C} 7$ transverse process just lateral to its origin from the lamina. Proper position is confirmed on an oblique projection. In oblique projection the needle tip should lie anterior to the anterior border of the foramen. Contrast $0.2 \mathrm{ml}$ is injected to confirm the characteristic spread and to exclude intravascular positioning of the needle tip, as described ${ }^{13}, 4-6 \mathrm{ml}$ lidocaine $1 \%$ is injected ${ }^{14}$, and the needle is withdrawn. After 30 minutes the patient is examined for the appearance of an ipsilateral Horner's syndrome, pain relief and subjective feeling of warmth in the ipsilateral arm.

For an RF SG block a 22G SMK C5 (Radionics, Burlington, MA) cannula with a 4 $\mathrm{mm}$ bare tip is introduced using the above approach. The electrode tip should lie anterior to the anterior border of the foramen. Stimulation is performed at $2 \mathrm{~Hz}$ and $50 \mathrm{~Hz}$, to exclude elose proximity to phrenic, recurrent nerves or the segmental nerve of $\mathrm{C} 7$ (Radionics 3Cplus, Burlington, MA). No stimulation should occur. Contrast $0.2 \mathrm{ml}$ is injected to confirm the characteristic spread, and to exclude intravascular positioning of the needle tip. After anaesthetisation with $2 \mathrm{ml}$ of $1 \%$ lidocaine, a 60 seconds $80^{\circ} \mathrm{C}$ lesion is then made with an RF lesion generator (Radionics 3Cplus, Burlington, MA).

\section{Method of literature search.}

To find articles for the second part of our research we carried out computer assisted search in MEDLINE and EMBASE, using the key words stellate ganglia block, cervicothoracic ganglion block, radiofrequency lesions.

For statistical analysis the SPSS for Windows version 7.5 software package (SPSS Inc. 1989-1996) was used. 


\section{RESULTS}

\section{Retrospective analyses of patient data}

226 patients received 237 prognostic blocks. The data of 3 patients which had undergone the procedure were not available. 88 patients reported more than $50 \%$ reduction of pain after a SG blockade. 78 patients were selected to undergo a RF SG. Eight patients were using coumarine derivates. To minimise the complications of bleeding they were treated with definitive lesioning without receiving a diagnostic block first. Ten patients responded with a reduction of pain for more than $50 \%$ after the prognostic block, but because of discomfort they refused a subsequent RF lesion. Patients characteristics are summarised in table 1.

Table 1. Patients characteristics.

\begin{tabular}{ll}
\hline Gender & $\begin{array}{l}\text { Male: } 99 \\
\text { Female: } 127\end{array}$ \\
$\begin{array}{l}\text { Age }(y r s)^{1} \\
(\text { mean } \pm \text { Std. Error) }\end{array}$ & $46.25 \pm 0.87$ \\
$\begin{array}{l}\text { Duration of pain }(\operatorname{mos})^{2} \\
\text { (mean } \pm \text { Std.Error) }\end{array}$ & $51.64 \pm 4.15$ \\
$\begin{array}{l}\text { VAS }- \text { Score } \\
\text { (mean } \pm \text { Std.Error) }\end{array}$ & $6.88 \pm 0.22$ \\
\hline
\end{tabular}

\footnotetext{
${ }^{1}$ Years

${ }^{2}$ Month
}

There were more females then males in our study, but no difference in treatment results was noted. Likewise, there was no association between age, pain duration, VAS, number of policlinic consultations without any diagnoses which may be reviewed as possible somatisation disorder, appearance of Horner's syndrome, time between the diagnostic and definitive blockade, effect of the blockade on the skin temperature and treatment results. Of the 86 patients who were treated with an RF lesion, thirty-five $(40.7 \%)$ noted "more then $50 \%$ " reduction of pain, whereas forty-seven $(54.7 \%)$ had "no effect" on pain, and four (4.7\%) patients noted "worsening" of pain (table 2). The data about the duration of pain relief were available only in 27 patients and showed an average duration of 52.4 (S.E: 7.78 ) weeks with a minimum and maximum of 2.2 respectively 186 weeks. 
Table 2. Results of the diagnostic blocks and the definitive lesions.

\begin{tabular}{|c|c|c|c|c|c|}
\hline \multicolumn{3}{|c|}{ Diagnostic Blocks } & \multicolumn{3}{|c|}{ Definitive Lesions } \\
\hline $\begin{array}{c}\text { Worsening } \\
\text { of pain }\end{array}$ & $\begin{array}{c}\text { No effect on } \\
\text { pain }\end{array}$ & $\begin{array}{l}\text { More then } 50 \\
\% \text { reduction } \\
\text { of pain }\end{array}$ & $\begin{array}{l}\text { Worsening } \\
\text { of pain }\end{array}$ & $\begin{array}{c}\text { No effect on } \\
\text { pain }\end{array}$ & $\begin{array}{l}\text { More then } 50 \\
\% \text { reduction } \\
\text { of pain }\end{array}$ \\
\hline
\end{tabular}

\begin{tabular}{|c|c|c|c|c|c|c|}
\hline $\begin{array}{l}\text { Post - traumatic } \\
\text { headache }\end{array}$ & . & 2 & 1 & * & 1 & - \\
\hline $\begin{array}{l}\text { Idiopathic pain in } \\
\text { the neck }\end{array}$ & . & . & 1 & $=$ & - & I \\
\hline $\begin{array}{l}\text { Post Whip - lash } \\
\text { syndrome }\end{array}$ & . & 2 & 2 & - & 2 & - \\
\hline CRPS I & 2 & 36 & 29 & 2 & 20 & 13 \\
\hline CRPS 2 & . & 3 & 5 & $=$ & 2 & 4 \\
\hline $\begin{array}{l}\text { Idiopathic pain in } \\
\text { the arm }\end{array}$ & 4 & 43 & 23 & 1 & 10 & 7 \\
\hline Joint ache & - & 2 & - & - & * & - \\
\hline $\begin{array}{l}\text { Deafferentiation } \\
\text { pain }\end{array}$ & - & 8 & 3 & = & 1 & 1 \\
\hline $\begin{array}{l}\text { Central pain } \\
\text { syndromes }\end{array}$ & - & 2 & 1 & - & - & 1 \\
\hline Ischemic pain & 1 & 4 & 5 & $=$ & 3 & 3 \\
\hline $\begin{array}{l}\text { Cervico- } \\
\text { brachiaigia } \\
\text { (degenerative) }\end{array}$ & $=$ & 9 & 5 & - & - & 3 \\
\hline $\begin{array}{l}\text { Head, neck and } \\
\text { upper-extremity } \\
\text { pain }\end{array}$ & $=$ & 5 & 5 & 1 & 4 & - \\
\hline $\begin{array}{l}\text { Postherpetic } \\
\text { neuralgia }\end{array}$ & $\approx$ & 1 & 3 & - & 3 & - \\
\hline $\begin{array}{l}\text { Atypical faciat } \\
\text { neuralgia }\end{array}$ & - & 2 & 1 & $=$ & - & - \\
\hline $\begin{array}{l}\text { Post - thoracotomy } \\
\text { pain }\end{array}$ & - & 4 & 4 & - & 1 & 2 \\
\hline Total & 7 & 123 & 88 & 4 & 47 & 35 \\
\hline
\end{tabular}




\section{Literature analyses}

The CD-ROM search resulted in thirty-two articles. Twenty articles of which 7 case reports, 6 retrospective studies, 7 prospective studies reported about the efficacy of SG block. Twelve studies including 2 retrospective studies and 10 case reports describe the possible complications of SG blockade. There was only one study on RF SG ${ }^{15}$. This study was excluded since therapeutic efficacy could not be judged from this paper, as pain scores before treatment were not given.

Possible complications after such a blockade include cardiac arrhythmia, pneumothorax, and nerve damage $16-25$. In two studies a total of more than 80.000 stellate blockades were reviewed 18,26 , The authors reported I to 2 severe complications like pneumothorax per 1000 blockades.

A review of 19 studies on efficacy is presented in table 3. A total of 1900 blockades was performed in 373 patients. In $154(41.3 \%)$ patients a partial pain relief occurred after treatment. Complete pain relief was found in 141 (37.8\%) of patients. Seventy-eight $(20.9 \%)$ patients reported no pain relief.

Table 3. Meta-analyses of literature of pain relief by stellate ganglion block.

\begin{tabular}{|c|c|c|c|c|c|c|}
\hline Diagnose & Patients & $\begin{array}{l}\text { Number of } \\
\text { blockades }\end{array}$ & Technique & No pain relief & $\begin{array}{c}\text { Partial pain } \\
\text { relief }\end{array}$ & $\begin{array}{l}\text { Complete pain } \\
\text { relief }\end{array}$ \\
\hline $\mathrm{RSD}^{1}$ & 110 & 800 & & $15(13.6 \%)$ & $58(52.7 \%)$ & $38(34.6 \%)$ \\
\hline $\mathrm{PHN}^{2}$ & 105 & 126 & 1 & $18(17.1 \%)$ & $27(25,7 \%)$ & $60(57.1 \%)$ \\
\hline Causalgia & 1 & & 1 & & & I (100\%) \\
\hline Pain eci & 10 & 24 & 1 & $4\left(40^{\circ} \%\right)$ & I $(10 \%)$ & $5(50 \%)$ \\
\hline $\begin{array}{l}\text { Radiculo - } \\
\text { pathy }\end{array}$ & 1 & 9 & 1 & $I(100 \%)$ & & \\
\hline $\begin{array}{l}\text { Shoulder- } \\
\text { hand synd. }\end{array}$ & 72 & 473 & 2 & $23(31.9 \%)$ & $35(48.6 \%)$ & $14(19.4 \%)$ \\
\hline Inflam-mation & 14 & 96 & & $6(42.9 \%)$ & $4(28.6 \%)$ & $4(28,6 \%)$ \\
\hline $\begin{array}{l}\text { Vascular } \\
\text { disease }\end{array}$ & 21 & 177 & 2 & $2(10 \%)$ & $12(57.1 \%)$ & $7(33.3 \%)$ \\
\hline Other & 39 & 195 & & $9(23.1 \%)$ & $17(43.6 \%)$ & $13(33.3 \%)$ \\
\hline Total & 373 & 1900 & & $78(20.9 \%)$ & $154(41.3 \%)$ & $141(37.8 \%)$ \\
\hline
\end{tabular}

\footnotetext{
Reflex sympathetic dystrophy

${ }^{2}$ Post herpetic neuralgia
} 


\section{DISCUSSION}

In this retrospective study of 226 consecutively treated patients we have reviewed the efficacy of RF lesions of the SG in patients with chronic pain in the cervicothoracobrachial region.

Historically SG blockade in chronic pain syndromes is done with the injection of a local anaesthetic, thus providing only temporary relief. To circumvent this problem we employ RF current for SG blockades since 1992. This technique was chosen because of the controllability, patient comfort and few adverse effects 11,12 . To select patient for this procedure diagnostic blockade was performed with 4-6 ml lidocaine $1-2 \%$. Patients reporting more than $50 \%$ pain relief subsequently underwent the RF procedure.

Our study demonstrated that $40 \%$ of these selected patients reported a reduction of pain of more than $50 \%$ for an average duration of 52 weeks. The efficacy of the RF SG blockade in the total (unselected) population of 226 patients is $15.5 \%$. Our meta-analysis of the literature on pain relief after a SG blockade shows a partial pain relief in $41,3 \%$ and a complete pain relief in $37.8 \%$ of patients using an average of five SG blocks per patient. When comparing our indications and results with reports in the literature, several considerations have to be taken in account.

In our retrospective study we divided the degree of pain relieve in three subgroups: "worsening of pain", "no effect on pain" and "more than $50 \%$ reduction of pain" (table 2). Patients who noted no pain reduction, some pain reduction, little pain reduction and partial pain reduction were referred to the subgroup "no effect on pain". Only patients who reported a reduction of pain of more than $50 \%$ were referred to the third subgroup. So the patients with "no effect on pain" have to be compared with the subgroups "no pain relief" and "partial pain relief" in the meta-analysis of SG blocks. The subgroup "more than $50 \%$ reduction of pain" in our study has to be compared with the subgroup "complete pain relief" in the literature analysis (tables 2 and 3). Moreover, in our approach the prognostic blocks were not used for treatment purposes but only for selecting patients for an RF lesion of the SG. Therefore it would methodologically be correct to compare only the results of patients who received the RF lesion with the results of other studies. Finally, an RF lesion of the SG, when effective, leads to pain reduction of 52 weeks average. Information on the duration of pain relief by repetitive local anaesthetic injections as reported in the literature is not available.

The question remains as to the high proportion of false-positive diagnostic SG blocks. Theoretically the RF lesion should reduce the pain after a positive prognostic SG block. 
However in this study only $40.70 \%$ of patients, selected by a positive diagnostic block, reported a reduction of pain after an RF lesion. There are several possible explanations for this phenomenon. Anatomical variations of the $\mathrm{SG}^{1,2}$ may hinder exact localisation by the RF needle, while these will not pose a problem for the easily spreading local anaesthetic 27,28 in a diagnostic procedure. Another explanation is offered by the possible placebo response. It has been shown that treatment expectations can increase endogenous opioids in plasma and cerebrospinal fluid, which in turn will cause analgesia for a short time 29 . This relatively shortlasting effect will lead to a positive diagnostic block, whereas the same phenomenon in an RF procedure will not produce a long lasting pain reduction. Thirdly, the effectiveness of RF SG versus prognostic blockade may reflect differences in pathophysiology of the various diagnostic categories as to the involvement of the sympathetic nervous system. It is likely that local anaesthetic injections will affect somatic structures, in contrast to an isolated RF lesion of the SG.

Our study demonstrates that the clinical effectiveness of RF SG blockade may be improved at following two levels. Precise anatomic localisation of the SG may lead to increased clinical effect. This could be achieved by ultrasound ${ }^{30}$, magnetic resonance imaging ${ }^{10}$ and computed tomography ${ }^{31}$. Our retrospective study shows that the therapeutic effects of an RF SG block vary per diagnostic subgroup. When using a cut-off value of $50 \%$ of patients reporting more than $50 \%$ pain relief per diagnostic subgroup, only CRPS2, ischemic pain, cervico-brachialgia and post-thoracotomy pain, appears to respond to an RF SG block, which is in line with work by Wilkinson et al, using radiofrequency to target upper thoracic sympathetic ganglia ${ }^{32,33}$. It appears that these four diagnostic groups are most likely to benefit from an RF-SG block (after a positive diagnostic block).

In summary, although the efficacy of an RF SG blockade appears to be in line with other SG blockade procedures reported in the literature, its clinical effects remain to be proven in a randomised controlled trial. Given the potential of harmful complications ${ }^{16-25}$, it would even be questionable if it is ethical to continue the routine clinical use of RF SG blocks without supportive data from such a trial. 


\section{Kefferenter}

1. Moore DM. Stellate Ganalion Block. Illinoi: Charles C Thomas, 1954:280.

2. Perlow S, Vehe KL. Gross anatomy of the stellate and lumbar sympathetic ganglia. American Journal of Surgery 1935; $30: 454.458$.

3. Bannister L.H, Berry MM, Dyson M, Dussek JE, Ferguson MWJ. Gray's anatomy: Churchil Livingstone.

4. Carron H, Litwiller R. Stellate Ganglion Block. Anest Analg 1975; 54(5):567-570.

5. Rauchfuss VE, Bohland W, Sauer D. Stellate block in discases in the area of the upper limb. Z61 Chir 1971; 96:851-864.

6. Malmqvist BL-A, Bengtsson M, Sorensen S. Efficacy of Stellate Ganglion Block: A Clinical Study with Bupivacaine. Reg Anesthesia 1992; 17:340-347

7. Leipzig TJ, Mullian SF, Causalgic pain relieved by prolonged procaine amide sympathetic blockade. J Neurosurg 1984; 60:1095-1096

8. Todd DT. Prolonged stellate block in treatment of reflex sympathetic dystrophy. Agressologie 1991: 32:281-282.

9. Weissenberg W. Die Effektivitat der Sympathikusblocade mit unterschiedlichen Techniken. Regional Anoesthesie 1987: 10-96-103.

10. Slappendel R, Thijssen HOM, Crul BJP, Merx J.. The Stellate Ganglion in Magnetic Resonance Imaging: A. Quantification of the Anathomic Variability, anesthesiology 1995; 83:424-426.

11. Van Kleef M, Spaans F, Dingemans W, Barendse GAM, Floor A, Sluiter ME. Effects and side effects of a percutaneous thermal lesion of the donsal root ganglion in patients with cervical pain syndrome. Pain 1993; 52:49-53.

12. North RB, Ham M, Zahurak M, Kidd DH. Radiofrequency lumbar facet denervation: analysis of prognostic factors. Pain $1994 ; 57: 77+83$

13. Van Suijlekom JA, Weber WE, Van Kleef M. Treatment of Spinal Pain by Means of Radiofrequency Procedures - Part II: Thoracic and Cervical Areas. Pain Reviews 1999; 6:175-191.

14. Van Klecef M, Sluiter ME. Radiofrequency lesions in the treatment of pain of spinal origin. In: Gildenberg LP, ed. Textbook of stereotactic on functional neurosurgery. New York: MeGraw Hill, 1998:1585.

15. Geurts JWR, Stolker RJ. Percutaneous radiofrequency lesion of the stellate ganglion in the treatment of pain in the upper extremity reflex sympathetic dystrophy. The Pain Clinic 1993; 6:17-25.

16. Jackson DA. Reflex Sympathetic Dystrophy Syndrome: Two Case Studies. J Pos Anest Nurs 1993; 80(5):327-331.

17. Bruyns T, Devulder J. Vermeulen H, Colvenear dL, Rolly G. Possibie inadvertent subdural block following attempred stellate ganglion blockade. Anaesthesia 1991; 46:747-749.

18. Wulf H. Maier C. Komplikation und Nebenwirkungen bei Blockaden des Ganglion stellatum. Anaesthesist 1992; 41:146151.

19. Adriani J. Parmicy J, Ochsner A. Fatalities and complications after attempts at stellate ganglion block. Sungery 1952; $32: 615-619$

20. Orkin LR, Papper EM, Rovenstine EA. The complications of stellate and thoracic sympathetic nerve blocks. J Thoracic Surg 1950; 20:911-922.

21. Ellis JS, Ramamurthy S. Seizur Following Stellate Ganglion Block after Negative Aspiration and Test Dose. Anesthesiology 1986; 64:533.534.

22. Seot DL. Ghia JN, Teeple E. Aphasia and Hemiparesis following Stellate Ganglion Block. Anesth Analg 1983; 62:10381040

23. Stannard CF. Glynn CJ. Smith SP. Dural puncture during attempted stellate ganglion block. Anaesthesia 1990; 45;952954

24. Stohr M. Mayer K. Petruch F. Armplexusparese nach Stellatumblockade und Plexusanasthesie, Drsh med Wschr 1978: $103.68-70$

25. MeCallum MID, Glynn CJ. Intercostal Neuralgia Following Stellate Ganglion Block. Anaesthesia 1986; 41:850-852 
26. Volkman J. Betrachtungen uber Zwischenfalle bei fast 78000 Grenzstrangblockaden. Bruns Beitr Klin Chir 1952; 185:288-301.

27. Bauman JM, Middaugh RE, Cawthon MA, Hartshome MF, Menk E, Baysinger C. Radionuclide-anesthetic flow study: a new technique for the study of regional anesthesia. $J$ Nucl Mnd 1986; 27:1487-1480.

28. Guntamukkala M, Hardy PA. Spread of injectate after stellate ganglion block in man: an anatomical study. British Journal of Anassthesia 1991: 66:643-644.

29. Benedetti F, Amanzio M. The neurobiology of placebo analgesia: from endogenous opioids to cholecystokinin. Progness in Neurobiology 1997; 51:109-125.

30. Kapral S, Kraft P, Gosch M, Fleischmann D, Weinstabl C. Ultrasound imaging for Stellate Ganglion block: direct visualization of puncture site and local anesthetic spread. Reg Anesth 1995: 20(4):323-328.

31. Erickson SJ, Hogan QH. CT- guided Injection of the Stellate Ganglion: Description of Technique and Efficacy of Sympathetic Blockade. Radiology 1993; 188:707-709.

32. Wilkinson HA. Radiofrequency percutaneous upper-thoracie sympathectomy. Technique and review of indications: $N$ Engl J Med 1984; 311:34-6.

33. Wilkinson HA. Percutaneous radiofrequency upper thoracic sympathectomy. Neurasurgery 1996; $38: 715 \cdot 25$. 


\section{CHAPTER 7}

Spinal Cord Stimulation in Complex Regional Pain Syndrome: cervical and lumbar devices are comparably effective

Tymour Forouzanfar, Marius Kemler, Wilhelm E.J. Weber,

Alfons G.H. Kessels and Maarten van Kleef.

Published in $\mathrm{Br}$. J. Anaesth 2004; 92(3): 348-353 


\section{ABSTRACT}

Objectives: Spinal Cord Stimulation (SCS) has been used since 1967 for the treatment of patients with chronic pain. However, long-term effects of this treatment have not been reported. The present study investigated the long-term effect of cervical and lumbar SCS in patients with Complex Regional Pain Syndrome Type I.

Methods: Thirty-six patients with a definitive implant were included in this study. A pain diary was obtained from all patients prior to treatment, as well as 6 months, 1 and 2 years post implant. All patients were asked to complete a 7-point Global Perceived Effect (GPE) scale and the Euroqol- 5D (EQ-5D) at each post-implant assessment point.

Results: The pain intensity was reduced at 6 months, 1 and 2 years post implant ( $\mathrm{p}<$ $0.05)$. However, the repeated measures ANOVA showed a statistically significant, linear increase of the VAS ( $p=0.03$ ). According to the GPE at least $42 \%$ of the cervical SCS patients and $47 \%$ of the lumbar SCS patients reported at least "much improvement". The health status of the patients, as measured on the EQ-5D, was improved after treatment $(P<0.05)$. This improvement was noted both from the social as from patients' perspective. Complications and adverse effects occurred in $64 \%$ of the patients and consisted mainly of technical defects. There were no differences between cervical and lumbar groups with regard to outcome measures.

Conclusion: SCS reduces the pain intensity in the majority of the CRPS I patients and improves health status. There is no difference in outcome of pain relief and complications hetween cervical and lumbar SCS. 


\section{INTRODUCTION}

Complex Regional Pain Syndrome Type I (CRPS I) is a disabling syndrome', associated with continuous pain that is not related to the territory of a single nerve and is disproportionate to the inciting event ${ }^{2}$. As there is no objective test available, diagnosis of CRPS I is based solely on signs and symptoms ${ }^{3,4}$. In line with these diagnostic difficulties, therapy for CRPS I has also been unsatisfactory. Although many treatments are used, we recently found in a metaanalysis that most of them lack a sound scientific basis ${ }^{5,6}$.

Spinal cord stimulation (SCS) is widely used in the treatment of CRPS $\mathrm{I}^{7.13}$, and we were able to show its effectiveness in a randomised controlled study ${ }^{14}$. Follow-up in this study, however, was only six months. As there is anecdotal evidence that the clinical effects of SCS decrease over time, and as there is controversy regarding the use of SCS in the cervical region, we undertook a prospective study to address these issues. We prospectively measured pain, global perceived effect, quality of life, complications and side effects of SCS in 36 CRPS I patients. Of these, 19 had devices positioned in the cervical region and 17 in the lumbar region.

\section{PATIENTS AND METHODS}

\section{Patients}

The Hospital's Institutional Review Board approved the study protocol. The study started in 1997. Informed consent was obtained from all patients. All patients had to fulfil the diagnostic criteria CRPS I as stated by the IASP ${ }^{15}$. At the time of the study these criteria were the most valid diagnostic criteria available. In addition, patients had to show impaired function and extension of symptoms outside the area of trauma (table 1). Further, disease duration was at least six month and conventional treatments (i.e. sympathetic block, transcutaneous electrical nerve stimulation and conventional pain medication) had failed. 
Table 1. Diagnostic criteria for CRPS I'.

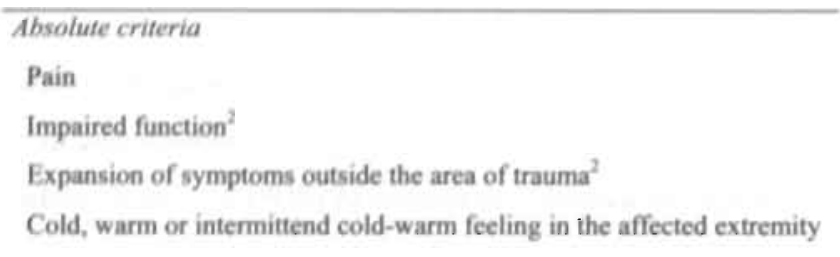

Relative criteria

Edema

Increased nail grouwth

Increased hair grouwth

Hyperhydrosis

Abnormal skin colouring

Hypesthesia

Hyperalgesia

Mechanical and/or thermal allodynia

Patchy demineralization of bone

All absolute criteria together with at least three relative criteria were
needed for the diagnosis of CRPS I
${ }^{2}$ Additional critria to those of the IASP

\section{Test stimulation}

All patients initially underwent test stimulation. The patient was placed in the prone position after an intravenous injection of cefuroxim $(1500 \mathrm{mg})$ was given. A $5-\mathrm{cm}$ vertical midline incision was performed over the thoracic or lumbar spine, depending on the affected extremity. The epidural space was localized with a Tuohy needle. For lumbar electrode placement level L3-L4 was chosen. The cervical electrode was inserted between Th3-Th4. Using direct fluoroscopy an SCS electrode (Pisces Quad lead, model 3487A; Medtronic, Minneapolis, MN) was introduced via the needle into the epidural space and connected to an external pulse generator (model 3625; Medtronic). The optimal position was considered to have been reached when the paresthesiae induced by stimulation totally covered the painful area. Then, the needle was withdrawn and the electrode was fixed with special clips and connected to the external stimulator.

After a test period of 7 days the temporary lead was removed. During the test period, patients were advised to perform all normal daily activities in order to obtain a good impression of the implant's effect. The permanent SCS system was implanted when during the testing period the patient reported either at least $50 \%$ reduction in pain intensity as 
measured on a $10 \mathrm{~cm}$ Visual Analogue Scale (VAS), which was anchored by 2 extremes of pain; "no pain" on the left and "the worst possible pain" on the right end;, or "much improvement" on the 7-point global perceived effect (GPE) scale. The GPE was translated from English in to Dutch ${ }^{14}$. The GPE categories include: best ever, much improved, improved, not improved/not worse, much worse, and worst ever.

\section{Implantation of the SCS system}

The Quad lead was implanted as described in the Test Stimulation section. After the lead was positioned, the patient was sedated and a pulse generator (Itrel 3, model 7425; Medtronic) was implanted in the subcutaneous tissue in the left lower anterior abdominal wall, and connected to the electrode by a tunnelled extension lead (model 7495-51 or 7495-66; Medtronic). After closing the skin, the pulse generator was activated and adjusted using a console programmer (model 7432; Medtronic). Initial stimulation was started at a rate of $85 \mathrm{~Hz}$ and a pulse width of $210 \mu \mathrm{sec}$. Patients could control the stimulation intensity by adjusting the amplitude from 0 to $10 \mathrm{~V}$ with a patient programmer (model 7434-NL; Medtronic). Post-implantation, patients remained in the hospital for 24 hours, during which period they received two doses of cefuroxim $(750 \mathrm{mg})$ intravenously. The following day, after the position of the electrode was verified by $\mathrm{x}$-ray, the patient was discharged. Further adjustments in the programming could be made on an outpatient basis. Post-implantation, no restrictions were placed on patient activities. 


\section{Patients' assessments during follow-up}

The assessments were done before treatment and 6, 12 and 24 months after implantation. All patients were asked to score their pain 3 times per day over a course of 4 days on a $10 \mathrm{~cm}$ Visual Analogue Scale (VAS) ${ }^{16-18}$.

In addition, all patients rated the global perceived effect (GPE) on pain on a sevenpoint scale, as indicated above.

All patients fulfilled the Euroqol 5D (EQ-5D) ${ }^{19}$ before the treatment and at follow-up after 1 and 2 years. The EQ-5D consists of two parts. The first part records self-reported health problems in five dimensions: mobility, self-care, usual activities, pain or discomfort, and anxiety or depression. Each dimension is subdivided into three categories, including no problem, moderate problems and extreme problems. By combining one category from each of the five dimensions a total of 243 "health states" are defined. The second part records the perception of patients' overall health on a $100 \mathrm{~mm}$ visual analogue scale $(0$ denoting death and 100 perfect health). The data of the EQ-5D are represented in three distinct forms ${ }^{20}:(1)$ as a profile, based on the patients category of problem in each of the five dimensions (EQ-5D profile); (2) as a social score by applying a suitable weighting system obtained from the UK national survey. Some patients score negatively, indicating that from a social perspective their state is regarded as worse than death; (3) as a VAS, representing a quantitative measure of the patient's valuation of his own global health status. (EQ-5D VAS).

The questionnaires were mailed to the patients by post. They were asked to fulfil the tests and return them by post.

Complications and adverse effects were also documented during policlinic check up. Complications were defined as unpleasant, new, physical experiences for the patient, and included spinal tap, post spinal headache, and infection. Adverse effects were defined as technical failure, including: technical procedure problems during the implantation, revision of the pulse generator pocket, lead dislocation, defective pulse lead, pulse generator failure, device removal, device re-implantation and pain resulting from pulse generator, lead or plug and electrical stimulation elsewhere.

\section{Statistical Analysis}

Changes were tested using a paired t-test and a McNemar test. The difference between cervical and lumbar SCS were tested using a two way ANOVA and Chi-square test. 
The changes/progress of pain using more than two points of time was analysed with a repeated measures ANOVA with the VAS at I/2, 1 and 2 years after the intervention. A probability value of less than 0.05 was considered statistically significant.

\section{RESULTS}

\section{Patients}

The study population consisted of 36 consecutive patients, who were classified according to the location of the SCS implantation, i.e. cervical or lumbar. As demonstrated in table 2 there were 19 patients with a cervical device and 17 patients with a lumbar. In the cervical group there were 8 male and 11 female patients with a mean age of 38 years and a mean VAS of 7 $\mathrm{cm}$. Four male and 13 female patients received a lumbar SCS. The mean age of these patients was 42 years and the mean VAS was $7.6 \mathrm{~cm}$.

Table 2. Patient characteristics.

\begin{tabular}{lcc}
\hline & Cervical & Lumbar \\
\hline Age $($ mean \pm SD. & $38.3 \pm 8.3$ & $41.9 \pm 11.9$ \\
Gender - no. $(\%)$ & $8(42.1)$ & $4(23.5)$ \\
Male & $11(57.9)$ & $13(76.5)$ \\
Female & $7.0 \pm 1.9$ & $7.6 \pm 1.4$ \\
Visual analogue score - cm $($ mean \pm SD.) & $0.3 \pm 0.3$ & $0.2 \pm 0.4$ \\
EQ-5D Social (Mean * SD.) & $48.1 \pm 21.7$ & $45.1 \pm 14.7$ \\
EQ-5D Personal - mm (Mean \pm SD.) & & \\
\hline
\end{tabular}

All patients, were treated with the SCS for at least 2 years. In 4 patients the SCS was removed after 1 year, which will be further discussed in section Complications. One patient in the cervical group refused further participation without explanation 1 year post-implantation.

\section{$V$ AS and EQ-5D}

The results of the VAS and EQ-5D are shown in table 3. At all follow-up periods the pain intensity was decreased compared with the baseline $(p<0.001)$; the VAS scores for individual patients are shown in table 4 . The pain intensity increased in time as demonstrated in figure 1. The repeated measures ANOVA showed a statistically significant, linear increase of the VAS ( $\mathrm{p}=0.03)$. We found no significant differences in outcome between cervical and lumbar SCS. At all follow up measurements at least $50 \%$ of the patients with cervical SCS 
and $40 \%$ of the patients with lumbar SCS reported a relative pain reduction of at least $50 \%$ as measured on the VAS. According to the GPE at least $42 \%$ of the cervical SCS and $47 \%$ of the lumbar SCS reported at least "much improvement" during measurements.

Table 3. Outcomes at follow up periods.

\begin{tabular}{|c|c|c|c|c|}
\hline & Baseline & $\begin{array}{l}0.5 \text { year } \\
\text { follow-up }\end{array}$ & $\begin{array}{c}1 \text { year } \\
\text { follow-up }\end{array}$ & $\begin{array}{l}2 \text { years } \\
\text { follow-up }\end{array}$ \\
\hline Cervical region & $N=19$ & $N=19$ & $N=19$ & $N=16$ \\
\hline Visual analogue score $-\mathrm{cm}$ (Mean $+\mathrm{SD}$.) & $7.0 \pm 1.9$ & $3.5 \pm 2.6$ & $3.7 \pm 2.9$ & $3.9 \pm 2.5$ \\
\hline Visual analogue score - no. $(\%)^{\prime}$ & - & $12(63.2)$ & $12(63.2)$ & $8(50.0)$ \\
\hline Global Perceived effect - no. $(\%)^{2}$ & - & $8(42.1)$ & $12(63.2)$ & $10(62.5)$ \\
\hline EQ-5D Social (Mean * sd) & $0.3 \pm 0.3$ & $=$ & $0.5 \pm 0.3$ & $0.5 \pm 0.2$ \\
\hline EQ-5D Personal - mm (Mean *s.d) & $48.1 \pm 21.7$ & - & $68.5 \pm 19.4$ & $54.4 \pm 22.9$ \\
\hline Lumbar region & $N=17$ & $N=17$ & $N=17$ & $N=15$ \\
\hline Visual analogue score - $\mathrm{cm}$ (Mean * s.d.) & $7.6 \pm 1.4$ & $3.8 \pm 1.0$ & $4.1 \pm 2.2$ & $4.2 \pm 2.5$ \\
\hline Visual analogue score - no. $(\%)^{\prime}$ & - & $11(64.7)$ & $10(58.8)$ & $6(40.0)$ \\
\hline Global Perceived effect - no. $(\%)^{2}$ & - & $8(47.1)$ & $8(47.1)$ & $8(53.3)$ \\
\hline EQ-5D Social (Mean * s.d.) & $0.2 \pm 0.4$ & - & $0.4 \pm 0.4$ & $0.4 \pm 0.3$ \\
\hline EQ-5D Personal - mm (Mean is.d.) & $45.1 \pm 14.7$ & & $66.9 \pm 16.0$ & $52.6 \pm 16.3$ \\
\hline
\end{tabular}

\footnotetext{
Tumber (\%) of patients. reporting a relative pain reduction of at least $50 \%$ as measured on the VAS.

${ }^{2}$ Number $(\%)$ of patients reporting at least "much improved" on global perceived effect.
} 
Table 4. VAS scores for individual patients at follow up periods.

\begin{tabular}{|c|c|c|c|c|c|c|}
\hline Patients & $\operatorname{Sex}^{1}$ & Age & Baseline & $\begin{array}{l}0.5 \text { year } \\
\text { follow-up }\end{array}$ & $\begin{array}{c}1 \text { year } \\
\text { follow-up }\end{array}$ & $\begin{array}{c}2 \text { year } \\
\text { follow-up }\end{array}$ \\
\hline
\end{tabular}

\section{Cervical region}

\begin{tabular}{|c|c|c|c|c|c|c|}
\hline 1 & F & 46 & 6.3 & 2.9 & 2.5 & 4.5 \\
\hline 2 & $F$ & 34 & 9.2 & 7.6 & 7.6 & 7.8 \\
\hline 3 & $\mathrm{M}$ & 35 & 8.5 & 4.4 & 3.3 & 3.2 \\
\hline 4 & $\mathbf{F}$ & 34 & 8.6 & 1.9 & 0.2 & 0.5 \\
\hline 5 & $F$ & 39 & 9.6 & 3.8 & 4.4 & 4.8 \\
\hline 6 & M & 55 & 8.3 & 7.4 & 8.0 & 7.9 \\
\hline 7 & $\mathbf{F}$ & 38 & 8.5 & 6.5 & 8.9 & 8.6 \\
\hline 8 & $\mathrm{M}$ & 33 & 8.5 & 8.9 & 9.8 & \\
\hline 9 & M & 47 & 6.1 & 5.8 & 6.2 & \\
\hline 10 & $\mathbf{F}$ & 49 & 4.4 & 0.0 & 0.0 & 0.4 \\
\hline 11 & $\mathrm{M}$ & 26 & 5.2 & 0.8 & 1.0 & 2.4 \\
\hline 12 & M & 53 & 4.8 & 2.2 & 3.0 & - \\
\hline 13 & $\mathbf{F}$ & 32 & 4.1 & 2.1 & 3.8 & 4.5 \\
\hline 14 & M & 40 & 8.4 & 2.9 & 3.7 & 2.1 \\
\hline 15 & $\mathbf{F}$ & 37 & 8.9 & 1.4 & 1.7 & 2.2 \\
\hline 16 & $\mathrm{~F}$ & 34 & 6.7 & 0.5 & 1.3 & 1.8 \\
\hline 17 & $\mathrm{~F}$ & 39 & 5.1 & 2. & 1.5 & 3.5 \\
\hline 18 & $M$ & 26 & 7.9 & 3.8 & 3.0 & 5,9 \\
\hline 19 & $\mathrm{~F}$ & 31 & 4.5 & 1.8 & 1.2 & 3.0 \\
\hline
\end{tabular}

Lumbar region

\begin{tabular}{|c|c|c|c|c|c|c|}
\hline 1 & $F$ & 33 & 7.0 & 3.0 & 3.2 & - \\
\hline 2 & $F$ & 28 & 9.7 & 5.4 & 4.3 & - \\
\hline 3 & $\mathrm{~F}$ & 57 & 7.3 & 6.0 & 4.8 & 4.4 \\
\hline 4 & F & 35 & 8.6 & 7.8 & 6.9 & 7.0 \\
\hline 5 & $M$ & 28 & 6.9 & 5.9 & 6.1 & 6.7 \\
\hline 6 & $F$ & 53 & 8.7 & 5.2 & 8.7 & 10 \\
\hline 7 & M & 44 & 9.1 & 4.2 & 4.2 & 3.9 \\
\hline 8 & $M$ & 36 & 7.9 & 3.8 & 6.7 & 5.9 \\
\hline 9 & F & 29 & 6.0 & 2.4 & 2.9 & 3.5 \\
\hline 10 & F & 59 & 5.9 & 1.1 & 2.8 & 3.6 \\
\hline 11 & F & 50 & 6.9 & 2.2 & 5.1 & 1.1 \\
\hline 12 & F & 28 & 8.9 & 6.6 & 4.9 & 4.5 \\
\hline 13 & $\mathrm{~F}$ & 42 & 6.8 & 0.7 & 1.3 & 4.0 \\
\hline 14 & $\mathbf{F}$ & 56 & 4.7 & 1.6 & 1.7 & 1.7 \\
\hline 15 & $F$ & 57 & 7.8 & 1.0 & 0.4 & 0.5 \\
\hline 16 & $F$ & 49 & 9.2 & 3.1 & 3.0 & 2.6 \\
\hline 17 & $\mathrm{M}$ & 28 & 8.2 & 4.1 & 3.1 & 3.0 \\
\hline
\end{tabular}

${ }^{\mathrm{T}} \mathrm{F}=$ female, $\mathrm{M}=\mathrm{male}$ 


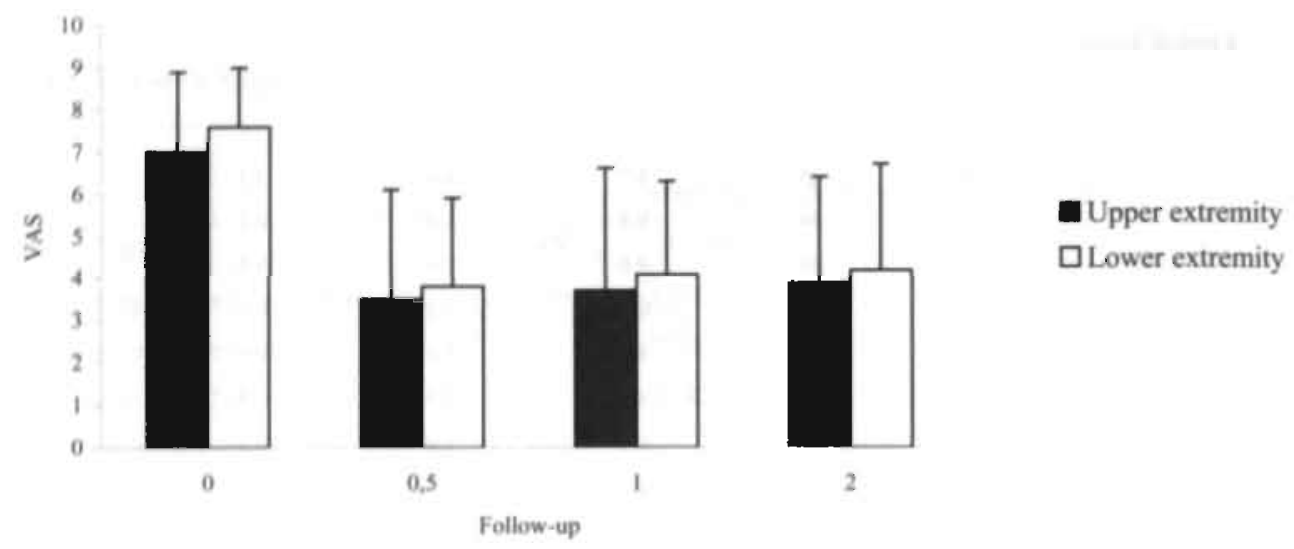

\section{Healih-related quality of life (HRQL)}

As demonstrated in table 3, HRQL of all patients prior to treatment was lower than any follow-up score $(\mathrm{P}<0.05)$. The personal $\mathrm{HRQL}$ score also demonstrated an increase for each follow-up period $(\mathrm{P}<0.02)$. We found this in all patients.

In figure 2 the un-weighted response to the EQ-5D is presented at baseline and at 2 follow-up periods. At the follow-up periods the number of patients reporting "extreme problems" for the categories "usual activities" and "pain and discomfort" decreased in both the cervical and the lumbar group $(P<0.01)$. In the dimension anxiety and depression $50 \%$ of the patients noted "no problems" at baseline, which increased in both groups at the follow-up periods ( $P<0.02$ ). The other EQ-5D dimensions did not change significantly. Differences between cervical and lumbar SCS were not significant. 
Figure 2. EQ-5D health dimensions; the bars represent scores before treatment and at one- and two year followup periods.

a. CRPS I in the upper extremity.

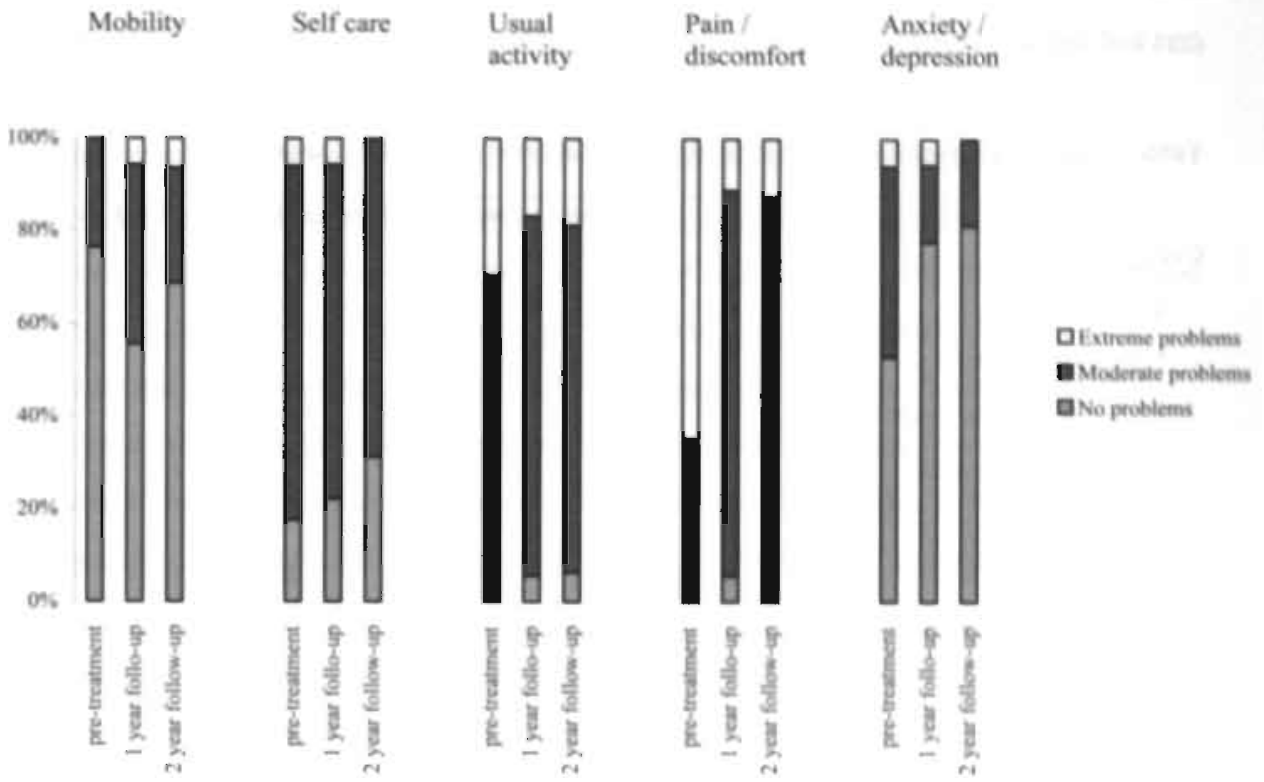

b. CRPS I in the lower extremity.

Mobility

Self care

Usual

activity
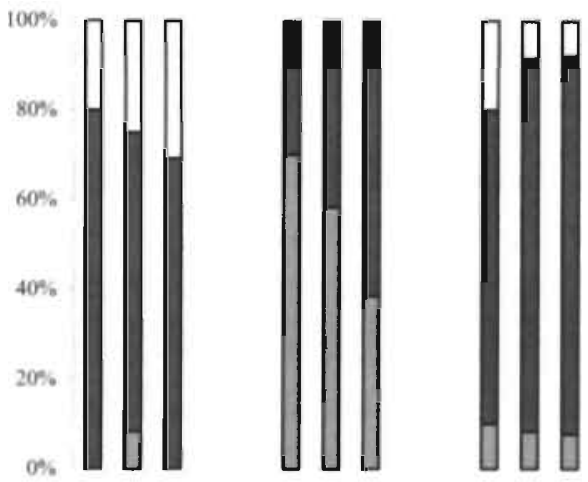

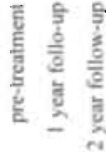

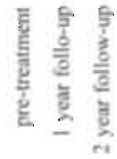

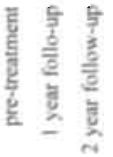
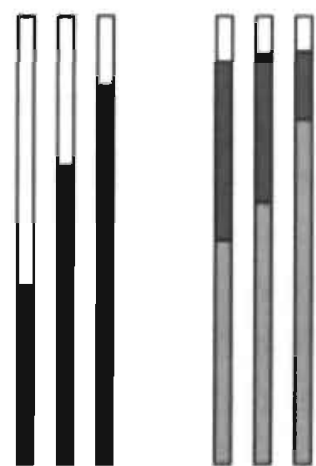

DExtreme problems Doderate probiems

En No problems

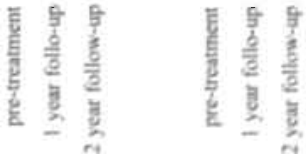

Anxiety /

depression 


\section{Complications}

Table 5 presents the complications and adverse effects during and after implantation of the SCS device. A total of 23 patients ( 10 patients with a lumbar device and 13 patients with a cervical device) developed complications or adverse effects.

Table 5. Complications and adverse effects of SCS implantation in 36 CRPS I patients.

\begin{tabular}{|c|c|c|c|}
\hline & Lower extremity & Upper extremity & Total \\
\hline \multicolumn{4}{|l|}{ Complications } \\
\hline Spinal tap & 3 & & 3 \\
\hline Post spinal headache & 1 & & 1 \\
\hline Technical procedure problems & & 1 & 1 \\
\hline Infection (suspicion of) & & 1 & 1 \\
\hline \multicolumn{4}{|l|}{ Adverse effects } \\
\hline Revision pulse-generator pocket & 4 & 3 & 7 \\
\hline Dislocation of lead & 1 & 5 & 6 \\
\hline Defective pulse Îcad & 2 & 2 & 4 \\
\hline Technical failure pulse- generator & 1 & 1 & 2 \\
\hline Stimulation elsewhere & 1 & 2 & 3 \\
\hline Removal SCS-system & 2 & 2 & 4 \\
\hline Re-implantation SCS-system & & 1 & 1 \\
\hline Pain resulting from pulsegenerator/lead/plug & & 3 & 3 \\
\hline
\end{tabular}

We encountered complications related to implantation of the temporary system as well as the permanent system in 6 patients. Three of these patients also had adverse effects, which will be discussed later. In 3 patients a spinal tap with a lumbar SCS complicated implantation of the temporary lead. One patient suffered a post-spinal headache, and a blood-patch was required. In one patient with CRPS I of the upper extremity it was not possible to localize the epidural space at the usual level. Therefore the implantation of the extended lead had to be performed at a lower thoracic level.

Thirty-one adverse effects were noted in 20 patients. Because of a rotation of the pulse-generator and subsequent painful sensations, revision of the pulse-generator pocket was performed in 5 patients. Substantial weight loss resulted in pocket revision in two other cases. 
Inadequate paresthesiae or paresthesiae in other locations required repositioning of the lead in I patient with CRPS I in the lower extremity and in 5 patients with affected upper extremity. In two cases no satisfactory re-positioning was obtained. Lead failure resulted in replacement in 4 patients. Because of technical failure, replacement of the pulse-generator was needed in 2 cases.

The complete SCS system was removed in 2 patients with a cervical SCS and 2 patients with a lumbar SCS, which resulted in stopping the treatment. Dislocation of the cervical lead occurred more frequently, but this was not significant as compared to the lumbar group ( $\mathrm{p}=0.17$ ). In one patient the complete permanent system was removed because of suspicion of infection. However, bacteriological cultures were negative, Reimplantation resulted in the same complains as the first implant, which could indicate a reaction to the constituents of the implant. The reimplant was also removed. One patient suffered from secondary ulcerative colitis (UC). A relationship between the SCS system and UC disease activity was suggested, which resulted in the removal of the lead system ${ }^{13}$. In one case the system was removed because of increased pain during stimulation, and in one other because of the inability to obtain effective stimulation.

\section{DISCUSSION}

Complex Regional Pain Syndrome is a pain syndrome of unclear pathophysiology and typically affects the hand and arm or foot and leg. The diagnosis of CRPS is a clinical diagnosis and based on absolute and relative criteria (IASP 1994). Pain and impaired function are mandatory for the diagnosis. Therefore the goal of treatment in patients with CRPS is to relieve pain and improve function. Recent reviews have shown ${ }^{5,21,22}$ that the number of effective therapies in the treatment of CRPS are limited.

Spinal cord stimulation have been suggested as a therapy for pain relief when other treatment modalities have failed ${ }^{23}$. The exact physiological mechanism of pain relief by SCS in patients with CRPS is poorly understood. It has been suggested that SCS works through a spectrum of neurophysiological mechanisms ${ }^{24}$. Studies in nerve-lesioned rats showed that SCS results in an increased release of GABA in the dorsal horn resulting in a decrease of excitatory amino acid glutamate and aspartate ${ }^{25}$.

The clinical effects of SCS in CRPS have been established in a limited number of uncontrolled studies. ${ }^{12,26}$. We recently documented the clinical short-term effects in a 
randomised controlled study ${ }^{14}$. Little is known about the long-term effect and complications of SCS.

In $44-61 \%$ of patients the CRPS is located in the upper extremity 27,28 . That means that in the majority of patients, treatment with SCS cervical lead placement is indicated. It is widely held that SCS should be used with caution in the cervical region. In the cervical region the posterior epidural space is the smallest and may prevent adequate lead placement. The mobility of the cervical spine and the local anatomy should restrict effectiveness and may lead to more and worse complications. This present study addresses these two issues.

Contrary to the prevailing view, we found that the SCS device was slightly more effective in patients with a cervical implantation than lumbar implantation although this difference is not significant. All patients reported a significant reduction of pain relief of at least $50 \%$ after 6 months after implantation.

After one year and two years follow-up there is a slight but significant increase of pain in both groups indicating that the effect is declining. The reduction of the VAS after two years of 3.1 point in the cervical group and 3.4 point in the lumbar group are considered to be clinical relevant ${ }^{22}$. Decrease of pain was also reflected in health status. Health status of the patients measured on the EO-5D increased after SCS (figure 2). This increase was the same in both groups and mainly duc to decrease of pain, discomfort, anxiety and depression. Complications of the procedure (i.e.: spinal taps, post-spinal headache, no access to the epidural space and infection) were seen in 6 of the 36 patients. Spinal taps only happened in the first 10 patients; thereafter we changed the technique for identifying the epidural space from "loss of resistance" to fully fluoroscopic control. Adverse effects (i.e.: technical failures) were seen in both the cervical and the lumbar group. Dislocation of the lead happened somewhat more frequently in the cervical group, but this difference was not significant.

In conclusion, SCS is effective in patients with chronic CRPS 1, even after 2 years of treatment. In our study there were no significant differences in outcome on pain and quality of live between cervical and lumbar implantation of the lead. Cervical implantation was not associated with a higher complication rate.

\section{CONCLUSION}

SCS is effective in patients with chronic CRPS 1, even after 2 years of treatment. In our study there were no significant differences in outcome on pain and quality of life between cervical 
and lumbar implantation of the lead. Cervical implantation was not associated with a higher complication rate. 


\section{References}

1. Veldman PH, Reynen HM, Amtz IE, Goris RJ. Signs and symptoms of reflex sympathetic dystrophy: prospective study of 829 patients. Lancet 1993;342:1012-6.

2. Schurmann M, Gradl G, Andress HJ, Furst H, Schildberg FW. Assessment of peripheral sympathetic nervous function for diagnosing early post-traumatic complex regional pain syndrome type 1. Pain 1999;80:149-59.

3. Ochoa J. Pain mechanisms in neuropathy. Curr Opin Neurol 1994;7:407-14.

4. Ochoa JL. Essence, investigation, and management of \&quot;neuropathic\&equot; pains: hopes from acknowledgment of chaos. Muscle Nerve 1993;16:997-1008.

5. Kingery W. A critical review of controlled clinical trials for peripheral neuropathic pain and complex regional pain syndromes. Pain 1997;73:123-39.

6. Jadad A, Carroll D, Glynn C, al e. Intravenous regional sympathetic blockade for pain relief in reflex sympathetic dystrophy: a systematic review and a randomized, double-blind crossover study. Pain Symptom Manage 1995:10:13-20.

7. Broggi G, Servello D. Dones I. Carbone G. Italian multicentric study on pain treatment with epidural spinal cord stimulation. Stereotact Funct Neurosurg 1994;62:273-8.

8. Meglio M. Cioni B. Rossi GF. Spinal cord stimulation in management of chronic pain. A 9-year experience. $J$ Neurosurg 1989;70:519-24

9. North RB, Kidd DH, Zahurak M, James CS, Long DM. Spinal cord stimulation for chronic, intractable pain: experience over two decades. Neurosurgery 1993;32:384-94.

10. Barolat G, Schwartzman R, Woo R. Epidural spinal cord stimulation in the management of reflex sympathetic dystrophy. Stereotact Funct Neurosurg 1989;53:29-39.

11. Robaina FJ, Dominguez M, Diaz M, Rodriguez JL, de Vera JA. Spinal cord stimulation for relief of chronic pain in vasospastic disorders of the upper limbs. Neurosurgery 1989;24:63-7.

12. Kumar K, Nath RK, Toth C. Spinal cord stimulation is effective in the management of reflex sympathetic dystrophy. Neurosurgery 1997:40:503-8.

13. Kemler MA, Barendse GA, Van Kleef M. Relapsing ulcerative colitis associated with spinai cord stimulation. Gastroenterology 1999;117:215-7.

14. Kemler MA, Barendse GA, van Kleef M et al. Spinal cord stimulation in patients with chronic reflex sympathetic dystrophy. $N$ Engl J Med 2000;343:618-24.

15. Merskey K, Bogduck N. Classification of chronic pain: descriptions of chronic pain syndromes and definitions of pain term 2nd edition. In: Press WI, ed. Seattle, 1994.

16. Jensen M, Karoly P, Braver S. The measurement of elinical pain intensity: a comparison of six methods. Pain $1986 ; 27: 117-26$.

17. Jamison R, Bron G. Validation of hourly pain intensity profiles with chronic pain patients. Pain $1991: 45: 123-8$.

18. Jensen M, MeFarland C. Increasing the reliability and validity of pain intensity measurement in chronic pain patients. Pain 1993:55:195-203.

19. Group T. Euroqol - a new facility for the measurement of health-related quality of life. Helath Policy 1990;16:199-208. 
20. Kind P, Dolan P, Gudex C, Williams A. Variations in population health status: results from a United Kingdom national questionnaire survey, Bmj 1998;316:736-41.

21. Perez RS, Burm PE, Zuurmond WW et al, Interrater reliability of diagnosing complex regional pain syndrome type I. Acta-Anaesthesiol-Scand 2002;46:447-50.

22. Forouranfar T, Koke AJ, van Kleef M, Weber WE. Treatment of complex regional pain syndrome type I. Eur. J. Pain 2002;6:105-22.

23. Stanton Hicks M. An updated interdisciplinary elinical pathway for CRPS: report of an expert panel. Pain Practice 2002:2:1-16.

24. Meyerson BA, Linderoth B. Mechanisms of spinal cord stimulation in neuropathic pain. Newrol Res 2000;22:285-92.

25. Stiller CO, Cui JG, O'Connor WT, Brodin E, Meyerson BA, Linderoth B. Release of gamma-aminobutyric acid in the dorsal hom and suppression of tactile allodynia by spinal cord stimulation in mononeuropathic rats. Neurosurgery 1996;39:367-74.

26. Oakley JC, Weiner RL. Spinal cord stimulation for compoex regional pain symdrome: a prospective study of 19 patients at two centers. Neuromodulation 1999;2:74-50.

27. Harden RN, Bruehl S, Galer BS et al. Complex regional pain syndrome: are the IASP diagnostic criteria valid and sufficiently comprehensive? Pain 1999;83:211-9.

28. Allen G, Galer BS, Schwartz L. Epidemiology of complex regional pain syndrome: a retrospective chart review of 134 patients. Pain 1999;80:539-44. 
- 108 - 


\section{GENERAL DISCUSSION}

\section{AND CONCLUSIONS}




\section{GENERAL DISCUSSION}

Complex regional pain syndrome (CRPS) Type I and II are neuropathic pain syndromes accompanied with sudomotor and vasomotor disturbances. CRPS I, which corresponds to the common image of Reflex Sympathetic Dystrophy (RSD) is defined as a painful, disabling syndrome ${ }^{1}$. The Consensus Conference of the International Association for Study of Pain (IASP) defined CRPS I as a post-traumatic syndrome that presents with spontaneous pain that is not related to the territory of a single nerve and is disproportionate to the inciting event ${ }^{1,2}$. The diagnostic criteria include: (a) pain, allodynia, or hyperalgesia; (b) evidence at some time of edema, vasomotor and sudomotor change in the pain region; and (c) no other conditions that would otherwise account for the degree of pain and dysfunction. CRPS is differentiated from other neuropathic pain syndromes by the existence of edema, vasomotor and sudomotor disturbances.

Currently practiced treatments of CRPS I include radical scavengers ${ }^{3}$, regional intravenous sympathetic blocks ${ }^{4}$ and neuromodulation 5 . Kingery et al ${ }^{6}$ reviewed existing trials for CRPS management in 1997 and demonstrated that there is limited support for the effectiveness of topical DMSO (dimethylsulfoxyde), epidural clonidine, intravenous regional blocks and intranasal calcitonine. Jadad et $\mathrm{al}^{4}$ showed that there is no evidence for the efficacy of regional intravenous sympathetic blockade (RIS). Controversy exists about the effectiveness of therapeutic interventions for the management of CRPS I. In order to ascertain appropriate therapies we conducted a review of existing randomised controlled trials of therapies for this disabling disease.

We identified 27 randomised trials, of which 18 were placebo controlled. The heterogeneity of the studies and the small sample sizes precluded the drawing of firm conclusions about the efficacy or effectiveness of any of the interventions studied on CRPS I patients. On basis of our review we conclude that there is limited to no evidence for efficacy of sympathetic blocks (Stellate ganglion block or RIS block), radical scavenging, prednisolone administration, acupuncture and manual lymph drainage. Calcium regulating drugs and Qigong exercises seem to be promising treatment modalities. However, further high quality studies are required before the place of these treatments in pain therapy can be established. The search for eligible trials about prevention resulted in 2 high quality randomised placebo controlled studies in which vitamin $\mathrm{C}$ and intravenous guanethidine were investigated on CRPS I patients 7.8 . Vitamin C prevented CRPS I while guanethidine did not prevent the development of CRPS I. Both studies had small sample sizes and no other 
randomised placebo controlled studies were identified. Therefore there is limited evidence whether any interventions can significantly prevent CRPS I.

The review showed not only limited evidence for the currently used treatment and prevention modalities of CRPS I but it also demonstrated several main problems in CRPS I studies, which will be discussed below.

\section{Clinically relevant pain reduction}

In the CRPS I literature most clinical studies use pain ratings as the primary outcome measure. Mostly, in these studies a significant pain reduction after treatment is defined as successful $4,9-12$. Some authors define a pain reduction of 30 to $50 \%$ as successful ${ }^{13-15}$. However, a clinically relevant pain reduction in patients with CRPS I is still not defined.

In our study we found that in both "successfull" and "non successful" patients according the Global Perceived Effect, the pain was reduced significantly. However, the CRPS I patients defined a relative pain reduction of $58 \%$ or more on a VAS as "successful". Furthermore, a relative pain reduction of $50 \%$ and more as cut-off point proved to be the most accurate point with the best sensitivity and specificity. For absolute pain reduction, $3 \mathrm{~cm}$ on VAS could be defined as an accurate cut-off point

\section{Single pain rating vs. multiple pain rating}

In clinical studies with patients suffering from CRPS I, pain is usually assessed by a single pain rating. This rating is consequently used as the primary outcome measure, assuming that it is equivalent to multiple pain ratings. However to our knowledge this assumption had never been investigated in CRPS ! patients.

We compared the validity of the single pain ratings in patients with CRPS I with multiple pain rating test and demonstrated that a single pain rating ("recalled average" pain) correlates well with multiple pain ratings ("actual average" pain) in a group of patients suffering from CRPS I. There was a high degree of agreement between both methods. Furthermore, both ratings measure significant pain reduction after treatment, however "recalled average" pain reflects greater change in pain intensity.

\section{Bio-electrical Impedance Assessment (MFBIA) as an objective measure}

The diagnoses and evaluation of CRPS I is based solely on subjective clinical symptoms including burning pain, sensory abnormalities, diminished strength, hyperhidrosis, hypertrichosis, skin colouring changes and atrophy of the involved tissue (skin, muscle, bone) 


\section{6, 17. There is a clinical need for an objective measure of the severity of the patient's}

condition. In order to develop an objective measure for CRPS I we performed a pilot study on the use of Bio-electrical Impedance Assessment in patients with CRPS I.

MFBIA, a non-invasive electrical assessment, is accepted for measuring body cell mass and has been shown to be valid in measuring the intra and extra cellular fluid volume in each body segment ${ }^{18-20}$.

Our data demonstrate that the impedance spectrum of the affected limbs in CRPS I patients is altered compared to the contra lateral side and to limbs in a control group. The phase angle, which is defined as the relation between the resistance (ability of an medium to conduct an alternating electrical current) and the reactance (resistive effect due to capacitance produced by tissue interface and cell membrane) was significantly less in the affected limbs than in normal limbs and this could indicate significant change in intra- and extra cellular fluid ratios. In addition, the MFBIA measured a significant increase of the MFBIA frequency $\left(\omega_{0}\right)$ at which the reactance and the phase angle are maximal in the affected limbs of CRPS I patients compared with the contralateral limb and the control group and the resistance $(R)$ was also increased in affected limbs. The decrease of the phase angle was mainly caused by the increase in resistance $(R)$, which is defined as the ability of a medium to conduct electrical current and not due to changes in the resistive effect produced by tissue interface and cell membrane (reactance). The entities $\omega_{0}$ and phase angle of the MFBIA proved to be moderate sensitive and specific for CRPS I in the lower limbs compared with either the left or the right limbs of the control group.

\section{The use of Stellate Ganglion Block(SGB) and Spinal Cord Stimulation(SCS) in CRPS I}

Stellate Ganglion Block(SGB) ${ }^{21}$ and Spinal Cord Stimulation(SCS) ${ }^{5,22,} 23$ are currently used treatment modalities in the treatment of CRPS I. However, information on the effectiveness of SGB and the long term effect SCS, is scarce.

We investigated retrospectively the use of SGB and prospectively the long term effect of SCS in patients suffering from CRPS 1. The retrospective study of 226 chronic pain patients treated with RF lesions of the SG demonstrated that $40 \%$ of pre-selected patients reported a reduction of pain of more than $50 \%$ for an average duration of 52 weeks. Patients with a positive prognostic blockade were selected for RF lesions. The efficacy of the RF SG blockade in the total (unselected) population of 226 patients was $15,5 \%$.

The clinical effectiveness of RF SG blockade may be improved at following two levels. Precise anatomic localisation of the SG may lead to increased clinical effect. This 
could be achieved by ultrasound 24 , magnetic resonance imaging 25 and computed tomography 26 . The results show that the therapeutic effects of an RF SG block vary per diagnostic subgroup. When using a cut-off value of $50 \%$ of patients reporting more than $50 \%$ pain relief per diagnostic subgroup, only CRPS2, ischemic pain, cervico-brachialgia and postthoracotomy pain, appears to respond to an RF SG block, which is in line with work by Wilkinson et al, using radiofrequency to target upper thoracic sympathetic ganglia26.28, The prospective study on the effect of SCS demonstrated that all patients initially reported a significant reduction of pain intensity and a relative pain reduction of at least $50 \%$, during all follow-up periods pain reduction declined in all patients, $42 \%$ of the patients reported at least "much improvement" over the two-year follow-up. Health status of the patients measured on the EQ-5D increased after receiving the SCS device. This increase was mainly caused by the decrease of pain and discomfort, and anxiety and depression. There were no differences between patients with a cervical or lumbar SCS.

\section{CONCLUSIONS}

There is limited evidence to support the effectiveness of commonly used interventions for treating or preventing RSD or CRPS I. More prospective controlled trials are needed in this field.

In CRPS I patients a significant pain reduction after treatment using a VAS does not necessarily imply that the patient defines the treatment as successful. A relative pain reduction of $50 \%$ or more and an absolute pain reduction of at least $3 \mathrm{~cm}$ on. VAS are accurate in predicting a successful pain reduction after a given treatment. Furthermore as in back pain patients, a single rating of pain "on average" ("recalled average" pain) is an accurate predictor of the actual "average pain" in patients suffering of CRPS I. Both pain ratings proved also to be accurate enough to determine reliable changes in pain over time.

MFBlA measurement is a promising assessment for measuring tissue properties in effected limbs of CRPS I patients when compared with the contra-lateral side and compared to limbs in a control group. The relation of the impedance to these properties is indirect and has not been completely defined. The MFBIA measures the tissue resistivity, which is affected by relative volumes and electrolytic balances between the intra- and extra cellular fluids and these factors vary among individuals. 
Although the efficacy of an RF SG blockade appears to be in line with other SG blockade procedures reported in the literature, its clinical effects remain to be proven in a randomised controlled trial. Given the potential of harmful complications, it would even be questionable if it is ethical to continue the routine clinical use of RF SG blocks without supportive data from such a trial.

SCS seems to be effective in treating chronic therapeutic resistant CRPS I. The presented results demonstrate that SCS reduces the pain intensity in the majority of patients suffering of CRPS I. Despite the substantial complications and adverse effects, the heath state increased. This was mainly due to decrease in the level of pain, discomfort, anxiety and depression. There were no significant differences between cervical and lumbar SCS. 


\section{References}

1. Menkey KR, Bogduck N. Classification of Chronic Pain: Descriptions of Chronic Pain Syndromes and Difinitions of Pain Term. Seattle, WA: IASP Press, 1994.

2. Schurmann M, Gradl G, Andress HJ, Furst H, Schildberg FW. Assessment of peripheral sympathetic nervous function for diagnosing early post-traumatic complex regional pain syndrome type I. Pain 1999; 80:149-59.

3. Zuurmond WW, Langendijk PN, Bezemer PD, Brink HE, de Lange J, van loenen AC. Treatment of acute refles sympathetic dystrophy with DMSO 500 in a fatty cream. Acta Anocxtheriol Scand 1996; 40-364-7.

4. Jadad AR, Carroll D, Glyne CJ, McQuay HJ. Intravenous regional sympathetic blockade for pain relief in reflex sympathetic dystrophy: a systematic review and a randomized, double-blind crossover study, J Pain Symptom Mancove 1995; 10:13-20.

5. Kemler MA, Barendse GA, van Kleef M, et al. Spinal cord stimulation in patients with chronie reflex sympathetic dystrophy, N Engl J Mhd 2000; 343:618-24.

6. Kingery WS. A critical review of controlled clinical trials for peripheral neuropathic pain and complex regional pain syndromes [see comments]. Pain 1997: 73:123-39.

7. Gschwind C, Fricker R, Lacher G, Jung M. Does peri-operative guanethidine prevent reflex sympathetic dystrophy? J Hand Surg $[\mathrm{Br}]$ 1995; 20:773-5.

8. Zollinger PE, Tuinebreijer WE, Kreis RW, Breederveld RS. Effect of vitamin C on frequency of reflex sympathetic dystrophy in wrist fractures; a randomised trial. Lancet 1999; 354:2025-8.

9. Hanna MH, Peat SJ. Ketanserin in reflex sympathetic dystrophy. A double-blind placebo controlled cross-over trial. Pain 1989; 38:145-50.

10. Kho HK. The impect of acupuncture on pain in patients with reflex sympathetic dystrophy. Pain Clin 1995; 8:59-61.

11. Kettler RE, Abram SE. Intravenous regional droperidol in the management of reflex sympathetic dystrophy: a doubleblind, placebo-controlled, crossover study, Anesthesiology 1988; 69:933-6.

12. Korpan MI, Dezu Y, Schneider B, Leitha T, Fialka-Moser V. Acupuncture in the treatment of posttraumatic pain syndrome. Acta Orthop Belg 1999; 65:197-201.

13. Blanchard J, Ramamurthy S, Waish N, Hoffman J, Schoenfeld L Intravenous regional sympatholysis: a double-blind comparison of guanethidine, reserpine, and normal saline. J Pain Symptom Manage 1990; 5:357-61.

14. Price DD, Long S, Wilsey B, Rafii A. Analysis of peak magnitude and duration of analgesia produced by local anesthetics injected into sympathetic ganglia of complex regional pain syndrome patients. Clin J Pain 1998; 14:216-226.

15. Verdugo RJ, Ochoa JL. 'Sympathetically maintained pain.' I. Phentolamine block questions the concept [see comments]. Neurology 1994; 44:1003- I0.

16. Bruchl $\mathrm{S}_{6}$, Harden RN, Galer BS, et al. External validation of IASP diagnostic criteria for Complex Regional Pain Syndrome and proposed research diagnostic criteria. International Association for the Study of Pain. Pain 1999; 81:147. 54.

17. Harden RN, Bruehl S, Galer BS, et al. Complex regionat pain syndrome: are the IASP diagnostic criteria valid and sufficiently comprehensive? Pain 1999; 83:211-9.

18. Van Kreel BK, Cox-Reyven N. Soeters P. Determination of total body water by multifrequency bio-electric impedance: development of several models. Med. Biol. Eng. Compur. 1998; 36:337-345.

19. Sasser DC, Gerth WA, Wu YC. Monitoring of segmental intra- and extracellular volume changes using electrical impedance spectroscopy. J Appl Physiol. 1993; 74:2180-7.

20. Baumgartner RN, Chumlea WC, Roche AF. Estimation of body composition from bioclectric impedance of body segments. Am J Clin Nutr 1989; 50:221-6.

21. Bonelli S, Conoscente F, Movilia PG, Restelli L, Francucci B, Grossi E. Regional intravenous guanethidine vs. stellate ganglion block in reflex sympathetic dystrophies: a randomized trial Pain 1983; 16:297-307. 
22. Kemler MA, Barendse GA, Van Kleef M, Van Den Wildenberg FA, Weber WE. Electrical spinal cord stimulation in reflex sympathetic dystrophy: retrospective analysis of 23 patients. $J$ Neuranurg 1999; 90:79-83.

23. Stanton-Hicks M, Salamon J. Stimulation of the central and peripheral nervous system for the control of pain. J Clin Neurophysiol 1997; 14:46-62.

24. Kapral S, Kraft P, Gosch M, Fleischmann D, Weinstabl C. Ultrasound imaging for Stellate Ganglion block: direct visualization of puncture site and local anesthetic spread. Reg Anesth 1995; 20(4):323-328.

25. Slappendel R, Thijsen HOM, Crul BJP, Merx JL. The Stellate Ganglion in Magnetic Resonance Imaging: A Quantification of the Anathomic Variability. anesthesiology 1995; 83:424-426.

26. Erickson SJ, Hogan QH. CT-guided Injection of the Stellate Ganglion: Description of Technique and Efficacy of Sympathetic Blockade. Radiology 1993; 188:707-709.

27. Wilkinson HA. Radiofrequency percutaneous upper-thoracic sympathectomy. Technique and review of indications. $N$ Engl J Med 1984; 311:34-6.

28. Wilkinson HA. Percutaneous radiofrequency upper thonacic sympathectomy. Neurosurgery 1996; 38:715-25. 
SUMMARY 
In chapter $\mathbf{2}$ we conducted a review of existing randomised controlled trials of therapies for CRPS I. Eligible trials were identified from the Cochrane, Pubmed, Embase and MEDLINE databases from 1966 through June 2000, from references in retrieved reports and from references in review articles. Twenty-six studies concerning treatment modalities were identified. Eighteen studies were randomised placebo-controlled trials and eight studies were randomised active- controlled trials. Three independent investigators reviewed articles for inclusion criteria using a 15-item check list. Seventeen of the trials were of high quality according to the 15-item criteria. There was limited evidence for the effectiveness of these interventions because of the heterogeneity of treatment modalities. The search for trials concerning prevention of RSD/CRPS I resulted in 2 eligible studies. Both were of high quality and dealt with two different interventions. There is limited evidence for their preventive effect.

The aim of the study presented in chapter 3 was to investigate the degree of pain reduction in patients with CRPS I that can be defined as "successful". Sixty-one CRPS I patients rated their pain on a Visual Analogue Scale (VAS, 0-10) before treatment and on three occasions after treatment at 6 months, 1 year and 2 years. Patients also rated a Global Perceived Effect (GPE) for their pain relief at the same time periods. The GPE items were classified as "successful" or "unsuccessfull". The mean absolute and relative pain reduction (VAS) was calculated for both "successful" and "unsuccessful" GPE classifications for each time period. Sensitivity and specificity analyses were performed. The patients defined a relative pain reduction of $58 \%$ (s.d.: 23.4 ) or more as "successful", whereas in both "successful" and "unsuccessful" patients the pain was reduced significantly on the VAS. Furthermore, sensitivity and specificity analyses demonstrated that a cut-off point of $50 \%$ relative pain reduction and a $3 \mathrm{~cm}$ absolute pain reduction on VAS have the highest likelihood that patients report "successful" on the GPE. We conclude that a relative pain reduction of $50 \%$ or more and an absolute pain reduction of at least $3 \mathrm{~cm}$ on VAS are accurate in predicting a successful pain reduction after a given treatment.

Chapter 4 describes comparison of multiple and single pain ratings in patients with CRPS 1 . Correlation, agreement and reliability analyses were performed between the average pain intensity measured 3 times a day over a course of 4 days and one single pain rating 
(designated as "recalled average" pain by the patient) before treatment and 1-, 3- and 6 months after treatment. The patient population consisted of 54 patients suffering from CRPS I in a randomized trial. The results show that both measurements correlate and agree excellently . Furthermore, both ratings measure significant pain reduction after treatment. However "recalled average" pain reflects greater change in pain intensity. In patients with CRPS I a single pain rating is an accurate predictor of the average pain measured by a multiple pain rating test. Moreover, both assessments are accurate enough to determine changes in pain over time with an effective treatment.

In chapter 5 we evaluated the value of Multi-Frequency Bioelectrical Impedance Analysis (MFBIA) in patients suffering from Complex Regional Pain Syndrome Type I (CRPSI). We hypothesised that, patients with CRPS I have altered tissue properties in the affected limbs compared with the non-affected limbs and with limbs from unaffected individuals (control limbs). 28 patients suffering from CRPS I and in 18 healthy right-handed participated in the study. Receiver operating characteristic (ROC) analyses and areas under the curve (AUC) were performed to analyse the sensitivity and specificity of the MFBIA to detect CRPS I. Our data showed the phase angle $(\Phi)$, which is defined as the relation between the resistance (ability of an medium to conduct an alternating electrical current) and the reactance (resistive effect due to capacitance produced by tissue interface and cell membrane) was decreased in the CRPS I limbs compared with both the contralateral side $(p=0.004)$ and limbs $(p=0.02)$ from unaffected individuals. The MFBIA frequency $\left(\omega_{0}\right)$ at which the reactance and the phase angle are maximal was increased in CRPS I limbs compared with both the contralateral side $(p=0.02)$ and the control limbs $(p=0.01)$. The sensitivity and specificity of $\omega_{0}$ for detecting CRPS I in the lower limb were 0.91 and 0.85 compared with lower limbs in unaffected individuals. In the upper limb, however, sensitivity and specificity were best when the right hand in unaffected individuals was used as the control. The sensitivity and specificity of $\omega_{0} 0.75$ and 0.82 compared with right arm controls. The $\Phi$ values were 0.82 and 0.70 compared with the right arm controls. In conclusion the tissue properties are changed in the affected limb according the MFBIA.

In chapter 6 we evaluated the outcome of RF-SG as a therapy for CRPS I and other chronic pain syndromes. We reviewed 86 RF stellate ganglion procedures. Medical records containing treatment information were reviewed systematically. In our clinic, $39,5 \%$ of 221 patients who received a prognostic SG block subsequently underwent RF-SG. Of these 
patients $40,7 \%$ noted more then $50 \%$ reduction of pain, $54,7 \%$ had no effect on pain and $4,7 \%$ showed worsening of pain. Mean follow-up was 52 weeks. A systematic literature review search in MEDLINE on SG blockades was also performed. The computer assisted literature search resulted in thirty-one studies, twelve about complications and nineteen about the efficacy of stellate ganglia block. The analysis of these studies showed a partial pain relief in $41,3 \%$ of patients, complete pain relief in $37,8 \%$ and no pain relief in $20,9 \%$. The efficacy of the RF-SG blockade appears to be in line with other SG block procedures reported in the literature. Our retrospective study shows that a RF-SG block is most likely to be of benefit for patients suffering from CRPS2, ischemic pain, cervico-brachialgia, or post-thoracotomy pain. However, clinical efficacy remains to be proven in a randomised controlled trial.

The long term effect of cervical and lumbar Spinal Cord Stimulation (SCS) in patients with CRPS I is presented in chapter 7. Thirty-six patients with a definitive implant were included in this study. A pain diary was obtained in all patients prior to treatment, 6 month, 1- and 2 year post treatment. Further, all patients were asked to complete a 7-point Global Perceived Effect (GPE) scale and the Euroqol-5D (EQ-5D) at each post - treatment assessment period. The pain intensity was reduced 6 month, 1 - and 2 year post treatment (p $<0.05$ ). However, the repeated measures ANOVA showed a statistically significant, linear increase of the VAS ( $\mathrm{p}=0.03$ ) over this period. According to the GPE at least $42 \%$ of the cervical SCS patients and $47 \%$ of the lumbar SCS patients reported at least "much improvement" during measurements. Furthermore, the health state of the patients measured on the EQ-5D was increased after treatment $(\mathrm{P}<0.05)$. This increase was noted both from a social as from a patient's perspective. Complications and adverse effects occurred in $64 \%$ of the patients and consisted mainly of technical defects. There were no differences between cervical and lumbar groups with regard to outcome measures. In conclusion SCS reduces the pain intensity in the majority of the CRPS I patients and increases the health state but produces a high incidence of substantial complications and adverse effects. 
SAMENVATTING 
In hoofdstuk 2 tonen we een review van de bestaande gerandomiseerde gecontroleerde trials over therapieèn bij CRPS L. Bruikbare trials werden geïdentificeerd aan de hand van Cochrane, Pubmed, Embase en MEDLINE databestanden. Daarnaast, werden verwijzingen naar referenties van relevante artikelen gebruikt. Dit resulteerde in 26 artikelen betreffende behandeltechnieken. Achttien van deze studies waren gerandomiseerde placebogecontroleerde studies terwijl acht studies actiefgecontroleerde studies waren. Drie onafhankelijke onderzoekers hebben deze studies op hun kwaliteit beoordeeld. Hiervoor werd gebruik gemaakt van een vragenlijst bestaande uit 15 onderwerpen. Volgens de beoordeling is er weinig bewijs voor de effectiviteit van de bestaande behandeltechnieken. In onze studies hebben wij eveneens studies beoordeeld, welke preventieve technieken gebruikt hebben om zodoende CRPS I te voorkomen. Van twee van deze studies werd de kwaliteit beoordeeld. Beide studies waren van hoge kwaliteit echter over verschillende interventies. Derhalve, is er weinig bewijs voor hun effectiviteit.

De studie gepresentẹcrd in hoofdstuk $\mathbf{3}$ werd uitgevoerd om een pijnreductie te definiëren welke door CRPS I patiënten als succesvol beschouwd wordt. Hiervoor, hebben 61 CRPS I patiènten op een VAS schaal hun pijn aangeduid vóór een behandeling en 6 maanden, 1 jaar en 2 jaar na de behandeling. Daarnaast, hebben deze patiënten een Global Perceived Effect (GPE)-lijst aangaande hun pijn ingevuld. De GPE-items werden vervolgens geclassificeerd als succesvol en niet-succesvol. De absolute en relatieve pijn reductie volgens de VAS werd titgerekend voor zowel succesvol als niet-succesvol. Deze berekeningen werden voor alle meetmomenten uitgevoerd. Vervolgens werd de sensitiviteit en specificiteit geanalyseerd.

Uit de resultaten bleek dat patiënten een relatieve pijnreductie van $58 \%$ (s.d.: 23.4 ) of meer als succesvol beschouwen, terwijl bij zowel succesvolle als niẹt-succesvolle patięnten de pijn significant gedaald was. De sensitiviteit en specificiteit analyse toonden aan dat bij een cut-off point van $50 \%$ relatieve pijnreductie en $3 \mathrm{~cm}$ absolute pijnreductie op de VAS de hoogste kans bestaat dat een patiěnt een behandeling als succesvol beschouwt.

Hoofdstuk 4 beschrijft de vergelijking tussen een multipele en een enkelvoudige pijnmeting bij patiënten met CRPS I. Bij de multipele pijnmeting werd de gemiddelde pijnintensiteit gemeten gedurende 4 dagen, 3 keer per dag. Bij de enkelvoudige pijnmeting 
werden de patiënten geînstrueerd een schatting te maken van de gemiddelde pijn van de afgelopen week. Vervolgens werden er correlatie- en betrouwbaarheidsanalyses uitgevoerd. Daarnaast hebben we de overeenkomst tussen deze twee metingen onderzocht. De patiēnten populatie bestond uit 54 CRPS I patiēnten die betrokken waren bij een gerandomiseerde studie. De metingen zijn vier keer uitgevoerd, te weten vóór de behandeling. 1, 3 en 6 maanden na de behandeling. Uit onze berekeningen bleek dat beide metingen zeer goed correleerden en zeer goed met elkaar overeenkwamen. Beide metingen zijn overigens zeer goed instaat om significante verschillen voor en na de behandeling te meten. De enkele pijnmeting toonde echter grotere versehillen. Uit de resultaten concludeerden wij dat een enkelvoudige pijnmeting waarbij de patiênten een schatting maken van de gemiddelde pijn van de afgelopen week een accurate voorspelling is voor het daadwerkelijke gemiddelde. Daamaast zijn beide metingen in staat om verschillen te meten indien deze daadwerkelijk aanwezig zijn.

In hoofdstuk 5 evalueren we de waarde van Multi-Frequency Bioelectrical Impedance Analysis (MFBIA) in CRPS I. Ons hypothese was dat in patiënten met CRPS I, de weefsel proporties in de aangedane ledematen veranderd zijn vergeleken met de niet aangedane ledematen en de ledematen van een controle groep. 28 CRPS I patiënten en 18 gezonde rechtshandigen participeerden aan de studie. Om de sensitiviteit en de specificiteit van MFBIA in het detecteren van CRPS I te analyseren werden Receiver Operating Characteristics (ROC) analyse en Areas Under the Curve (AUC) uitgevoerd.

De resultaten toonden aan dat de fase hoek $(\Phi)$ verlaagd was in de aangedane ledematen vergeleken met de contralaterale zijde $(p=0.004)$ en ledematen van de controle groep $(p=$ 0.02). De fase hoek wordt gedefinieerd als de relatie tussen de weerstand (mogelijkheid van een medium een wisselstroom de geleiden) en de reactantie (capaciteit van weefsel oppervlak en cel membraan). De MFBIA frequentie $\left(\omega_{0}\right)$ waarbij de reactantie en de fase hoek maximaal zijn was gestegen in de aangedane ledematen vergeleken met de contralaterale zijde ( $p=$ 0.02 ) en de controle ledematen $(p=0.01)$. De sensitiviteit en de specificiteit van $\omega_{0}$ om CRPS I te detecteren aan de onderste extremiteiten waren 0.91 en 0.85 vergeleken met onderste extremiteiten van de controle patiënten. Bij de bovenste extremiteiten echter waren de sensitiviteit en de specificiteit het best bij vergelijking met de rechter arm van de controle groep $(0.75$ respectievelijk 0.82 ). De waarden van $\Phi$ waren 0.82 en 0.70 vergeleken met de rechterarm van controle groep. Aldus, volgens de MFBIA, zijn de weefsel proporties veranderd in de CRPS I ledematen. 
In hoofdstuk 6 evalueren we de radiofrequente laesies van de ganglion stellatum (RFSG) als therapie bij verschillende chronische pijnsyndromen. We hebben 86 RF-SG procedures geêvialueerd. Medische statussen van de patiënten werden systematisch geanalyseerd. Daarnaast werd een analyse van beschikbare literatuur gedaan. Hiervoor werden door middel van MEDLINE geschikte artikelen betreffende SG-blokkades geselecteerd. In ons kliniek ondergingen $39.5 \%$ van 221 patiënten, die een prognostische SG blok kregen, een RS-SG. Van deze patiënten rapporteerde $40.7 \%$ een pijnreductie van meer dan $50 \%, 54.7 \%$ had geen pijn reductie en $4.7 \%$ rapporteerde verergering van de pijnklachten. Het effect van de behandeling duurde gemiddeld 52 weken. Voor ons literatuuronderzoek hebben we 31 studies geselecteerd, 12 over complicaties en 19 betreffende de effectiviteit van SG-blokkades. Een meta-analyse van deze studies toonde een gedeeltelijke pijn reductie bij $41.3 \%$ van de patiênten, complete pijnreductie bij $37.8 \%$ en geen pijnreductie bij $20.9 \%$. De effectiviteit van RF-SG blokkades bleek overeen te komen met andere SG-blokkades in de literatuur. Ons retrospectief onderzoek toont aan dat RF-SG meest effectief is bij patiënten met CRPS II, ischemische pijn, cervico-brachialgie en post-thoracotomie pijn. Echter, het klinisch effect behoort door middel van gerandomiseerde placebo gecontroleerde studies aangetoond te worden.

De lange termijn effect van cervicale en lumbale SCS in CRPS I patiënten is in hoofdstuk 7 gepresenteerd. Zesendertig patiënten met een definitieve implantaat werden in de studie geinncludeerd. De patiënten hebben tijdens de studie viermaal een pijndagboek ingevuld: voor de behandeling. 6 maanden, 1 en 2 jaar na de behandeling. Daarnaast werd door đe patiënten tijdens de follow-up metingen een Global Perceived Effect (GPE) en de Euroqol-5D (EQ-5D) ingevuld. Zes maanden, 1, en 2 jaar na de behandeling was de pijn gereduceerd $(\mathrm{p}<0.05$ ). Echter, een herhaalde ANOVA toonde een significante, lineaire verhoging van de VAS $(\mathrm{p}=0.03)$. Volgens de GPE, hebben $42 \%$ van de cervicale SCS patiënten en $47 \%$ van de lumbale SCS patiènten minimaal "veel verbetering" aangegeven. De gezondheidsstatus gemeten op de EQ-5D was verhoogd na de behandeling $(p<0.05)$. Deze verhoging was zowel volgens sociaal perspectief als patiênt perspectief. Complicaties en bijwerkingen kwamen voor bij $64 \%$ van de patiënten. Deze bestonden voornamelijk ụit technische defecten. Er was geen verschil in resultaten tussen de cervicale en de lumbale groep. We concluderen dat SCS de pijn reduceert in de meeste patiënten met CRPS I en de gezondheidsstatus verhoogt. De incidentie van complicaties en bijwerkingen zijn hoog. 


\section{Dankwoord}

In 1999 kreeg ik de kans om te promoveren bij de afdeling Anesthesie en Pijnbestrijding van het Academisch Ziekenhuis Maastricht. Zonder te aarzelen heb ik deze kans genomen en ben gestart met mijn onderzoek. Tijdens mijn twee-jarig onderzoek hebben zowel mensen op de werkvloer als mensen in mijn privésfeer een steentje bijgedragen aan het totstand komen van dit proefschrift. Deze mensen wil ik graag bedanken.

Prof. Dr. M. van Kleef, mijn promotor, wil ik bedanken voor zijn steun en vertrouwen in mijn werk, zonder welk mijn promotie niet mogelijk was. Beste dokter van Kleef, ondanks dat je tijdens ons allereerste gesprek bijna mijn hand hebt gekneusd, wil ik je bedanken dat je me toen als student assistent hebt aangenomen. Mijn carièrre als onderzoeker is toen begonnen. Tijdens het onderzoek heb ik je oprechte enthousiasme over mijn ideeĕn erg op prijs gesteld. Hierdoor werd namelijk de basis gelegd voor mijn manuscripten.

Dr. W. E. J. Weber, mijn co-promotor, wil ik bedanken voor zijn grote bijdragen aan mijn onderzoek en het totstand komen van de manuscripten. Wim, de vrijheid en ruimte die jij mij hebt gegund om als onderzoeker mijn eigen weg te gaan, hebben tot deze thesis geleid. Ik heb veel van je geleerd, niet alleen over onderzoek maar vooral over het alledaagse leven en de diplomatie in academische ziekenhuizen. Ook als begeleider op de pijnpoli heb je me geleerd hoe ik het beste kon communiceren met chronische pijnpatiënten. Bedankı voor je goede begeleiding en je interesse in het verdere verloop van mijn carrière.

Marius Kemler wil ik bedanken voor het meedenken en het verschaffen van informatie voor een deel van mijn proefschrift. Marius, ook naast het onderzoeksgebeuren kon ik het goed met jou en Bettien vinden. Ik vind het nog steeds jammer dat jullie in Groningen zitten.

Fons Kessels, de cynische statisticus, wil ik eveneens bedanken. Beste Fons, jou ken ik sinds mijn wetenschapstage, tijdens mijn geneeskundstudie. Ik moet eerlijk toegeven dat ik je hocuspocus taaltje toen niet begreep en nu nog steeds vaak niet begrijp. Ik wil je graag bedanken dat je altijd even tijd had om mij te helpen bij de statistische analyses.

Margriet Rouflart en Bernard van Kreel wil ik bedanken, dat ze met mij hebben meegedacht over het uitvoeren van de Multi-Frequency Bioelectrical Impedance Analysis (MFBIA). Margrietje en ome Ben, jullie tweetjes achter "het karretje" door het ziekenhuis was een foto waard. Beste Margrietje, je aanmoedigende praatjes ben ik natuurlijk niet vergeten. Vooral niet die harde schouderkloppen die ermee gepaard gingen. Ome Ben, je had altijd tijd om even bij een patiënt metingen uit te voeren. Het maakte niet uit wanneer ik je belde. Je kwam altijd. Ook heb je tevergeefs getracht mij je moeilijke berekeningen uit te 
leggen. Wel tien keer geloof ik. Dankzij jullie inzet is een basis gelegd voor een mogelijk objectief meetinstrument voor patiënten met Complex Regional Pain Syndrome Type I.

Inge Lamé en Albère Köke, jullie wil ik bedanken voor jullie bijdragen aan het totstand komen van enkele van mijn manuscripten. Ik had al gelukkig snel door dat een babbeltje met een kopje thee bij jullie, de beste remedie was voor zo'n dag waarop weer eens alles wilde mislukken.

Mieke Janssen, zonder welk het niet mogelijk was MFBIA-metingen bij de rat uit te voeren, verdient hierbij eveneens een dankwoord. Je had altijd wel tijd om met mij naar het CPV te gaan voor het nemen van biopten. Ook heb je veel moeite gedaan om de biopten te verwerken. Bedankt.

De warme ontvangst van "de damens van het secretariaat": Patrice, Sandra, Thea, Magda, Lilian, Astrid, Els en natuurlijk Resy zal ik niet snẹ vergeten. Zelfs, nu ik niẹt meer bij de afdeling werkzaam ben, word ik door jullie vriendelijk ontvangen. Het spreekwoord "Uit het oog, uit het hart" is bij jullie duidelijk niet van toepassing. Verder wil ik jullie allemaal bedanken, dat jullie altijd voor mij klaar stonden om te helpen.

Ook wil ik "de vrouwtjes van de poli" bedanken. Marianne, Emiliènne en Claire mijn ontgroening en jullie schunnig gepraat over mijn "rode Monster" zitten nog vers in mijn geheugen. De video film, die ik 4 jaar geleden van jullie gekregen heb, is nog steeds "leeg". Bedankt voor de fijne tijd op de poli. Daarnaast, wil ik jullie mededelen dat de arbo-arts heeft laten weten dat de bestraling door de computers en de monitors nog binnen de grenzen valt. Er is dus geen reden tot ongerustheid. Haaruitval en vermoeidheid zijn tekenen van ouderdom.

Dr. J. Patijn wil ik vooral bedanken voor de leermomenten tijdens mijn werkzaamheden als arts op de pijnpoli. Daarnaast bedank ik je ervoor dat je bereid was als lid van de beoordelingscommissie mijn proefschrift te beoordelen. Hopelijk heb je inmiddels het nut van de "Proximale Radiusreflex." voor het neurologisch onderzoek erkent.

Tevens wil ik mijn beoordelingscommissie bedanken. Prof. dr. A. Scherpbier, beste Albert, als begeleider van de PMO (Praktisch Medisch Onderwijs)-groep waarin ik zat, heb je getracht mij de nodige communicatieve vaardigheden, die ik als arts nodig heb, te leren. Nu, tien jaar later beoordeel je mijn proefschrift. Mijn dank voor alles. De andere leden, Prof. dr. M. Limburg, Prof. dr. R.G.T. Geesink en Prof.dr. W.W.A. Zuurmond wil ik bedanken dat ze mijn thesis hebben gelezen en beoordeeld. 
Mijn collega Antal van de Gaag wil ik bedanken voor de gezellige momenten in ons kleine assistenhok cq. opslagruimte. Beste Antal, dankzij jou zal ik het tweede jaar van mijn promotieonderzoek niet meer vergeten. We hebben veel gelachen maar ook veel frustrerende momenten meegemaakt.

Tom Vakurca, mijn beste vriend. Jou wil ik bedanken voor je vriendschap en je interresse in wat ik doe. Je was er altijd voor in om even te brainstormen over mijn onderzoek.

Hans van Geel en Maurice Hagedoren, jullie ken ik sinds het eerste respectievelijke tweede jaar van onze geneeskundestudie. Sindsdien hebben we een hechte vriendschap gekregen. Ik wil jullie bedanken voor het begrip en geduld dat jullie hadden, als ik weer eens geen tijd had om met jullie iets te ondernemen.

Sandy Hundepool, mijn maatje in Belgię. Tja, jij wilt dat ik een hele pagina over jou vol schrijf, maar je krijgt slechts een paar regeltjes van mij. Ondanks je drukke bestaan, had je altijd wel wat tijd om te discussiêren over mijn proefschrift. Je nuchtere kijk op het leven en je droge opmerkingen over de oneerlijkheid die wij regelmatig tijdens onze studie tandheelkunde in België mee maken, vind ik toppie.

Mijn vriendin en tevens mijn paranimf, Lindeke wil ik natuurlijk ook bedanken. Lin, we hebben door dik en dun een geweldige relatie opgebouwd. Ondanks je ongeduld en kritische kijk op alles heb je het tot nog toe goed vol gehouden bij mij en de fratsen die ik altijd weet uit te halen. Petje af. Je was altijd wel in om te brainstormen over mijn onderzoek. Wellicht weet je het niet meer, maar het vierde hoofdstuk van mijn proefschrift hebben we samen tijdens het koken bedacht. Zonder jouw steun en lach was alles stukken moeilijker geweest.

Ook mijn broer Mike, mijn paranimf, verdient een dankwoord. Mike, de 30 jaar dat ik je ken, kan ik oprecht zeggen dat je altijd klaar staat om te helpen. Daarvoor wil ik je bedanken. Sisse, mijn schoonzusje in spé, bij jou kon ik altijd terecht als mijn computer weer eens crashte. Bedankt voor je steun en gastvrijheid.

Last but not least wil ik mijn lieve ouders bedanken. Doordat jullie in 1984 besloten dat het voor Mike en mij beter zou zijn om van Iran naar Nederland te emmigreren, hebben jullie ons leven kansrijk gemaakt. En zie hier. Jullie onvoorwaardelijke liefde en steun waren en zijn onmisbaar voor datgenen wat ik gedaan heb en nog zal gaan doen. Bedankt voor alles! 


\section{Curriculum Vitae}

Tymour Forouzanfar is geboren op 22 februari 1973 te Teheran - Iran. Zijn lagere school heeft hij daar afgerond. In 1984 is hij naar Nederland verhuisd. Na het behalen van zijn VWO diploma op het Corriovallum College te Heerlen, is hij aan zijn studie geneeskunde begonnen aan de Universiteit Maastricht (1993-1999). In 1995 is hij naast zijn geneeskunde studie, gestart met een drie-jarige studie acupunctuur aan de Open Universiteit Amsterdam. Deze heeft hij in 1998 met succes afgerond. Tijdens zijn laatste jaar geneeskunde was hij als student-assistent werkzaam bij Prof. dr. M. van Kleef en Dr. W.E.J. Weber (afd. Anesthesie en pijnbestrijding). Na het behalen van zijn arts-diploma in oktober 1999, is hij begonnen aan zijn promotie onderzoek bij deze afdeling. Naast zijn wetenschappelijk werk, was hij actief betrokken bij de behandeling van acute en chronische pijnpatiënten. In oktober 2001 heeft hij zijn onderzoek afgerond en is vervolgens met zijn opleiding tandheelkunde aan de K.U.

Leuven - Belgiê gestart. in hetzelfde jaar heeft hij zijn acupunctuurpraktijk opgericht. In 2004 zal hij de studie tandheelkunde afronden en in opleiding gaan tot mond-, kaak- en gezichtschirurg. 
